\title{
WestVirginiaUniversity
}

THE RESEARCH REPOSITORY @ WVU

Graduate Theses, Dissertations, and Problem Reports

2012

\section{Impact of Diabetes on Colorectal Cancer Outcomes}

Neel A. Shah

West Virginia University

Follow this and additional works at: https://researchrepository.wvu.edu/etd

\section{Recommended Citation}

Shah, Neel A., "Impact of Diabetes on Colorectal Cancer Outcomes" (2012). Graduate Theses,

Dissertations, and Problem Reports. 669.

https://researchrepository.wvu.edu/etd/669

This Dissertation is protected by copyright and/or related rights. It has been brought to you by the The Research Repository @ WVU with permission from the rights-holder(s). You are free to use this Dissertation in any way that is permitted by the copyright and related rights legislation that applies to your use. For other uses you must obtain permission from the rights-holder(s) directly, unless additional rights are indicated by a Creative Commons license in the record and/ or on the work itself. This Dissertation has been accepted for inclusion in WVU Graduate Theses, Dissertations, and Problem Reports collection by an authorized administrator of The Research Repository @ WVU.

For more information, please contact researchrepository@mail.wvu.edu. 


\title{
Impact of Diabetes on Colorectal Cancer Outcomes
}

\author{
Neel A. Shah \\ Dissertation submitted to the \\ School of Pharmacy \\ at West Virginia University \\ in partial fulfillment of the requirements for the degree of
}

Doctor of Philosophy

in

Pharmaceutical and Pharmacological Sciences

\author{
S. Suresh Madhavan, MBA, Ph.D., Chair \\ Joel Halverson, Ph.D. \\ Cindy Tworek, Ph.D. \\ William P. Petros, Pharm.D., FCCP \\ Xiaoyun (Lucy) Pan, Ph.D. \\ Department of Pharmaceutical Systems and Policy \\ Morgantown, West Virginia \\ 2012
}

Keywords: Colorectal Cancer; Diabetes; Emergency Surgery; Mortality; Survival; Stage

Copyright 2012 Neel A. Shah 


\section{ABSTRACT \\ Impact of Diabetes on Colorectal Cancer Outcomes}

\section{Neel A. Shah}

Diabetes is one of the most common chronic comorbid condition seen in elderly CRC patients. Outcomes of CRC patients with diabetes specifically stage at diagnosis, emergency condition for CRC surgery, survival, and mortality have been insufficiently explored. The aims of the study were to investigate the association between diabetes and stage at diagnosis of CRC in elderly Medicare beneficiaries; to check the association of diabetes with presenting as an emergency condition for CRC surgery in the elderly and; to explore the effect of diabetes on survival of elderly Medicare beneficiaries with CRC. Using the SEER-Medicare data from 2003-2005, patients newly diagnosed with CRC were selected and divided into diabetic and nondiabetic cohorts. The two cohorts were compared in terms of stage at CRC diagnosis, emergency presentation for CRC surgery, and five year survival. Logistic regressions were used to check the association between diabetes and stage at diagnosis and emergency condition for CRC surgery. Survival analysis was employed compare time to death between diabetic and non-diabetic CRC patients. Covariates used in the study included the three most common comorbid conditions besides diabetes: coronary atherosclerosis, congestive heart failure, and chronic obstructive pulmonary disease, age, sex, race, tumor location, region in the country, patient location, and frequency of physician office visits. For survival analysis additional treatment variables chemotherapy, radiation, and surgery were included. For stage at diagnosis of CRC, diabetes showed a significant inverse association (OR 0.92; 95\% CI 0.85-1.00). On adding quintile of physician office visits this association was not significant. Odds of being diagnosed at a later stage was significantly associated with the least number of office visits (OR 2.13; 95\% CI 1.862.44) as was having a proximal tumor (OR 1.40, 95\% C 1.30-1.51) Although the odds of a diabetic patient being an emergency patient were lower than a non-diabetic, this was not statistically significant (OR 0.89; 95\% CI 0.79-1.01) Mortality risk was significantly greater for diabetic CRC patients than nondiabetics (HR 1.15, 95\% CI 1.09-1.20). Presenting emergently increased the risk of mortality (HR 1.61, 95\% CI 1.54-1.68). Surgery for CRC reduced the risk of mortality (HR 0.41, 95\% CI 0.39-0.43) and although in bivariate analyses patients who received chemotherapy were more likely to die, the hazard model showed a significant benefit associated with chemotherapy or radiation (HR 0.70, 95\% CI 0.67-0.74). The worse terminal outcomes seen in diabetic CRC patients indicates the need for early and timely screening to prevent the disease or diagnosis at earlier stages. 


\section{CONTENTS}

Page

1. CHAPTER ONE

INTRODUCTION----

\section{CHAPTER TWO}

DIABETES AND STAGE AT DIAGNOSIS OF COLORECTAL CANCER IN THE

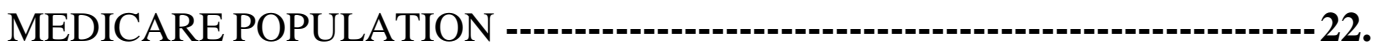

\section{CHAPTER THREE}

ASSOCIATION OF DIABETES AND PREDICTORS OF EMERGENCY CONDITION FOR COLORECTAL CANCER SURGERY IN THE MEDICARE POPULATION--- 45.

\section{CHAPTER FOUR}

IMPACT OF PRE-EXISTING DIABETES ON COLORECTAL CANCER

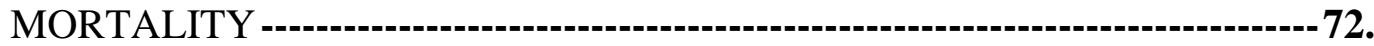

\section{CHAPTER FIVE}

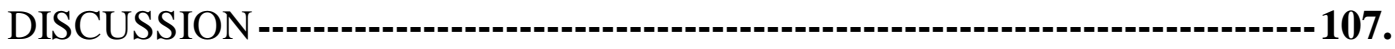




\section{ACKNOWLEDGMENTS}

I will always cherish the support of the following for work on this dissertation, and through my tenure as a graduate student.

My family, for giving me the physical and emotional space.

Dr Madhavan, for being a kind, sharp, and patient mentor.

Committee members, Drs. Joel Halverson, Cindy Tworek, Bill Petros, and Lucy Pan for their insight.

Dr. Usha Sambamoorthi, for her vision.

My closest friends spread across the world for always being there.

Graduate students in the department of Pharmaceutical Systems and Policy, for academic and nonacademic conversations.

Angie Frame, for her efficiency. 


\section{CHAPTER ONE}

INTRODUCTION 
Colorectal cancer (CRC) is the third most common form of cancer after prostate/breast and lung cancer in men and women in the United States (Ahuja, Chang, \& Gearhart, 2007) (Jemal, Siegel, Ward, Hao, Xu, \& Thun, 2009). In 2011 approximately 141,210 men and women were expected to be diagnosed and approximately 49,380 are expected to succumb to CRC The incidence of CRC is uncommon under the age of 50 years and younger patients' tumors are thought to predominantly be induced by heredity in those with a family history (Rim, Seeff, Ahmed, King, \& Coughlin, 2009). However, the incidence of colorectal adenomas, which are precursors to the cancer, rises with age and two thirds of all CRC occur in patients over the age of 65 (Holt, Kozuch, \& Mewar, 2009).

Although a definitive causal factor for CRC has not been identified, several risk factors have been hypothesized to lead to the cancer. These include family history and genetics, increasing age, male sex, previous colonic adenomas, and environmental factors such as consumption of red meat, high-fat diet, inadequate intake of fiber, sedentary lifestyle, smoking, high consumption of alcohol, diabetes mellitus and obesity (Centers for Disease Control and Prevention). A review of several studies with diverse endpoints and in diverse populations has shown that insufficient vitamin D has a causal association with CRC (Giovannucci E. , 2010). Inflammatory bowel diseases such as ulcerative colitis and Crohn's disease have also proven to be strongly associated with CRC, with one meta-analysis showing high a odds ratio (2.59) of developing CRC in Crohn's disease patients (von Roon, Reese, Teare, Constantinides, Darzi, \& Tekkis, 2007) (Eaden, Abrams, \& Mayberry, 2001).

Early stage CRC can be asymptomatic. Symptoms that may appear as the cancer progresses include blood (either bright red or very dark) in the stool; diarrhea, constipation, or feeling that the bowel does not empty completely; stools that are narrower than usual; frequent 
gas pains, bloating, fullness, or cramps; unexplained weight loss; fatigue; and nausea and vomiting. However, these symptoms are common to various other diseases/conditions and only pathologic abnormalities observed during screening for colorectal adenomas or tumors can confirm a diagnosis of cancer.

Staging of CRC is based on the TNM (Tumor, Node, Metastases) classification. Most colorectal cancers start off as adenomatous polyps that turn into adenocarcinomas (cancers that begin in cells that make and release mucus and other fluids). TNM classification is followed by staging which is linked to the survival rates as shown in Tables 1 and 2. 
Table 1. TNM Classification of Colorectal Cancer

\begin{tabular}{|c|c|c|}
\hline$T=$ primary tumour & $\mathrm{N}=$ regional lymph nodes & $\mathbf{M}=$ distant metastasis \\
\hline $\mathbf{T X}=$ primary tumour cannot be assessed & $\begin{array}{l}\mathbf{N X}=\text { regional lymph nodes cannot } \\
\text { be assessed }\end{array}$ & $\begin{array}{l}\text { MX=distant metastasis } \\
\text { cannot be assessed }\end{array}$ \\
\hline T0=no evidence of primary tumour & $\begin{array}{l}\text { N0=no regional lymph node } \\
\text { metastasis }\end{array}$ & M0 $=$ no distant metastasis \\
\hline $\begin{array}{l}\text { Tis=carcinoma in situ: intraepithelial or } \\
\text { invasion of lamina propria }\end{array}$ & $\begin{array}{l}\text { N1a=metastasis in one regional } \\
\text { lymph node }\end{array}$ & $\begin{array}{l}\text { M1a }=\text { distant metastasis to } \\
\text { one site }\end{array}$ \\
\hline T1=tumour invades submucosa & $\begin{array}{l}\text { N1b=metastasis in two to three } \\
\text { regional lymph nodes }\end{array}$ & $\begin{array}{l}\text { M1b=distant metastasis to } \\
\text { more than one site }\end{array}$ \\
\hline $\mathbf{T 2}=$ tumour invades muscularis propria & $\begin{array}{l}\text { N2a=metastasis in four to six } \\
\text { regional lymph nodes }\end{array}$ & \\
\hline $\begin{array}{l}\text { T3=tumour invades through the muscularis } \\
\text { propria into subserosa or into } \\
\text { nonperitonealised pericolic or perirectal } \\
\text { tissues }\end{array}$ & $\begin{array}{l}\mathbf{N 2 b}=\text { metastasis in seven or more } \\
\text { regional lymph nodes }\end{array}$ & \\
\hline $\begin{array}{l}\text { T4a=tumour penetrates the surface of the } \\
\text { visceral peritoneum }\end{array}$ & & \\
\hline $\begin{array}{l}\mathbf{T 4 b} \mathbf{b}=\text { tumour directly invades or is } \\
\text { histologically adherent to other organs or } \\
\text { structures }\end{array}$ & & \\
\hline
\end{tabular}

Source: (Gunderson, Jessup, Sargent, Greene, \& Stewart, 2010) 
Table 2. Colorectal Cancer staging based in TNM Classification

\begin{tabular}{|c|c|c|c|c|}
\hline & Stage I & Stage II & Stage III & Stage IV \\
\hline TNM staging & $\begin{array}{l}\text { T1 N0 M0 } \\
\text { T2 N0 M0 }\end{array}$ & $\begin{array}{l}\text { A: T3 N0 M0 } \\
\text { B: T4 N0 M0 }\end{array}$ & $\begin{array}{l}\text { A: T1-2 N1 M0 } \\
\text { B: T3-4 N1 M0 } \\
\text { C: Any T N2 M0 }\end{array}$ & Any T Any N M1 \\
\hline Definition & $\begin{array}{l}\text { Invades submucosa } \\
\text { (T1)/muscular } \\
\text { propria (T2) }\end{array}$ & $\begin{array}{l}\text { Invades subserosa, } \\
\text { nonperitonealized } \\
\text { pericolic/perirectal } \\
\text { tissues (T3). Invades } \\
\text { other organs or } \\
\text { structures/visceral } \\
\text { peritoneum (T4) }\end{array}$ & $\begin{array}{l}\text { Involves 1-3 (N1) or } \\
\text { more (N2) lymph } \\
\text { nodes }\end{array}$ & $\begin{array}{l}\text { Involves distant } \\
\text { metastases }\end{array}$ \\
\hline $\begin{array}{l}\text { Usual } \\
\text { Treatment }\end{array}$ & Surgery & $\begin{array}{l}\text { Surgery with or } \\
\text { without } \\
\text { chemotherapy }\end{array}$ & $\begin{array}{l}\text { Surgery with } \\
\text { chemotherapy }\end{array}$ & $\begin{array}{l}\text { Chemotherapy with } \\
\text { or without surgery }\end{array}$ \\
\hline $\begin{array}{l}\text { 5-year } \\
\text { Survival, 1990- } \\
1999\end{array}$ & $95 \%$ & $82 \%$ & $57 \%$ & $6 \%$ \\
\hline
\end{tabular}

Source: (Gloeckler Ries, Reichman, Lewis, Hankey, \& Edwards, 2003)

As many as $50 \%$ of the Western population develops adenomatous polyps in their lifetime but the lifetime risk for colon cancer is about $5 \%$ and only one in ten adenomas lead to cancer formation (Holt, Kozuch, \& Mewar, 2009). It cannot be determined which individuals with adenomas (or a histologically normal colon at risk for adenoma and cancer formation) will develop a cancer, and therefore, preventive methods use detection and removal of benign neoplastic colorectal adenomas to lower colon cancer formation and mortality (Muller \& 
Sonnenberg, 1995). Timely screening can lead to early detection of the cancer, better prognosis of the disease and improved observed survival rates (Miller, 2008). The advantage that CRC screening has over screening for other types of cancer is that with the appropriate test it can detect and remove cancer precursors, such as, adenomatous polyps, to decreased the incidence (Mandel, Bond, \& Church, 2000).

\section{Elderly and CRC}

The incidence of CRC increases with age and almost two-thirds of CRC cases occur in individuals over the age of 65 . Molecular and pathophysiological evidence as to why there is an increase in CRC incidence with age in humans is vague (Holt, Kozuch, \& Mewar, 2009). Relative survival rates from 1996-2000 have shown no significant difference between age groups up to 75 years, however after the age of 75 there is a decline in survival rates (Ries, Melbert, Krapcho, Stinchcomb, Howlader, \& Horner, 2007). Although the overall incidence and mortality is similar in both sexes, the age specific incidence is greater in men. Colorectal adenomas and cancer appear several years later in women probably due to protection by estrogen/progesterone. Some studies have shown that postmenopausal estrogen/progesterone hormone treatment in women can lower colorectal neoplasia risk by as much as 30\% (Johnson, et al., 2009) (Chlebowski, et al., 2004 ). Comorbidity, or illness other than the primary illness under treatment, is more common in the elderly (Shack, Rachet, Williams, Northover, \& Coleman, 2010 ). Older individuals also often present with chronic conditions that complicate the diagnostic and clinical management of CRC which leads to poorer prognosis and outcomes of the cancer (Yancik, et al., 1998 ) (Satariano \& Silliman, 2003). The three most common comorbid conditions with CRC seen in elderly patients are congestive heart failure, chronic 
obstructive pulmonary disease and diabetes mellitus (Gross, Guo, McAvay, Allore, Young, \& Tinetti, 2006 )

\section{Diabetes and CRC}

There is a large body of literature contributing to evidence about the association of diabetes mellitus with CRC. Most studies exploring the relationship between diabetes and CRC have studied type 2 diabetes mellitus or have not separated type 1 and type 2 diabetes. Epidemiological studies that have included type 1diabetes have not found a significant association between type 1 diabetes and CRC (Wideroff, et al., 1997) (Zendehdel, Nyrén, Ostenson, Adami, Ekbom, \& Ye, 2003). One of the first studies to document a high occurrence of diabetes mellitus in patients with colon cancer was published in 1984 by Williams and colleagues (Williams, Walsh, \& Jackson, 1984). Their observation of excessive simultaneous occurrence of diabetes mellitus in patients with colon cancer in a private clinic was documented by a retrospective review of records in the clinics and their associated community hospital.

The first Cancer Prevention Study of the American Cancer Association, initiated in 1959, was a large prospective epidemiological study of colorectal cancer incidence in diabetic patients (Will, Galuska, Vinicor, \& Calle, 1998). After following diabetics for 13 years and adjusting for known cancer risk factors they found that the increased risk of developing CRC compared to non-diabetics was $30 \%$ in men and $16 \%$ in women. Several subsequent prospective studies have come to the conclusion of increased risk of CRC in diabetic men and women (Wideroff, et al., 1997) (Hu, et al., 1999) (Weiderpass, Gridley, Nyrén, Ekbom, Persson, \& Adami, 1997 ). An increased risk of CRC has also been reported in case-control studies by La Vecchia et al and Le Marchand et al. (La Vecchia, Negri, Decarli, \& Franceschi, 1997 ) (Le Marchand, Wilkens, 
Kolonel, Hankin, \& Lyu, 1997). While La Vecchia reported an increased risk for rectal cancer than colon cancer in diabetic patients, LaMarchand found that there was an increased risk of developing a left-sided colon cancer whereas rectal cancer was greater in diabetic women than in diabetic men. The National Health and Nutrition Survey I (NHANES I) collected extensive baseline data via exam and questionnaire from 1971-1975 (Steeland et al, 1995). The subjects who were aged 25-74 years at the time were followed through 1987 for mortality and disease incidence via death certificate and hospital discharge data. For CRC results showed that for both men and women diabetes posed the highest risk but lack of physical non-recreational physical activity caused no increase in risk.

Following the growing epidemiological evidence of the association of diabetes with CRC, McKeown-Eyssen and Giovannucci proposed what came to be popularly known as the hyperinsulinemia hypothesis which suggested that high levels of insulin and glucose might be risk factors for colorectal carcinogenesis (McKeown-Eyssen, 1994) (Giovannucci E. , 1995). This hypothesis grew from trying to explain the link between colorectal cancer, diets high in fat and low in vegetables, and obesity and from the observations that insulin promotes the growth of colon cells in vitro and colon tumors in vivo. Hyperinsulinemia and hyperglycemia result from the dysregulation of the interrelationship between insulin secretion and insulin action, which can also eventually lead to the development of type 2 diabetes mellitus. CRC shares these risk factors with diabetes mellitus and the hyperinsulinemia hypothesis has been furthered by suggesting that because the onset of type 2 diabetes mellitus is characterized by insulin resistance, and in most cases, with hyperinsulinemia for compensation there is an increased level of insulin in type 2 diabetes patients as well which, as a by-product, leads to a complex chain of events promoting tumor growth in the colon (Jin, 2008). It also has been suggested that insulin is considered to be 
a growth factor and insulin receptors are observed in both normal as well as malignant colorectal cancer cells; insulin receptors can be bound by insulin-like growth factors, factors which can be expressed by colorectal cancers (Chang \& Ulrich, 2003 ).

The influence of diabetes mellitus on the mortality of patients with established colorectal cancer has been demonstrated by various authors but with conflicting conclusions. Results from a clinical trial by Meyerhardt, et al. were the first to be documented in 2003 when it was found that even after adjustment for other predictors of colon cancer, patients with diabetes and highrisk stage II or stage III colon cancer experienced a significantly higher rate of overall cancer mortality and cancer recurrence than non-diabetics (Meyerhardt, et al., 2003 ). Only one other prospective study in the United States has investigated this relationship finding a similar positive association (Coughlin, Calle, Teras, Petrelli, \& Thun, 2004). Retrospective studies have mixed conclusions about whether or not pre-existing diabetes affects CRC mortality. A study conducted in elderly patients in the Netherlands found that with co-morbidities such as diabetes, patients were treated less aggressively and had a worse survival than those with no concomitant disease (Lemmens, Janssen-Heijnen, Verheij, Houterman, \& Repelaer van Driel, 2005). Other retrospective cohort studies have concluded that diabetes did not affect short-term survival, cancer specific survival or stage at diagnosis of CRC (Shonka, Anderson, Panwalkar, Reed, Steen, \& Ganti, 2006) (Jullumstrø, Kollind, Lydersen, \& Edna, 2009). Poorly controlled type 2 diabetes independently predicts early onset of CRC, a more advanced stage at the time of presentation and a poorer 5-year survival (Siddiqui, Spechler, Huerta, Dredar, Little, \& Cryer, 2008 ). In a retrospective cohort study of Veterans’ Administration patients it was found that diabetes prevalent with CRC did not affect overall survival in their sample which could be due to excellent quality of diabetes care prior to and post cancer diagnosis (Chiao, Nambi, \& Naik, 
2010). There exist only two studies that have studied mortality in CRC patients with pre-existing diabetes in a large nationally representative sample (Coughlin, Calle, Teras, Petrelli, \& Thun, 2004) (Gross, Guo, McAvay, Allore, Young, \& Tinetti, 2006 ). Only the study by Gross et al was a retrospective cohort analysis and included incident cases only till the year 1999.

\section{Emergency Surgery for CRC}

Surgical resection is the only curative treatment of colorectal cancer, performed as an open, surgical procedure requiring hospitalization (Redaelli, Cranor, Okano, \& Reese, 2003) (Mitry, Barthod, Penna, \& Nordlinger, 2002). Potentially fatal complications of colorectal cancer include bowel perforation, peritonitis, and obstruction. These complications are considered surgical emergencies and are the initial presentation of colorectal cancer in an estimated $15 \%$ to $30 \%$ of patients with colorectal cancer (Diggs, Xu, Diaz, Cooper, \& Koroukian, 2007). In addition, patients with emergency room presentation of CRC have increased 30-day mortality and decreased 5-year survival compared to those scheduled for elective surgery (Mitchell, Inglis, Murdoch, \& Porter, 2007 ). Other studies have found that overall survival at 5 years was 57.5\% after elective and 39.1\% after emergency surgery for CRC (McArdle \& Hole, 2004). The Colorectal Cancer Collaborative Group in England examined how the outcomes of surgery in elderly patients differ from those in younger patients finding that elderly patients who had an increased frequency of comorbid conditions, were more likely to present with later-stage disease and undergo emergency surgery, and less likely to have curative surgery than younger patients (Colorectal Cancer Collaborative Group, 2000). Their systematic review also found that the incidence of postoperative morbidity and mortality increased progressively with advancing age. Performance of surgery in the presence of comorbid 
conditions especially in the elderly can significantly increase mortality (Lemmens, JanssenHeijnen, Verheij, Houterman, \& Repelaer van Driel, 2005). A study conducted in the Netherlands found that among patients with colorectal cancer, comorbidity in general, cardiovascular diseases, COPD, venous thromboembolism and diabetes had a negative effect on overall survival after surgery. Currently there are no retrospective cohort studies conducted in the United States in the extant literature that compare the outcomes of emergency surgery for CRC in patients with and without pre-existing diabetes.

\section{Need for the Study}

Several epidemiological studies have explored the outcomes of CRC in patients with preexisting diabetes. Long term mortality in CRC patients with diabetes has been shown to be greater than in patients without diabetes by all studies. Although previously conducted prospective cohort studies have controlled for bowel obstruction and bowel perforation, (i.e. an emergency condition) they have had the disadvantage of not adjusting for other comorbid conditions and including only high risk stage I and stage II CRC patients. Retrospective studies that have been conducted in the United States largely suffer from small sample sizes or were limited to studying a sample that were residents of a single state, and are therefore not generalizable to a national population (Polednak A. P., 2006) (Siddiqui, Maddur, Naik, \& Cryer, 2008 ). Some of these studies either had samples whose median age was less than 65 years or did not exclusively focus on the elderly, who form two-thirds of all incident CRC cases, as previously mentioned. The linked Surveillance, Epidemiology and End-Results (SEER)Medicare data are a large population-based source of information for cancer-related epidemiologic and health services research. Till the year 1999 there were only 11 SEER areas 
that participated in the SEER program representing 14\% of the US population (Warren, Klabunde, Schrag, Bach, \& Riley, 2002). With the addition of four more states, the SEER program will cover $25 \%$ of the US population. Retrospective analysis looking at the outcomes of CRC in patients with comorbid conditions such as diabetes using the SEER-Medicare database has been conducted by one study which included patients representing only the 11 SEER areas (Gross, Guo, McAvay, Allore, Young, \& Tinetti, 2006 ). This study also did not adjust for emergency presentation of CRC with bowel obstruction or bowel perforation.

Outcomes associated with emergency presentation of CRC have been explored by several European studies. Only two studies have compared outcomes associated with emergency surgery and elective surgery for CRC in the United States (Smothers, Hynan, Fleming, Turnage, Simmang, \& Anthony, 2003 ) (Kim, Mittal, Konyalian, King, Stamos, \& Kumar, 2007). Both studies were limited by their extremely small sample sizes (29 and 209 patients) and one study failed to comprehensively adjust for variables such as comorbid conditions and stage at presentation. Only one retrospective cross-sectional study of a nationally representative sample has evaluated the predictors of emergency presentation for CRC. (Diggs, Xu, Diaz, Cooper, \& Koroukian, 2007) This study used hospitalized in-patient data for just one year and included the non-elderly, uninsured patients with third-party payers other than Medicare and did not segregate comorbid conditions. No other study exploring the predictors of emergency surgery has been conducted in the United States nor has there been a retrospective population based analysis comparing the likelihood of emergency CRC surgery in the diabetic elderly versus non-diabetic elderly patients. In addition, there are no studies in the US which have looked at the differential association of diabetes with stage at diagnosis in a large nationally representative population. Studies in other parts of the world show mixed results. 
Literature clearly signifies the positive association of diabetes in the incidence of CRC. Studies have shown poorer outcomes of patients with comorbid diabetes and CRC compared to CRC in non-diabetic patients, especially in the elderly. Emergency presentation with CRC, which is an indicator of poor cancer and poor screening practices, is seen in almost a quarter of the cases that present with CRC. A statistic from a nationally representative database has shown that diabetic elderly women are less likely to undergo screening for CRC. This is also true for ethnic minorities and persons of lower socioeconomic status. Poor screening practices, such as not using the correct method or not screening in a timely fashion can lead to later detection of cancer and increases the chances of presenting as an emergency case. This is directly associated with poorer prognosis of the disease and worse outcomes than if the cancer is detected earlier. Current screening guidelines do not consider diabetics as a special case for earlier screening or more frequent CRC screening. McBean and Yu have reported that elderly diabetic women are less likely than elderly non-diabetic women to receive colorectal cancer screening in the 11 SEER areas studied between 1999-2002. (McBean \& X, 2007) If a strong association is found between diabetics with later stage at presentation, and emergency presentation with CRC it may help strengthen the case for earlier and more frequent screening for CRC in diabetic patients. In addition it could also be an indicator of the quality of care provided to diabetics by endocrinologists or physicians, awareness of screening guidelines by healthcare providers and raise questions at the patient and provider level about the reasons behind such screening behavior. Survival analysis of diabetics with CRC compared to non-diabetics conducted in a population which is nationally representative and covers almost $28 \%$ of the US population will also favor the same argument. 
The first aim of this study is to investigate the association between diabetes and stage at diagnosis of CRC in an elderly population. The association of other covariates such as coronary atherosclerosis, chronic obstructive pulmonary disease (COPD), congestive heart failure (CHF), age, race, sex, region in the US, patient location, and the frequency of physician office visits with stage at CRC diagnosis will also be explored.

A second aim is to check the association of diabetes with presenting as an emergency condition for CRC surgery in the elderly. This will be followed by an investigation of predictors of emergency condition of CRC surgery in the elderly using large nationally representative registry data.

Finally, the study aims to explore the effect of diabetes on survival of elderly Medicare beneficiaries with CRC. This will also explore the association of the covariates including three most common comorbid conditions (coronary atherosclerosis, chronic obstructive pulmonary disease heart failure), in addition to diabetes, emergency admission, and treatment variables and how they affect survival in a CRC patient. 


\section{References}

Ahuja, N., Chang, D., \& Gearhart, S. L. (2007). Disparities in Colon Cancer Presentation and InHopistal Mortality in Maryland: A Ten Year Review. Annals of Surgical Oncology, 14(2), 411416.

American Cancer Society. (2009). Cancer Facts \& Figures 2009. Atlanta: American Cancer Society.

Chang, C. K., \& Ulrich, C. M. (2003 ). Hyperinsulinaemia and hyperglycaemia: possible risk factors of colorectal cancer among diabetic patients. Diabetologia. , 595-607.

Chiao, E. Y., Nambi, P. V., \& Naik, A. D. (2010). The impact of diabetes process and outcome quality measures on overall survival in patients with co-morbid colorectal cancer. $J$ Cancer Surviv. , 381-7.

Chlebowski, R. T., Wactawski-Wende, J., Ritenbaugh, C., Hubbell, F. A., Ascensao, J., Rodabough, R. J., et al. (2004 ). Estrogen plus progestin and colorectal cancer in postmenopausal women. N Engl J Med. , 991-1004.

Colorectal Cancer Collaborative Group. (2000). Surgery for colorectal cancer in elderly patients: a systematic review. Lancet, 968-74.

Centers for Disease Control and Prevention. Colorectal cancer risk factors. (n.d.). Retrieved July 27, 2010, from Centers for Disease Control and Prevention :

http://www.cdc.gov/cancer/colorectal/basic_info/risk_factors.htm

Coughlin, S. S., Calle, E. E., Teras, L. R., Petrelli, J., \& Thun, M. J. (2004). Diabetes mellitus as a predictor of cancer mortality in a large cohort of US adults. Am J Epidemiol., 1160-7. 
Diggs, J. C., Xu, F., Diaz, M., Cooper, G. S., \& Koroukian, S. M. (2007). Failure to screen: predictors and burden of emergency colorectal cancer resection. Am J Manag Care., 157-64.

Eaden, J. A., Abrams, K. R., \& Mayberry, J. F. (2001). The risk of colorectal cancer in ulcerative colitis: a meta-analysis. Gut, 526-35.

Giovannucci, E. (1995). Insulin and colon cancer. Cancer Causes Control., 164-79.

Giovannucci, E. (2010). Epidemiology of vitamin D and colorectal cancer: casual or causal link? J Steroid Biochem Mol Biol, 349-54.

Gloeckler Ries, L. A., Reichman, M. E., Lewis, D. R., Hankey, B. F., \& Edwards, B. K. (2003). Cancer survival and incidence from the Surveillance, Epidemiology, and End Results (SEER) program. Oncologist, 541-52.

Gross, C. P., Guo, Z., McAvay, G. J., Allore, H. G., Young, M., \& Tinetti, M. E. (2006 ). Multimorbidity and survival in older persons with colorectal cancer. J Am Geriatr Soc. , 1898904.

Gunderson, L. L., Jessup, J. M., Sargent, D. J., Greene, F. L., \& Stewart, A. K. (2010). Revised TN categorization for colon cancer based on national survival outcomes data. J Clin Oncol, 26471.

Holt, P. R., Kozuch, P., \& Mewar, S. (2009). Colon cancer and the elderly: from screening to treatment in management of GI disease in the elderly. Best Pract Res Clin Gastroenterol., 889907. 
Hu, F. B., Manson, J. E., Liu, S., Hunter, D., Colditz, G. A., Michels, K. B., et al. (1999).

Prospective study of adult onset diabetes mellitus (type 2) and risk of colorectal cancer in women. J Natl Cancer Inst. , 542-7.

Jemal, A., Siegel, R., Ward, E., Hao, Y., Xu, J., \& Thun, M. J. (2009). Cancer Statistics, 2009. CA, 59(4), 225-249.

Jin, T. (2008). Why diabetes patients are more prone to the development of colon cancer? Med Hypotheses. , 241-4.

Johnson, J. R., Lacey, J. V., Lazovich, D., Geller, M. A., Schairer, C., Schatzkin, A., et al. (2009). Menopausal hormone therapy and risk of colorectal cancer. Cancer Epidemiol Biomarkers Prev., 196-203.

Jullumstrø, E., Kollind, M., Lydersen, S., \& Edna, T. H. (2009). Diabetes mellitus and outcomes of colorectal cancer. Acta Oncol. , 361-7.

Kim, J., Mittal, R., Konyalian, V., King, J., Stamos, M. J., \& Kumar, R. R. ( 2007). Outcome analysis of patients undergoing colorectal resection for emergent and elective indications. Am Surg., 991-3.

La Vecchia, C., Negri, E., Decarli, A., \& Franceschi, S. (1997 ). Diabetes mellitus and colorectal cancer risk. Cancer Epidemiol Biomarkers Prev. , 1007-10.

Le Marchand, L., Wilkens, L. R., Kolonel, L. N., Hankin, J. H., \& Lyu, L. C. (1997). Associations of sedentary lifestyle, obesity, smoking, alcohol use, and diabetes with the risk of colorectal cancer. Cancer Res., 4787-94. 
Lemmens, V. E., Janssen-Heijnen, M. L., Verheij, C. D., Houterman, S., \& Repelaer van Driel, O. J. (2005). Co-morbidity leads to altered treatment and worse survival of elderly patients with colorectal cancer. Br J Surg. , 615-23.

Mandel, J., Bond, J., \& Church, T. (2000). Reducing mortality from colorectal cancer by screening for fecal occult blood. $N$ Engl J Med, 1603-7.

McArdle, C. S., \& Hole, D. J. (2004). Emergency presentation of colorectal cancer is associated with poor 5-year survival. Br J Surg, 605-9.

McBean, M. A., \& X, Y. (2007). The Underuse of Screening Services Among Elderly Women With Diabetes. Diabetes Care, 1466-72.

McKeown-Eyssen, G. (1994). Epidemiology of colorectal cancer revisited: are serum triglycerides and/or plasma glucose associated with risk? Cancer Epidemiol Biomarkers Prev. , 687-95.

Meyerhardt, J. A., Catalano, P. J., Haller, D. G., Mayer, R. J., Macdonald, J. S., Benson, A. B., et al. (2003 ). Impact of diabetes mellitus on outcomes in patients with colon cancer. J Clin Oncol. , 433-40.

Miller, A. B. (2008). Implementation of colon cancer screening: techniques, costs, and barriers. Gastreneterol Clin N Am, 83-95.

Mitchell, A. D., Inglis, K. M., Murdoch, J. M., \& Porter, G. A. (2007 ). Emergency room presentation of colorectal cancer: a consecutive cohort study. Ann Surg Oncol. , 1099-104. .

Mitry, E., Barthod, F., Penna, C., \& Nordlinger, B. (2002). Surgery for colon and rectal cancer. Best Pract Res Clin Gastroenterol., 253-65. 
Muller, A., \& Sonnenberg, A. (1995). Protection by endoscopy against death from colorectal cancer. A case-control study among veterans. Arch Intern Med , 1741-8.

Polednak, A. P. (2006). Comorbid diabetes mellitus and risk of death after diagnosis of colorectal cancer: a population-based study. Cancer Detect Prev. , 466-72. .

Redaelli, A., Cranor, C. W., Okano, G. J., \& Reese, P. R. (2003). Screening, prevention and socioeconomic costs associated with the treatment of colorectal cancer. Pharmacoeconomics, 1213-38.

Ries, L. A., Melbert, D., Krapcho, M., Stinchcomb, D. G., Howlader, N., \& Horner, M. J. (2007). SEER Cancer Statistics Review, 1975-2005, National Cancer Institute. Bethesda: National Cancer Institute.

Rim, S. H., Seeff, L., Ahmed, F., King, J. B., \& Coughlin, S. S. (2009). Colorectal cancer incidence in the United States, 1999-2004 : an updated analysis of data from the National Program of Cancer Registries and the Surveillance, Epidemiology, and End Results Program. Cancer., 1967-76.

Satariano, W. A., \& Silliman, R. A. ( 2003). Comorbidity: implications for research and practice in geriatric oncology. Crit Rev Oncol Hematol., 239-48.

Shack, L. G., Rachet, B., Williams, E. M., Northover, J. M., \& Coleman, M. P. (2010 ). Does the timing of comorbidity affect colorectal cancer survival? A population based study. Postgrad Med $J, 73-8$. 
Shonka, N. A., Anderson, J. R., Panwalkar, A. W., Reed, E. C., Steen, P. D., \& Ganti, A. K. (2006). Effect of diabetes mellitus on the epidemiology and outcomes of colon cancer. Med Oncol. , 515-9.

Siddiqui, A. A., Maddur, H., Naik, S., \& Cryer, B. (2008 ). The association of elevated HbA1c on the behavior of adenomatous polyps in patients with type-II diabetes mellitus. Dig Dis Sci., $1042-7$.

Siddiqui, A. A., Spechler, S. J., Huerta, S., Dredar, S., Little, B. B., \& Cryer, B. ( 2008 ). Elevated HbA1c is an independent predictor of aggressive clinical behavior in patients with colorectal cancer: a case-control study. Dig Dis Sci., 2486-94.

Smothers, L., Hynan, L., Fleming, J., Turnage, R., Simmang, C., \& Anthony, T. (2003 ). Emergency surgery for colon carcinoma. Dis Colon Rectum., 24-30.

von Roon, A. C., Reese, G., Teare, J., Constantinides, V., Darzi, A. W., \& Tekkis, P. P. (2007). The risk of cancer in patients with Crohn's disease. Dis Colon Rectum , 839-55.

Warren, J. L., Klabunde, C. N., Schrag, D., Bach, P. B., \& Riley, G. F. (2002). Overview of the SEER-Medicare data: content, research applications, and generalizability to the United States elderly population. Med Care., 3-18.

Weiderpass, E., Gridley, G., Nyrén, O., Ekbom, A., Persson, I., \& Adami, H. O. (1997 ). Diabetes mellitus and risk of large bowel cancer. J Natl Cancer Inst. , 660-1.

Wideroff, L., Gridley, G., Mellemkjaer, L., Chow, W. H., Linet, M., Keehn, S., et al. (1997). Cancer incidence in a population-based cohort of patients hospitalized with diabetes mellitus in Denmark. J Natl Cancer Inst., 1360-5. 
Will, J. C., Galuska, D. A., Vinicor, F., \& Calle, E. E. (1998). Colorectal Cancer: Another Complication of Diabetes Mellitus? Am J Epidemiol., 816-25.

Williams, J. C., Walsh, D. A., \& Jackson, J. F. (1984). Colon carcinoma and diabetes mellitus. Cancer. , 3070-1.

Yancik, R., Wesley, M. N., Ries, L. A., Havlik, R. J., Long, S., Edwards, B. K., et al. (1998 ). Comorbidity and age as predictors of risk for early mortality of male and female colon carcinoma patients: a population-based study. Cancer, 2123-34.

Zendehdel, K., Nyrén, O., Ostenson, C. G., Adami, H. O., Ekbom, A., \& Ye, W. (2003). Cancer incidence in patients with type 1 diabetes mellitus: a population-based cohort study in Sweden. $J$ Natl Cancer Inst., 1797-800. 


\section{CHAPTER TWO}

Diabetes and Stage at Diagnosis of Colorectal Cancer in the Medicare Population 


\section{Introduction}

Colorectal cancer (CRC) is the third most common form of cancer after prostate/breast and lung cancer in the United States. (Gellad, Z.F. 2010; Jemal, A. 2010) In 2011, approximately 141,210 men and women were expected to be diagnosed and approximately 49,380 are expected to succumb to CRC. (American Cancer Society 2011) The incidence of colorectal adenomas, which are precursors to the cancer, rises with age and two thirds of all CRC occur in patients over the age of 65. (Holt, P.R. 2009)

Diabetes is one of three most common comorbid conditions seen in elderly patients with CRC. (Gross, C.P. 2006) Several prospective and case-control studies have come to the conclusion of increased risk of CRC in diabetic men and women. (Hu, F.B. 1999; Weiderpass, E. 1997; La Vecchia, C. 1997; Le Marchand, L. 1997) Diabetes and CRC share several risk factors such as diet low in fiber and high in fat, obesity, and hyperinsulinemia. (Giovannucci, E. 2001) In addition to the epidemiological evidence of the association of diabetes with CRC, the hyperinsulinemia hypothesis has suggested that high levels of insulin and glucose might be risk factors for colorectal carcinogenesis. (McKeown-Eyssen,G. 1994; Giovannucci, E. 2007) This hypothesis grew from trying to explain the link between colorectal cancer, diets high in fat and low in vegetables, obesity and from observations that insulin promotes the growth of colon cells in vitro and colon tumors in vivo. Hyperinsulinemia and hyperglycemia result from the dysregulation of the interrelationship between insulin secretion and insulin action, which can also eventually lead to the development of diabetes. The hyperinsulinemia hypothesis has been furthered by suggesting that because the onset of diabetes is characterized by insulin resistance, which could lead to hyperinsulinemia, there is an increased level of insulin in diabetes patients as 
well which, as a by-product, leads to a complex chain of events promoting tumor growth in the colon. (Jin, T. 2008)

Diabetes mellitus also influences mortality of patients with established colorectal cancer. Clinical trial results have shown that even after adjustment for other predictors of colon cancer, patients with diabetes and high-risk stage II or stage III colon cancer experienced a significantly higher rate of overall cancer mortality and cancer recurrence than non-diabetics. (Meyerhardt, J.A. 2003) A 16 year prospective study showed that after controlling for high body mass, diabetes was significantly associated with fatal colon cancer in men $(\mathrm{RR}=1.20,95 \%$ CI 1.06 1.37) and women ( $\mathrm{RR}=1.24,95 \% \mathrm{CI} 1.07$ - 1.43).(166 Coughlin,S.S. 2004) In addition, poorly controlled diabetes independently predicts early onset of CRC, a more advanced stage at the time of presentation, and a poorer 5-year survival. (Siddiqui, A.A. 2008)

Stage at diagnosis for colorectal cancer directly affects mortality and survival. Chances for survival are more than $90 \%$ for Stage I, $82 \%$ for Stage II, 57\% for Stage III and drop to 6\% for Stage IV patients. (Gloeckler Ries, L.A. 2003) Although diabetes has been shown to be associated with the incidence and affects the outcomes of CRC, there are no studies in the US which have looked at its differential association with stage at diagnosis. Studies in other parts of the world have mixed results. A study in 2,762 Taiwanese patients of whom $17 \%$ had diabetes, showed no significant difference in stage at diagnosis, although patients without diabetes were more frequently diagnosed with stage I (13.7 \% vs. $9.0 \%$ in diabetic patients).(Huang, Y.C. 2011) However, the study included both the elderly as well as younger patients. A Dutch study found that patients with diabetes were more often diagnosed with stage II and less often with stage I than patients without diabetes, with comparable numbers of stages III and IV. (van de Poll-Franse, L.V. 2012) A recent cross-sectional analysis of 539 colorectal cancer patients in 
Germany concluded that patients with diabetes were probably diagnosed earlier and therefore may be at lower risk for advanced stages of colon cancer at diagnosis. (Nagel, J.M. 2012)

The evidence from prospective and retrospective studies, clinical trials, and pathophysiological reports is substantial to claim that a diabetic patient is at increased risk for the development of CRC than the average patient. Detection of the cancer at earlier stages greatly improves the chances of survival. This, therefore, creates a case for detection of colorectal cancer at an earlier stage especially for diabetic patients.

This study aims to investigate the association between diabetes and stage at diagnosis of CRC in an elderly population. This study will be the first to report this relationship in a large nationally representative data. The results of the study will add to existing knowledge about the association of diabetes and colorectal cancer. The study will also explore the association of other covariates such as coronary atherosclerosis, chronic obstructive pulmonary disease (COPD), congestive heart failure (CHF), age, race, sex, region in the US, patient location, and the frequency of physician office visits with stage at CRC diagnosis which together can inform more effective CRC screening interventions.

\section{Methods}

Newly diagnosed CRC patients were identified in the linked Surveillance, Epidemiology, and End Results (SEER) - Medicare database from 2003 through 2005. All cases of incident cancer reported to the SEER registries are cross-matched with a master file of Medicare enrollment. Previous work has demonstrated excellent agreement among data sources in case ascertainment. (Potosky, A.L. 1993) Currently, SEER has 17 high quality registries participating in the program, representing 12 states, and with the Medicare data it effectively represents the elderly population of the entire United States. (Warren, J.L. 2002) 
Between 2003 and 2005 there were 30,340 cases aged 66 and over with a newly diagnosed malignant adenocarcinoma of the colon or rectum. Sixty-six was selected as the cutoff to ensure that each person would have at least 12 months of Medicare claims prior to the diagnosis of CRC. Cases were further included if they had 1) only one primary cancer, 2) were eligible for both Part A and B benefits for at least 12 months prior to cancer diagnosis, and 3) did not die in the same month as their cancer diagnosis. Cases with unknown race were eliminated $(\mathrm{N}=38)$. Cases were further deleted if the source of information was from autopsy or death certificate only $(\mathrm{N}=9)$. Finally, cases were deleted if their cancer stage was zero or unknown $(\mathrm{N}=5,059)$.

SEER reports disease stage using the third edition of the American Joint Committee on Cancer (AJCC) definition for the 2003 cases and AJCC Cancer Staging Manual $6^{\text {th }}$ edition definition for cases diagnoses in 2004 and 2005. Comprehensive stage categories were collapsed into stages I, II, III and IV. At stage II and over the cancer may expand to other organs and could also include distant metastases and lymph node involvement, which are strong predictors of outcome following surgical resection of the cancer. (Gloeckler Ries, L.A. 2003) In addition, chemotherapy is recommended for treatment only at stage II, III and IV. Therefore, a dichotomous variable “stage” was created by retaining stage I patients as “early stage” and collapsing stages II, III and IV into a second category, "late stage”.

Inpatient, outpatient, and physician claims for diabetes for each patient during a period of 12 months before diagnosis of CRC were searched. To maximize specificity, a patient was identified as diabetic if he or she had at least one inpatient claim or two outpatient claims for diabetes. (Hebert, P.L. 1999) Since the majority of the patients diagnosed with CRC are over the age of 65 years they tend to have a greater number of comorbid conditions than younger patients. 
Multimorbidity has a strong impact on the screening, treatment, and survival of patients. (Yancik, R. 1998; Extermann, M. 2000) Therefore, the association of diabetes with stage at diagnosis of CRC must be conducted using some of the most common chronic comorbid conditions seen in these patients as covariates. Comorbid conditions were searched using similar criteria and the three most common chronic conditions i.e. CHF, coronary atherosclerosis, and COPD were selected to be included as covariates.

Age was categorized as 66-69 years; 70-74 years; 75-79 years; 80-84 years; and 85 years and over. Race was categorized as white, black, and other. SEER areas to which the patients belonged were categorized as west, mid-west, south, and east depending on the region in the US. Location of the tumor was categorized as proximal (cecum to splenic flexure) and distal (descending colon to rectum). The categorization was based on the ease of cancer detection based on the method used for screening or diagnosis. Proximal cancers are identified primarily through the use of colonoscopy, unlike a sigmoidoscopy which would be unable to reach these areas. The number of physician office visits 12 months prior to cancer diagnosis was identified and the continuous variable was transformed into quintiles of office visits with the first quintile representing the highest number of office visits.

Diabetic patients were matched to non-diabetic patients using a propensity score analysis in order to control for confounding by factors related to treatment selection. (Rubin, D.B. 1997) Each Diabetic was matched with two non-diabetics on five characteristics, namely, age, sex, race, location of the tumor and the SEER region that the patient belonged to. Patients for whom there was no match were excluded. The final cohort consisted of 16,398 patients.

Patients with cancer detected at an early stage were compared to those detected at late stage and those with and without diabetes were compared, using Pearson chi-square tests for 
comparisons of proportions. Logistic regression was carried out to explore the association between diabetes status and early or late stage of CRC diagnosis using the Enter method with demographic characteristics, patient location, and region as covariates. A separate logistic regression was run adding number of physician office visits as a covariate. The multivariableadjusted models were constructed using a logit link and a binomial distribution. All statistical analyses were conducted using IBM SPSS 20.

\section{Results}

The mean age of the study cohort was 76.8 years (range 66 to 114) and there were $52.0 \%$ females. Patients were evenly distributed between all stages with $24.8 \%$ diagnosed at stage I, $29.9 \%$ at stage II, $26.8 \%$ at stage III, and $18.6 \%$ at stage IV. Tumors were equally divided as well, with 50.3\% located in the proximal area of the colon. There were 5,466 diabetics in the cohort.

Chi square analyses for stage at diagnosis (Table 1) showed significant differences between age groups. Patients over the age of 80 were more likely to be diagnosed at later stages than stage I. Significant relationships were seen between stage at diagnosis with presence of diabetes and coronary atherosclerosis. Proximal tumors were more likely to be diagnosed at later stage than distal tumors. Frequency of office visits was also related to stage at diagnosis; patients with fewer office visits had a greater chance of being diagnosed at late stage. Chi square analyses for presence of diabetes (Table 2) showed no differences in age, sex and race. There were more diabetics than non-diabetics that had coronary atherosclerosis (35.5\% vs 17.7\%), COPD (13.8\% vs $10.4 \%$ ) and CHF (19.5\% vs $8.0 \%$ ). Diabetics also had a higher frequency of office visits than non-diabetics. 
Two separate logistic regression models are presented. The first model (Table 3) shows that diabetes has a significant association with stage at presentation of CRC (OR 0.92; 95\% CI 0.85-1.00). Presence of coronary atherosclerosis has lower odds of presenting with later stage of the cancer (OR 0.85; 95\% CI 0.78-0.93). Proximal tumors had 35\% greater odds (OR 1.35; 95\% CI 1.26-1.46) of being diagnosed at later stages than tumors located distally. On adding quintile of office visits to the second model (Table 4) diabetes showed no association with stage at diagnosis of CRC. Elderly patients over the age of 80 were associated with late stage at diagnosis. Proximal tumor location continued to remain significantly associated with later stage at diagnosis (OR 1.40; 95\% CI 1.30-1.51). The number of office visits was significantly associated with stage at diagnosis with decreasing frequency of office visits associated with later stage at diagnosis.

\section{Discussion}

This study aimed to check the association of diabetes with stage at diagnosis of CRC in a large nationally representative sample of elderly Medicare beneficiaries. Previous studies in the US and other countries have tested this association in smaller samples with conflicting results. In this study, diabetes did not show a significant association with stage at diagnosis for CRC. However, diabetic CRC patients tend to have poorer outcomes than non-diabetic patients, and therefore it can be argued that the cancer should be detected at an earlier stage than non-diabetics due to the survival benefit provided at being treated at earlier stages. In addition, if left uncontrolled, diabetes outcomes in CRC patients are even worse than those with controlled diabetes. (Siddiqui, A.A. 2008) 
This study also showed that diabetics visited physicians more frequently than nondiabetics and were more likely to have comorbid conditions such as coronary atherosclerosis, COPD and CHF. This would predispose them to greater recommendations for screening for various diseases including for CRC and one would therefore expect them to be diagnosed at an earlier stage than non-diabetics. However, as seen in the regression model, after adjusting for the number of physician office visits this was not so. A review of barriers and facilitators to screening for CRC in patients over the age of 65 has reported that although Medicare's coverage of screening colonoscopy was consistently reported as a facilitator, the most cited barrier related to healthcare providers was lack of screening recommendation by a physician. (Guessous,I. 2010) Compared to average risk patients, i.e. patients over the age of 50 with no chronic diseases or history of cancer, diabetics are at an increased-risk for colorectal cancer. A recent study that examined screening patterns in individuals with varying risk for CRC found that compared to average risk patients, diabetics were less likely to be recommended by physicians for CRC screening and were also less likely to be adherent to a recommendation if one was made. (Felsen, C.B. 2011)

It is important to note that patients over the age of 80 are more likely to be diagnosed at a later stage than younger patients. This could be due to some guidelines cautioning against use of invasive methods for screening for patients over the age of 75 due to possible adverse effects of screening. (Qaseem, A. 2012) All guidelines specifically do not recommend using any invasive method for screening patients over the age of 85 .

The results in this study show that tumors detected within the proximal region in the colon are found to have progressed much more than the ones located in the distal region at the time of detection. Distal tumors are easier to detect with less invasive procedures such as 
sigmoidoscopy which cannot look at the large intestine in its entirety and is recommended more frequently than colonoscopies. Sigmoidoscopes cannot reach the proximal areas of the large intestine leading to tumors in those areas to go undetected. (Schoen, R.E. 2012) In addition, proximal tumor location even after controlling for stage has also been significantly associated with poorer mortality and survival as compared to distally located colon cancers. (Wray, C.M. 2009) This study points to a greater need for further investigation in the differential prevalence of colorectal tumor location in the elderly. Future studies should also investigate use of screening methods and their association with tumor location in the colorectal region and how it affects outcomes such as survival and mortality.

Although this study has several strengths including stringent inclusion and exclusion criteria, a large nationally representative sample, and registry level data, it must be seen in light of its limitations. We used previously employed algorithms to identify diabetic patients, however, we were unable to identify the duration of diabetes as well as clinical values such as HbA1C which may have significantly affected the stage at which patients were diagnosed with CRC. Siddiqui et al have reported that uncontrolled diabetes and therefore increased HbA1C levels leads to diagnosis of CRC at later stages than diabetes that is under control. (Siddiqui, A.A. 2008) Future studies in the elderly must take into consideration clinical values and duration of diabetes. Timely screening plays a crucial role in detecting the cancer at earlier stages and the data did not allow us to check for frequency of screening. This is especially true for sigmoidoscopy and colonoscopy procedures which are recommended to be performed at five year and ten year intervals, respectively. In addition, SEER-Medicare data do not include other important measures of health status, such as body mass index, diet, functional disabilities or geriatric syndromes. 
In conclusion, this study shows that the association between diabetes and stage at diagnosis of colorectal cancer in those 65 years and older, although not statistically significant, must be further explored. Tumor location in diabetics must be studied further with a focus on detecting proximal tumors at earlier stages. Dialogue between the physician and diabetic patient should be encouraged to discuss screening for CRC. Diabetic patients should be screened for the cancer either more frequently or begin at an age earlier than the average risk patient in order to detect the cancer at early. 


\section{References}

American Cancer Society. Colorectal cancer facts \& figures 2011-2013. . 2011.

Coughlin SS, Calle EE, Teras LR, Petrelli J, Thun MJ. Diabetes mellitus as a predictor of cancer mortality in a large cohort of US adults. Am J Epidemiol. 2004;159(12):1160-1167. doi: 10.1093/aje/kwh161.

Extermann M. Measurement and impact of comorbidity in older cancer patients. Crit Rev Oncol Hematol. 2000;35(3):181-200.

Felsen CB, Piasecki A, Ferrante JM, Ohman-Strickland PA, Crabtree BF. Colorectal cancer screening among primary care patients: Does risk affect screening behavior? J Community Health. 2011;36(4):605-611. doi: 10.1007/s10900-010-9348-0.

Gellad ZF, Provenzale D. Colorectal cancer: National and international perspective on the burden of disease and public health impact. Gastroenterology. 2010;138(6):2177-2190. doi: 10.1053/j.gastro.2010.01.056.

Giovannucci E. Metabolic syndrome, hyperinsulinemia, and colon cancer: A review. Am J Clin Nutr. 2007;86(3):s836-42.

Giovannucci E. Insulin, insulin-like growth factors and colon cancer: A review of the evidence. $J$ Nutr. 2001;131(11 Suppl):3109S-20S. 
Gloeckler Ries LA, Reichman ME, Lewis DR, Hankey BF, Edwards BK. Cancer survival and incidence from the surveillance, epidemiology, and end results (SEER) program. Oncologist. 2003;8(6):541-552.

Gross CP, Guo Z, McAvay GJ, Allore HG, Young M, Tinetti ME. Multimorbidity and survival in older persons with colorectal cancer. J Am Geriatr Soc. 2006;54(12):1898-1904. doi: 10.1111/j.1532-5415.2006.00973.x.

Guessous I, Dash C, Lapin P, et al. Colorectal cancer screening barriers and facilitators in older persons. Prev Med. 2010;50(1-2):3-10. doi: 10.1016/j.ypmed.2009.12.005.

Hebert PL, Geiss LS, Tierney EF, Engelgau MM, Yawn BP, McBean AM. Identifying persons with diabetes using medicare claims data. Am J Med Qual. 1999;14(6):270-277.

Holt PR, Kozuch P, Mewar S. Colon cancer and the elderly: From screening to treatment in management of GI disease in the elderly. Best Pract Res Clin Gastroenterol. 2009;23(6):889907. doi: 10.1016/j.bpg.2009.10.010.

Hu FB, Manson JE, Liu S, et al. Prospective study of adult onset diabetes mellitus (type 2) and risk of colorectal cancer in women. J Natl Cancer Inst. 1999;91(6):542-547.

Huang YC, Lin JK, Chen WS, et al. Diabetes mellitus negatively impacts survival of patients with colon cancer, particularly in stage II disease. J Cancer Res Clin Oncol. 2011;137(2):211220. doi: 10.1007/s00432-010-0879-7.

Jemal A, Siegel R, Xu J, Ward E. Cancer statistics, 2010. CA Cancer J Clin. 2010;60(5):277300. doi: 10.3322/caac.20073. 
Jin T. Why diabetes patients are more prone to the development of colon cancer? Med Hypotheses. 2008;71(2):241-244. doi: 10.1016/j.mehy.2008.03.025.

La Vecchia C, Negri E, Decarli A, Franceschi S. Diabetes mellitus and colorectal cancer risk. Cancer Epidemiol Biomarkers Prev. 1997;6(12):1007-1010.

Le Marchand L, Wilkens LR, Kolonel LN, Hankin JH, Lyu LC. Associations of sedentary lifestyle, obesity, smoking, alcohol use, and diabetes with the risk of colorectal cancer. Cancer Res. 1997;57(21):4787-4794.

McKeown-Eyssen G. Epidemiology of colorectal cancer revisited: Are serum triglycerides and/or plasma glucose associated with risk? Cancer Epidemiol Biomarkers Prev. 1994;3(8):687695.

Meyerhardt JA, Catalano PJ, Haller DG, et al. Impact of diabetes mellitus on outcomes in patients with colon cancer. J Clin Oncol. 2003;21(3):433-440.

Nagel JM, Bucker S, Wood M, et al. Less advanced stages of colon cancer in patients with type 2 diabetes mellitus: An unexpected finding? Exp Clin Endocrinol Diabetes. 2012;120(4):224-228. doi: 10.1055/s-0031-1299704.

Potosky AL, Riley GF, Lubitz JD, Mentnech RM, Kessler LG. Potential for cancer related health services research using a linked medicare-tumor registry database. Med Care. 1993;31(8):732748. 
Qaseem A, Denberg TD, Hopkins RH,Jr, et al. Screening for colorectal cancer: A guidance statement from the american college of physicians. Ann Intern Med. 2012;156(5):378-386. doi: 10.1059/0003-4819-156-5-201203060-00010.

Rubin DB, Estimating causal effects from large data sets using propensity scores. Ann Intern Med. 1997;127(8 Pt 2):757-63.

Schoen RE, Pinsky PF, Weissfeld JL, et al. Colorectal cancers not detected by screening flexible sigmoidoscopy in the prostate, lung, colorectal, and ovarian cancer screening trial. Gastrointest Endosc. 2012;75(3):612-620. doi: 10.1016/j.gie.2011.10.024.

Siddiqui AA, Spechler SJ, Huerta S, Dredar S, Little BB, Cryer B. Elevated HbA1c is an independent predictor of aggressive clinical behavior in patients with colorectal cancer: A casecontrol study. Dig Dis Sci. 2008;53(9):2486-2494. doi: 10.1007/s10620-008-0264-4.

van de Poll-Franse LV, Haak HR, Coebergh JW, Janssen-Heijnen ML, Lemmens VE. Diseasespecific mortality among stage I-III colorectal cancer patients with diabetes: A large populationbased analysis. Diabetologia. 2012. doi: 10.1007/s00125-012-2555-8.

Warren JL, Klabunde CN, Schrag D, Bach PB, Riley GF. Overview of the SEER-medicare data: Content, research applications, and generalizability to the united states elderly population. Med Care. 2002;40(8 Suppl):IV-3-18. doi: 10.1097/01.MLR.0000020942.47004.03.

Weiderpass E, Gridley G, Nyren O, Ekbom A, Persson I, Adami HO. Diabetes mellitus and risk of large bowel cancer. J Natl Cancer Inst. 1997;89(9):660-661. 
Wray CM, Ziogas A, Hinojosa MW, Le H, Stamos MJ, Zell JA. Tumor subsite location within the colon is prognostic for survival after colon cancer diagnosis. Dis Colon Rectum. 2009;52(8):1359-1366. doi: 10.1007/DCR.0b013e3181a7b7de.

Yancik R, Wesley MN, Ries LA, et al. Comorbidity and age as predictors of risk for early mortality of male and female colon carcinoma patients: A population-based study. Cancer. 1998;82(11):2123-2134. 
Table 1: Characteristics of patients by Stage at Diagnosis of CRC

\begin{tabular}{|c|c|c|c|c|c|}
\hline \multirow[t]{2}{*}{ Patient Characteristic } & \multicolumn{4}{|c|}{ Stage at Diagnosis } & \multirow[t]{2}{*}{$p$} \\
\hline & Early & & Late & & \\
\hline & $\mathrm{N}$ & $\%$ & $\mathrm{~N}$ & $\%$ & \\
\hline Age Group & & & & & 0.004 \\
\hline $66-69$ & 730 & $18.0 \%$ & 2,085 & $16.9 \%$ & \\
\hline $70-74$ & 962 & $23.7 \%$ & 2,823 & $22.9 \%$ & \\
\hline $75-79$ & 1,070 & $26.4 \%$ & 3,124 & $25.3 \%$ & \\
\hline $80-84$ & 776 & $19.1 \%$ & 2,452 & $19.9 \%$ & \\
\hline 85 and over & 521 & $12.8 \%$ & 1,855 & $15.0 \%$ & \\
\hline Sex & & & & & 0.295 \\
\hline Male & 1,977 & $48.7 \%$ & 5,893 & $47.8 \%$ & \\
\hline Female & 2,082 & $51.3 \%$ & 6,446 & $52.2 \%$ & \\
\hline Race & & & & & 0.379 \\
\hline White & 3,246 & $80.0 \%$ & 9,888 & $80.1 \%$ & \\
\hline Black & 416 & $10.2 \%$ & 1,322 & $10.7 \%$ & \\
\hline Other & 397 & $9.8 \%$ & 1,129 & $9.1 \%$ & \\
\hline Diabetes & & & & & 0.003 \\
\hline No & 2,629 & $64.8 \%$ & 8,303 & $67.3 \%$ & \\
\hline Yes & 1,430 & $35.2 \%$ & 4,036 & $32.7 \%$ & \\
\hline Atherosclerosis & & & & & 0.000 \\
\hline No & 3,007 & $74.1 \%$ & 9,509 & $77.1 \%$ & \\
\hline Yes & 1,052 & $25.9 \%$ & 2,830 & $22.9 \%$ & \\
\hline COPD & & & & & 0.055 \\
\hline No & 3,558 & $87.7 \%$ & 10,953 & $88.8 \%$ & \\
\hline Yes & 501 & $12.3 \%$ & 1,386 & $11.2 \%$ & \\
\hline CHF & & & & & 0.183 \\
\hline No & 3,553 & $87.5 \%$ & 10,897 & $80.5 \%$ & \\
\hline Yes & 506 & $12.5 \%$ & 1,442 & $11.7 \%$ & \\
\hline Region & & & & & 0.736 \\
\hline West & 1,525 & $37.6 \%$ & 4,677 & $37.9 \%$ & \\
\hline Midwest & 624 & $15.4 \%$ & 1,881 & $15.2 \%$ & \\
\hline South & 798 & $19.7 \%$ & 2,336 & $18.9 \%$ & \\
\hline East & 1,112 & $27.4 \%$ & 3,445 & $27.9 \%$ & \\
\hline Tumor Site & & & & & 0.000 \\
\hline Distal Tumor & 2,249 & $55.4 \%$ & 5,895 & $47.8 \%$ & \\
\hline Proximal Tumor & 1,810 & $44.6 \%$ & 6,444 & $52.2 \%$ & \\
\hline Quintile Office Visits & & & & & 0.000 \\
\hline First & 1,025 & $25.3 \%$ & 2,556 & $20.7 \%$ & \\
\hline Second & 919 & $22.6 \%$ & 2,573 & $20.9 \%$ & \\
\hline Third & 833 & $20.5 \%$ & 2,430 & $19.7 \%$ & \\
\hline Fourth & 749 & $18.5 \%$ & 2,316 & $18.8 \%$ & \\
\hline Fifth & 533 & $13.1 \%$ & 2,464 & $20.0 \%$ & \\
\hline
\end{tabular}

Continued 
Table 1: Characteristics of patients by Stage at Diagnosis of CRC

\begin{tabular}{lrlrll}
\hline Patient Characteristic & \multicolumn{4}{c}{ Stage at Diagnosis } & $p$ \\
& Early & \multicolumn{4}{c}{ Late } \\
\hline Patient Location & & & & & 0.141 \\
Big Metro & 2,225 & $54.8 \%$ & 6,993 & $56.7 \%$ & \\
Metro & 1,143 & $28.2 \%$ & 3,390 & $27.5 \%$ & \\
Urban & 248 & $6.1 \%$ & 708 & $5.7 \%$ & \\
Less Urban & 369 & $9.1 \%$ & 994 & $8.1 \%$ & \\
Rural & 74 & $1.8 \%$ & 254 & $2.1 \%$ & \\
\hline TOTAL & 4,059 & & 12,399 & & \\
\hline
\end{tabular}


Table 2: Characteristics of patients by Diabetes Status

\begin{tabular}{|c|c|c|c|c|c|}
\hline \multirow[t]{3}{*}{ Patient Characteristic } & \multicolumn{4}{|c|}{ Presence of Diabetes } & \multirow[t]{3}{*}{$p$} \\
\hline & \multicolumn{2}{|c|}{ No } & \multicolumn{2}{|l|}{ Yes } & \\
\hline & $\mathrm{N}$ & $\%$ & $\mathrm{~N}$ & $\%$ & \\
\hline Age Group & & & & & 0.150 \\
\hline $66-69$ & 1,919 & $17.6 \%$ & 896 & $16.4 \%$ & \\
\hline $70-74$ & 2,528 & $23.1 \%$ & 1,257 & $23.0 \%$ & \\
\hline $75-79$ & 2,738 & $25.0 \%$ & 1,456 & $26.6 \%$ & \\
\hline $80-84$ & 2,165 & $19.8 \%$ & 1,063 & $19.4 \%$ & \\
\hline 85 and over & 1,582 & $14.5 \%$ & 794 & $14.5 \%$ & \\
\hline Sex & & & & & 0.683 \\
\hline Male & 5,259 & $48.1 \%$ & 2,611 & $47.8 \%$ & \\
\hline Female & 5,673 & $51.9 \%$ & 2,855 & $52.2 \%$ & \\
\hline Race & & & & & 0.320 \\
\hline White & 8,788 & $80.4 \%$ & 4,346 & $79.5 \%$ & \\
\hline Black & 1,132 & $10.4 \%$ & 606 & $11.1 \%$ & \\
\hline Other & 1,012 & $9.3 \%$ & 514 & $9.4 \%$ & \\
\hline Stage & & & & & 0.003 \\
\hline Early & 2,629 & $24.0 \%$ & 1,430 & $26.2 \%$ & \\
\hline Late & 8,303 & $76.0 \%$ & 4,036 & $73.8 \%$ & \\
\hline Coronary Athero & & & & & 0.000 \\
\hline No & 8,992 & $82.3 \%$ & 3,524 & $64.5 \%$ & \\
\hline Yes & 1,940 & $17.7 \%$ & 1,942 & $35.5 \%$ & \\
\hline COPD & & & & & 0.000 \\
\hline No & 9,797 & $89.6 \%$ & 4,714 & $86.2 \%$ & \\
\hline Yes & 1,135 & $10.4 \%$ & 752 & $13.8 \%$ & \\
\hline CHF & & & & & 0.000 \\
\hline No & 10,052 & $92.0 \%$ & 4,398 & $80.5 \%$ & \\
\hline Yes & 880 & $8.0 \%$ & 1,068 & $19.5 \%$ & \\
\hline Region & & & & & 0.440 \\
\hline West & 4,138 & $37.9 \%$ & 2,064 & $37.8 \%$ & \\
\hline Midwest & 1,637 & $15.0 \%$ & 868 & $15.9 \%$ & \\
\hline South & 2,111 & $19.3 \%$ & 1,023 & $18.7 \%$ & \\
\hline East & 3,046 & $27.9 \%$ & 1,511 & $27.6 \%$ & \\
\hline Tumor Site & & & & & 0.799 \\
\hline Distal Tumor & 5,437 & $49.7 \%$ & 2,707 & $49.5 \%$ & \\
\hline Proximal Tumor & 5,495 & $50.3 \%$ & 2,759 & $50.5 \%$ & \\
\hline Quintile Office Visits & & & & & 0.000 \\
\hline First & 1,714 & $15.7 \%$ & 1,867 & $34.2 \%$ & \\
\hline Second & 2,027 & $18.5 \%$ & 1,465 & $26.8 \%$ & \\
\hline Third & 2,133 & $19.5 \%$ & 1,130 & $20.7 \%$ & \\
\hline Fourth & 2,283 & $20.9 \%$ & 782 & $14.3 \%$ & \\
\hline Fifth & 2,775 & $25.4 \%$ & 222 & $4.1 \%$ & \\
\hline
\end{tabular}


Table 2: Characteristics of patients by Diabetes Status

\begin{tabular}{lrrrrr}
\hline Patient Characteristic & \multicolumn{4}{c}{ Presence of Diabetes } & \multirow{2}{*}{$p$} \\
& \multicolumn{2}{c}{ No } & Yes & \\
\hline Patient Location & & & & & \\
Big Metro & 6,143 & $56.2 \%$ & 3,075 & $56.3 \%$ & 0.814 \\
Metro & 3,001 & $27.5 \%$ & 1,532 & $28.0 \%$ & \\
Urban & 641 & $5.9 \%$ & 315 & $5.8 \%$ & \\
Less Urban & 923 & $8.4 \%$ & 440 & $8.0 \%$ & \\
Rural & 224 & $2.0 \%$ & 104 & $1.9 \%$ & \\
\hline TOTAL & 10,932 & $100.0 \%$ & 54,66 & $100 \%$ & \\
\hline
\end{tabular}


Table 3: Association of diabetes with stage at diagnosis of Colorectal Cancer

\begin{tabular}{|c|c|c|c|c|c|c|}
\hline \multirow{2}{*}{ Patient Characteristic } & & \multirow[b]{2}{*}{$p$} & \multirow[b]{2}{*}{ Sig } & \multirow[b]{2}{*}{ Odds } & \multicolumn{2}{|c|}{ 95\% C.I.for Odds } \\
\hline & & & & & Lower & Upper \\
\hline \multirow{2}{*}{ Comorbidities } & Diabetes & .039 & $* * *$ & 0.92 & 0.85 & 1.00 \\
\hline & Coronary Athero & .000 & $* * *$ & 0.85 & 0.78 & 0.93 \\
\hline \multirow{6}{*}{ Age Group } & COPD & .200 & & 0.93 & 0.83 & 1.04 \\
\hline & CHF & .957 & & 1.00 & 0.89 & 1.12 \\
\hline & $66-69$ & .019 & Referent & & & \\
\hline & $70-74$ & .658 & & 1.03 & 0.92 & 1.15 \\
\hline & $75-79$ & .905 & & 1.01 & 0.90 & 1.12 \\
\hline & $80-84$ & .158 & & 1.09 & 0.97 & 1.23 \\
\hline \multirow{5}{*}{$\begin{array}{l}\text { Sex } \\
\text { Race }\end{array}$} & 85 and over & .004 & $* * *$ & 1.21 & 1.06 & 1.39 \\
\hline & Female & .518 & & 0.98 & 0.91 & 1.05 \\
\hline & White & .395 & Referent & & & \\
\hline & Black & .516 & & 1.04 & 0.92 & 1.17 \\
\hline & Other & .254 & & 0.93 & 0.82 & 1.06 \\
\hline \multirow{3}{*}{$\begin{array}{l}\text { Tumor Location } \\
\text { Region in the US }\end{array}$} & Proximal & .000 & $* * *$ & 1.35 & 1.26 & 1.46 \\
\hline & WEST & .941 & Referent & & & \\
\hline & MIDWEST & .653 & & 0.97 & 0.87 & 1.09 \\
\hline \multirow{8}{*}{ Patient Location } & SOUTH & .561 & & 0.97 & 0.87 & 1.08 \\
\hline & EAST & .755 & & 0.99 & 0.90 & 1.08 \\
\hline & Big Metro & .153 & Referent & & & \\
\hline & Metro & .148 & & 0.94 & 0.86 & 1.02 \\
\hline & Urban & .264 & & 0.92 & 0.78 & 1.07 \\
\hline & Less Urban & .040 & & 0.86 & 0.75 & 0.99 \\
\hline & Rural & .524 & & 1.09 & 0.83 & 1.43 \\
\hline & Constant & .000 & & 2.64 & & \\
\hline
\end{tabular}

Coronary Athero = Coronary Atherosclerosis; COPD = Chronic Obstructive Pulmonary Disorder; $\mathrm{CHF}=$ Congestive Heart Failure Referent group for Diabetes, Coronary Atherosclerosis, COPD and CHF are No Diabetes, No Coronary Atherosclerosis, No COPD and No CHF respectively

Referent group for female is male

Referent group for proximal tumor location is distal tumor location 
Table 4: Association of diabetes with stage at diagnosis of Colorectal Cancer

\begin{tabular}{|c|c|c|c|c|c|c|}
\hline \multirow[b]{2}{*}{ Patient Characteristic } & & \multirow[b]{2}{*}{$p$} & \multirow[b]{2}{*}{ Sig } & \multirow[b]{2}{*}{ Odds } & \multicolumn{2}{|c|}{ 95\% C.I.for Odds } \\
\hline & & & & & Lower & Upper \\
\hline \multirow{2}{*}{ Comorbidities } & Diabetes & .309 & & 1.04 & 0.96 & 1.13 \\
\hline & Coronary Athero & .370 & & 0.96 & 0.87 & 1.05 \\
\hline \multirow{6}{*}{ Age Group } & COPD & .750 & & 1.02 & 0.91 & 1.14 \\
\hline & CHF & .214 & & 1.08 & 0.96 & 1.22 \\
\hline & $66-69$ & .000 & Referent & & & \\
\hline & $70-74$ & .357 & & 1.05 & 0.94 & 1.18 \\
\hline & $75-79$ & .258 & & 1.07 & 0.95 & 1.19 \\
\hline & $80-84$ & .009 & $* * *$ & 1.18 & 1.04 & 1.33 \\
\hline \multirow{5}{*}{$\begin{array}{l}\text { Sex } \\
\text { Race }\end{array}$} & 85 and over & .000 & $* * *$ & 1.32 & 1.15 & 1.50 \\
\hline & Female & .483 & & 1.03 & 0.95 & 1.11 \\
\hline & White & .342 & Referent & & & \\
\hline & Black & .988 & & 1.00 & 0.89 & 1.13 \\
\hline & Other & .145 & & 0.91 & 0.80 & 1.03 \\
\hline \multirow{3}{*}{$\begin{array}{l}\text { Tumor Location } \\
\text { Region in the US }\end{array}$} & Proximal & .000 & $* * *$ & 1.40 & 1.30 & 1.51 \\
\hline & WEST & .820 & Referent & & & \\
\hline & MIDWEST & .503 & & 0.96 & 0.86 & 1.08 \\
\hline \multirow{7}{*}{ Patient Location } & SOUTH & .373 & & 0.95 & 0.85 & 1.06 \\
\hline & EAST & .730 & & 0.98 & 0.90 & 1.08 \\
\hline & Big Metro & .081 & Referent & & & \\
\hline & Metro & .090 & & 0.93 & 0.86 & 1.01 \\
\hline & Urban & .192 & & 0.90 & 0.77 & 1.05 \\
\hline & Less Urban & .020 & & 0.85 & 0.74 & 0.97 \\
\hline & Rural & .623 & & 1.07 & 0.82 & 1.41 \\
\hline
\end{tabular}

Continued 
Table 4: Association of diabetes with stage at diagnosis of Colorectal Cancer

\begin{tabular}{|c|c|c|c|c|c|c|}
\hline \multirow[b]{2}{*}{ Patient Characteristic } & & \multirow[b]{2}{*}{$p$} & \multirow[b]{2}{*}{ Sig } & \multirow[b]{2}{*}{ Odds } & \multicolumn{2}{|c|}{ 95\% C.I.for Odds } \\
\hline & & & & & Lower & Upper \\
\hline \multirow{6}{*}{$\begin{array}{l}\text { Quintile of Office } \\
\text { Visits }\end{array}$} & First Quintile & .000 & Referent & & & \\
\hline & Second & .007 & $* * *$ & 1.16 & 1.04 & 1.29 \\
\hline & Third & .000 & $* * *$ & 1.25 & 1.12 & 1.40 \\
\hline & Fourth & .000 & $* * *$ & 1.37 & 1.21 & 1.54 \\
\hline & Fifth & .000 & $* * *$ & 2.13 & 1.86 & 2.44 \\
\hline & Constant & & & 1.671 & & \\
\hline
\end{tabular}

Coronary Athero = Coronary Atherosclerosis; COPD = Chronic Obstructive Pulmonary Disorder; $\mathrm{CHF}=$ Congestive Heart Failure

Referent group for Diabetes, Coronary Atherosclerosis, COPD and CHF are No Diabetes, No Coronary Atherosclerosis, No COPD and No CHF respectively

Referent group for female is male

Referent group for proximal tumor location is distal tumor location

First quintile in Office Visits represents highest number of office visits and fifth represents the lowest 


\section{CHAPTER THREE}

Association of Diabetes AND PREDictors of EMERgency CONDITION FOR ColorectAL Cancer Surgery in the Medicare Population 


\section{Introduction}

Colorectal cancer (CRC) is ranked third in incidence and mortality of all cancers in both men and women. (American Cancer Society, 2011; Gellad \& Provenzale, 2010; Jemal, Siegel, Xu, \& Ward, 2010) In 2011 approximately 141,210 men and women were expected to be diagnosed and approximately 49,380 are expected to succumb to CRC. (American Cancer Society, 2011) Screening for CRC can identify polyps or abnormal growths before they turn cancerous. Disparities in screening, treatment, and survival persist even with incidence and mortality from CRC decreasing significantly due to increasing screening rates. (Gellad \& Provenzale, 2010) (Hao, Jemal, Zhang, \& Ward, 2009; Hoff \& Dominitz, 2010; Meissner, Breen, Klabunde, \& Vernon, 2006)

The incidence of CRC is uncommon under the age of 50 years where it is predominantly in tumors induced by heredity and with a family history. However, between the ages of 50 and 85 years the incidence increases exponentially, with two-thirds of all cancers occurring in patients over the age of 65. (Everhart \& Ruhl, 2009; Ries et al., 2007; Rim, Seeff, Ahmed, King, \& Coughlin, 2009)

Comorbidity, or illnesses other than the primary illness under treatment, is more common in the elderly. (Shack, Rachet, Williams, Northover, \& Coleman, 2010) Older individuals also often present with chronic conditions that complicate the diagnostic and clinical management of CRC which leads to poorer prognosis and outcomes of the cancer. (Satariano \& Silliman, 2003; Yancik et al., 1998) In their review of population-based studies including CRC patients 65 years and older, Faivre and colleagues reported that comorbidity was shown to be an independent prognostic factor. (Faivre, Lemmens, Quipourt, \& Bouvier, 2007). The study added that 
comorbidities such as previous malignancy, cardiovascular diseases, chronic obstructive pulmonary disease (COPD), hypertension and diabetes decreased 5-year survival compared to patients with CRC with no comorbidity. The three most common comorbid conditions seen in elderly patients with CRC are congestive heart failure, chronic obstructive pulmonary disease and diabetes mellitus. (Gross et al., 2006) There is a lack of studies exploring the association of chronic comorbid conditions with the diagnosis of CRC.

Of all comorbid conditions, the association of diabetes with CRC has been studied most extensively and has been established with prospective, case-control and retrospective studies providing overwhelming evidence. (Elwing, Gao, Davidson, \& Early, 2006; Hu et al., 1999; Hu et al., 1999; Limburg et al., 2005; Limburg et al., 2006; Vinikoor et al., 2009; Will, Galuska, Vinicor, \& Calle, 1998) Unlike with other diseases, in addition to the epidemiological evidence, pathophysiological evidence has also contributed in understanding the link between diabetes and CRC. (Giovannucci, 2001; Jin, 2008; McKeown-Eyssen, 1994) Diabetes also affects the outcomes of CRC as reported by several investigators. Reports from around the world have concluded that diabetic CRC patients have worse outcomes than non-diabetic patients which may either be a results of less aggressive treatment of the cancer or poorly controlled diabetes. (Coughlin, Calle, Teras, Petrelli, \& Thun, 2004; Gross et al., 2006; Lemmens et al., 2005; Meyerhardt et al., 2003; Siddiqui et al., 2008) Surgical resection is the only curative treatment of colorectal cancer, performed as an open, surgical procedure requiring hospitalization. (Mitry, Barthod, Penna, \& Nordlinger, 2002; Redaelli, Cranor, Okano, \& Reese, 2003) Emergency presentation with CRC, which is an indicator of poor prognosis, and poor screening practices, is seen in almost a quarter of the cases that present with CRC. (Kim et al., 2007; Polednak, 2000; Smothers et al., 2003) A nationally representative database has shown that diabetic elderly 
women are less likely to undergo screening for CRC. (Limburg et al., 2005) This is also true for ethnic minorities and persons of lower socioeconomic status. (Hood et al., 2010; Rich, Kuyateh, Dwyer, Groves, \& Steinberger, 2011) Poor screening practices, such as not using the correct method or not screening in a timely fashion can lead to later detection of cancer and increases the chances of presenting as an emergency case. This is directly associated with poorer prognosis of the disease and worse outcomes than if the cancer is detected earlier.

Potentially fatal complications of colorectal cancer include bowel perforation, peritonitis, and obstruction. These complications are considered surgical emergencies and are the initial presentation of colorectal cancer in an estimated $15 \%$ to $30 \%$ of patients with colorectal cancer. (Diggs, Xu, Diaz, Cooper, \& Koroukian, 2007)In addition, patients with emergency room presentation of CRC have increased 30-day mortality and decreased 5-year survival compared to those scheduled for elective surgery. (Mitchell, Inglis, Murdoch, \& Porter, 2007)

Predictors of presenting as an emergency have been examined by Polednak who used the Connecticut tumor registry to estimate the frequency and characteristics of first inpatient hospital admission through an emergency department (ED) among more than 11,000 patients. (Polednak, 2000). He found that age greater than 75 years, black race, and proximal cancer were significant predictors of admission through the ED. A study by Diggs and colleagues used hospital discharge data to examine the association of demographic characteristics, insurance status and number of comorbidities with emergency condition for CRC resection surgery. They found that older age, being male, black and being uninsured increased the likelihood of presenting emergently. (Diggs et al., 2007) However, the study by Polednak did not examine any comorbid conditions such as diabetes and was limited to patients in Connecticut, and Diggs' study is limited by the fact that they used discharge data not incident data, used elderly as well as 
younger patients, was lacking in information on stage of cancer, and had no information on specific comorbid conditions. No other study in the US has attempted to study the predictors of emergency condition for CRC surgery.

As evidence shows diabetic patients are at an increased risk for the development of CRC and are predisposed to worse outcomes than a non-diabetic CRC patient. A diabetic patient presenting as an emergency condition for CRC surgery could compound the prognosis, with a potential for poorer chances of survival. Therefore, it is imperative to check the association of diabetes and other covariates with presenting emergently for CRC surgery. This study is the first to comprehensively study the predictors of emergency condition for CRC resection surgery in newly diagnosed CRC patients over 65 years of age. This study is also the first to report the association of diabetes and other frequently seen comorbid conditions in CRC patients over 65 years of age with emergency condition for surgical resection. The aim of the study is to check the association of diabetes with presenting as an emergency condition for CRC surgery in those over 65 years of age. A second aim is to indentify predictors of emergency condition of CRC surgery in those over 65 years of age using a large nationally representative registry data.

\section{Methods}

$\underline{\text { Data }}$

The study was a retrospective cross sectional analysis of data from the Surveillance, Epidemiology and End Results-Medicare (SEER-Medicare) files for the years 2003 to 2005. The SEER-Medicare data reflect the linkage of two large population-based sources of data that provide detailed information about Medicare beneficiaries with cancer. The data come from the 
SEER program of cancer registries that collect clinical, demographic and cause of death information for persons with cancer and the Medicare claims for covered health care services from the time of a person's Medicare eligibility until death. The linkage of these two data sources results in a unique population-based source of information that can be used for an array of epidemiological and health services research. Previous work has demonstrated excellent agreement among data sources in case ascertainment. (Potosky, Riley, Lubitz, Mentnech, \& Kessler, 1993) Currently, SEER has 17 high quality registries participating in the program, representing 12 states, and with the Medicare data it effectively represents the elderly population of the entire United States. (Warren, Klabunde, Schrag, Bach, \& Riley, 2002)

\section{Cohort}

Between 2003 and 2005 there were 30,340 cases aged 66 and over with a newly diagnosed malignant adenocarcinoma of the colon or rectum. Sixty-six was selected as the cutoff to ensure that each person would have at least 12 months of Medicare claims prior to the diagnosis of CRC. Cases were further included if they had 1) only one primary cancer, 2) were eligible for both Part A and B benefits for at least 12 months prior to cancer diagnosis, and 3) did not die in the same month as their cancer diagnosis. Cases with unknown race were eliminated $(\mathrm{N}=38)$. Cases were further deleted if the source of information was from autopsy or death certificate only $(\mathrm{N}=9)$. Finally, cases were deleted if their cancer stage was zero or unknown $(N=5,059)$. Cases were also excluded if they did not undergo any type of CRC resection surgery $(\mathrm{N}=4,152)$.

The next step was to identify patients who underwent CRC resection procedures in the colon and rectum. These patients were identified using the International Classification of 
Diseases, Ninth Revision, Clinical Modification (ICD-9-CM) procedure codes for colon resection (codes 45.7x and 45.8), rectal resection (codes 48.4x, 48.5, 48.6x), and other operations on the intestine including colostomy and ileostomy (codes 46.1-2). (Diggs et al., 2007; Etzioni, Beart, Madoff, \& Ault, 2009; Hayanga et al., 2010) Patients were identified as being an emergency case for CRC surgery if they also had diagnosis codes of bowel perforation, peritonitis, or obstruction. The ICD-9-CM diagnosis codes used to determine which patients met these criteria included other specified intestinal obstruction (code 560.8), unspecified intestinal obstruction (code 560.9), peritonitis in infectious diseases (code 567.0), other suppurative peritonitis (code 567.2), other specified peritonitis (code 567.8), unspecified peritonitis (code 567.9), and perforation of the intestine (code 569.83). The final cohort for this study consisted of 21,082 patients.

\section{Construction of Variables}

Inpatient, outpatient, and physician claims for diabetes for each patient during a period of 12 months before diagnosis of CRC were searched. To maximize specificity, a patient was identified as diabetic if he or she had at least one inpatient claim or two outpatient claims for diabetes. (Hebert et al., 1999) Since majority of the patients diagnosed with CRC are over the age of 65 years they tend to have a greater number of comorbid conditions than younger patients. Multimorbidity has a strong impact on the screening, treatment, and survival of patients. (Extermann, 2000; Yancik et al., 1998) Therefore, the association of diabetes with emergency surgery for CRC must be conducted using some of the most common chronic comorbid conditions seen in these patients as covariates. Comorbid conditions were searched using similar criteria and the three most common chronic conditions i.e. congestive heart failure (CHF), coronary atherosclerosis, and COPD were selected to be included as covariates. 
SEER reports disease stage using the third edition of the American Joint Committee on Cancer (AJCC) definition for the 2003 cases and AJCC Cancer Staging Manual $6^{\text {th }}$ edition definition for cases diagnoses in 2004 and 2005. Comprehensive stage categories were collapsed into stages I, II, III and IV. Stage at diagnosis for colorectal cancer directly affects mortality and survival. Chances for survival are more than $90 \%$ for Stage I, 82\% for Stage II, 57\% for Stage III and drop to 6\% for Stage IV patients. $\{\{189$ Gloeckler Ries,L.A. 2003\} $\}$ Due to these differential survival rates between the stages, patients were categorized as being “Early Stage” (Stage I and II) or "Late Stage” (Stages III and IV) patients.

Age was categorized as 66-69 years, 70-74 years, 75-79 years, 80-84 years, and 85 years and over. Race was categorized as white, black, and other. SEER areas to which the patients belonged were categorized as west, mid-west, south, and east depending on the region in the US. Location of the tumor was categorized as proximal (cecum to splenic flexure) and distal (descending colon to rectum). The categorization was based on the ease of cancer detection based on the method used for screening or diagnosis. Proximal cancers are identified primarily through the use of colonoscopy, unlike a sigmoidoscopy which would be unable to reach these areas. The number of physician office visits 12 months prior to cancer diagnosis was identified and the continuous variable was transformed into quintiles of office visits with the first quintile representing the highest number of office visits.

\section{Analyses}

Patients undergoing emergency versus elective surgery for CRC were initially compared using descriptive statistics against the independent variables using Pearson chi-square tests for comparison of proportions. Similarly patients with and without diabetes were also compared using the bivariate statistic. 
The association of diabetes with emergency surgery for CRC was analyzed by employing multivariate logistic regression. After check the goodness-of-fit using the Hosmer-Lemeshow test statistic, the final model using the Enter method was analyzed. The predictors of emergency surgery for colorectal cancer were tested in the same model. The multivariable-adjusted models were constructed using a logit link and a binomial distribution. All statistical analyses were conducted using IBM SPSS 20.

\section{Results}

In a sample of 21,082 patients, the mean age was 77.4 years (range 66 to 106 years). There were 56.5\% female patients and the sample was largely white (85.3\%). There were 22.2\% diabetic patients, $22.0 \%$ of the sample had coronary atherosclerosis, and the proportion of patients that had COPD and CHF were $10.8 \%$ and $10.6 \%$, respectively. The sample had a proportion of $23.1 \%$ patients that were diagnosed at Stage I, $33.8 \%$ at stage II, $29.4 \%$ at stage III and $13.7 \%$ at stage IV. Tumor location was evenly distributed among the patients with $54.1 \%$ patients having a proximal tumor. The number of patients that were classified as having an emergency condition for CRC surgery was 2,242 or $10.4 \%$ of the sample.

The bivariate analysis for emergency versus non-emergency patients showed that older patients were more likely to be a candidate for emergency surgery for CRC (Table 1). This was especially seen in patients over the age of 80 years. Patients classified as emergency candidates were more likely to be diagnosed at later stages than earlier stages and there was a significantly greater likelihood of a patient having a distal tumor than a proximal tumor. The results also showed that patients with lower frequency of office visits were more likely to be classified as an emergency rather than non-emergency case. There was also a significant difference between 
diabetics and non-diabetics in their distribution between emergency and non-emergency condition for CRC surgery.

The distribution of patients between diabetics and non-diabetics by age showed that with increasing age in the elderly, the proportion of diabetics increased and peaked between the age range 75-79 years and then decreased thereafter (Table 2). There were more diabetic women in the sample than men, and there were more diabetic patients of black and other races than white patients. Diabetic patients represented the most frequently visited category in terms of quintiles of physician office visits, and the eastern region of the US had a greater proportion of diabetics than the rest of the country.

Logistic regression results (Table 3) indicated that although the odds of a diabetic patient being an emergency patient were lower than a non-diabetic, this was not statistically significant (OR 0.89; 95\% CI 0.79-1.01). Coronary atherosclerosis patients had lower odds of being classified as emergency (OR 0.82; 95\% CI 0.72-0.93) whereas those with COPD had increased odds (OR 1.28; 95\% CI 1.11-1.49). Patients with late stage at diagnosis had a 75\% greater chance of being emergency patients than stage I patients (OR 1.75; 95\% CI 1.60-1.91). Proximal tumor location lent itself to being negatively associated with being classified as an emergency case for CRC surgery. Compared to whites, blacks were more prone to being emergency cases (OR 1.27; 95\% CI 1.08-1.49). The regression also showed that compared to the highest quintile of office visits, patients belonging to the lowest quintile had greater odds of being an emergency patient (OR 1.48; 95\% CI 1.26-1.74). 


\section{Discussion}

This study is the first to report the association of diabetes with emergency surgery for CRC, and explore the predictors of emergency colorectal cancer surgery in a large nationally representative sample. The study showed that although the odds of being an emergency patient for CRC surgery were lower for diabetic patients, this association was not significant. However, this result must be interpreted in light of the fact that diabetic patients belonged to the highest quintile in terms of physician office visits. Previous reports of a Medicare population have mentioned that having any physician office visit, increased number of office visits, and visits with primary care physicians are associated with increased CRC test use. (Schenck et al., 2011) Klabunde and colleagues have reported that having a chronic condition such as diabetes is a predictor of receiving a physician recommendation for CRC screening. (Klabunde, Schenck, \& Davis, 2006) Increased number of physician office visits increases the chances of being recommended for a screening test; and clinician recommendation for a screening test has been proven to be a strong predictor in the elderly as well as young patients to adhere to screening practices for CRC. (Felsen, Piasecki, Ferrante, Ohman-Strickland, \& Crabtree, 2011; Gilbert \& Kanarek, 2005)

This study also showed that compared to Whites, Black patients were more likely to be classified as an emergency condition for CRC surgery. It has been reported that Blacks, Hispanics, and American Indians/Alaska Natives were less likely to report receiving a recommendation for sigmoidoscopy compared to Whites. (Coughlin \& Thompson, 2005) Whites are also more likely than Blacks to report ever receiving a provider recommendation for a colonoscopy. Although the proportion of patients receiving recommendations for colonoscopy/sigmoidoscopy increased over time, the gap between races remained unchanged, 
even after controlling for insurance status. (Rich et al., 2011) A study by Hood and colleagues has reported that although over $80 \%$ of their sample of 439 blacks was covered by insurance, less than 50\% reported receiving a recommendation to screen for CRC. (Hood et al., 2010) This calls for immediate intervention and strategies for improving physician recommendation in this subgroup of the population.

This study also showed that the odds of being an emergency case for CRC surgery were higher for patients over the age of 80 years. However, this may be due to several guidelines cautioning against use of invasive methods for screening of patients over the age of 75 because of possible adverse effects of screening. Thus it is possible that the cancer does not get detected in early stages in this age group. (Qaseem et al., 2012) All the guidelines specifically do not recommend using any invasive method for screening patients over the age of 85 .

The results of this study also showed that having a proximal tumor decreased the odds of being an emergency case for CRC surgery. This study is the first to report an association between tumor location and emergency condition for surgery for CRC. However, it has been reported that screening for CRC does not have a survival benefit in patients with proximal cancers despite recent epidemiologic studies suggesting an overall shift to more proximal sites of colon cancer distribution. (Wong, 2010) Proximal cancer tumor biology also makes it hard for them to be detected. There are underlying differences in the biology of proximal and distal CRC neoplasia that may contribute to the variable effectiveness of colonoscopy. (Baxter, Warren, Barrett, Stukel, \& Doria-Rose, 2012) This may mean that proximal tumors were possibly underrepresented in the sample in this study. Further investigation into the association between tumor location and emergency condition for CRC surgery is warranted. 
Strengths of this study include the use of population based data from a cancer registry that is globally recognized as an authoritative source of information on cancer incidence in the United States. Detailed demographic and cancer data on stage and tumor location allowed for multivariable regression analysis of emergency condition for CRC surgery variations in patients with and without diabetes that adjusted for several potential major confounders.

Despite its strengths the limitations of the study must be acknowledged. Previously employed algorithms were used to identify diabetic patients. However, the study was unable to identify the duration of diabetes as well as clinical values such as HbA1C which may have significantly affected the stage at which patients were diagnosed with CRC. Siddiqui et al have reported that uncontrolled diabetes and therefore increased HbA1C levels leads to diagnosis of CRC at later stages than diabetes that is under control. (Siddiqui et al., 2008) Future studies in the elderly must take into consideration clinical values and duration of diabetes. The study population was limited to those undergoing resection procedures, and many patients presenting in emergency settings with CRC but who did not undergo surgery such as severe cases in which surgery would have been unsuccessful or the patient refused treatment, may not have been represented.

Emergency surgery for CRC can have a significant impact on the progression of the disease. Predictors of emergency surgery such as race, and tumor location, must be explored further to avoid the burden associated with the condition. Stage at diagnosis is significantly associated with emergency surgery, which can be avoided by regular CRC screening. 


\section{References}

American Cancer Society. (2011). Colorectal cancer facts \& figures 2011-2013. Atlanta, GA: American Cancer Society.

Baxter, N. N., Warren, J. L., Barrett, M. J., Stukel, T. A., \& Doria-Rose, V. P. (2012). Association between colonoscopy and colorectal cancer mortality in a US cohort according to site of cancer and colonoscopist specialty. Journal of Clinical Oncology : Official Journal of the American Society of Clinical Oncology, doi:10.1200/JCO.2011.40.4772

Coughlin, S. S., Calle, E. E., Teras, L. R., Petrelli, J., \& Thun, M. J. (2004). Diabetes mellitus as a predictor of cancer mortality in a large cohort of US adults. American Journal of Epidemiology, 159(12), 1160-1167. doi:10.1093/aje/kwh161

Coughlin, S. S., \& Thompson, T. (2005). Physician recommendation for colorectal cancer screening by race, ethnicity, and health insurance status among men and women in the united states, 2000. Health Promotion Practice, 6(4), 369-378. doi:10.1177/1524839905278742

Diggs, J. C., Xu, F., Diaz, M., Cooper, G. S., \& Koroukian, S. M. (2007). Failure to screen: Predictors and burden of emergency colorectal cancer resection. The American Journal of Managed Care, 13(3), 157-164.

Elwing, J. E., Gao, F., Davidson, N. O., \& Early, D. S. (2006). Type 2 diabetes mellitus: The impact on colorectal adenoma risk in women. The American Journal of Gastroenterology, 101(8), 1866-1871. doi:10.1111/j.1572-0241.2006.00651.x 
Etzioni, D. A., Beart, R. W.,Jr, Madoff, R. D., \& Ault, G. T. (2009). Impact of the aging population on the demand for colorectal procedures. Diseases of the Colon and Rectum, 52(4), 583-90; discussion 590-1. doi:10.1007/DCR.0b013e3181a1d183

Everhart, J. E., \& Ruhl, C. E. (2009). Burden of digestive diseases in the united states part II: Lower gastrointestinal diseases. Gastroenterology, 136(3), 741-754. doi:10.1053/j.gastro.2009.01.015

Extermann, M. (2000). Measurement and impact of comorbidity in older cancer patients. Critical Reviews in oncology/hematology, 35(3), 181-200.

Faivre, J., Lemmens, V. E., Quipourt, V., \& Bouvier, A. M. (2007). Management and survival of colorectal cancer in the elderly in population-based studies. European Journal of Cancer (Oxford, England : 1990), 43(15), 2279-2284. doi:10.1016/j.ejca.2007.08.008

Felsen, C. B., Piasecki, A., Ferrante, J. M., Ohman-Strickland, P. A., \& Crabtree, B. F. (2011). Colorectal cancer screening among primary care patients: Does risk affect screening behavior? Journal of Community Health, 36(4), 605-611. doi:10.1007/s10900-010-9348-0

Gellad, Z. F., \& Provenzale, D. (2010). Colorectal cancer: National and international perspective on the burden of disease and public health impact. Gastroenterology, 138(6), 2177-2190. doi:10.1053/j.gastro.2010.01.056

Gilbert, A., \& Kanarek, N. (2005). Colorectal cancer screening: Physician recommendation is influential advice to marylanders. Preventive Medicine, 41(2), 367-379. doi:10.1016/j.ypmed.2005.01.008 
Giovannucci, E. (2001). Insulin, insulin-like growth factors and colon cancer: A review of the evidence. The Journal of Nutrition, 131(11 Suppl), 3109S-20S.

Gloeckler Ries, L. A., Reichman, M. E., Lewis, D. R., Hankey, B. F., \& Edwards, B. K. (2003). Cancer survival and incidence from the surveillance, epidemiology, and end results (SEER) program. The Oncologist, 8(6), 541-552.

Gross, C. P., Guo, Z., McAvay, G. J., Allore, H. G., Young, M., \& Tinetti, M. E. (2006). Multimorbidity and survival in older persons with colorectal cancer. Journal of the American Geriatrics Society, 54(12), 1898-1904. doi:10.1111/j.1532-5415.2006.00973.x

Hao, Y., Jemal, A., Zhang, X., \& Ward, E. M. (2009). Trends in colorectal cancer incidence rates by age, race/ethnicity, and indices of access to medical care, 1995-2004 (united states). Cancer Causes \& Control : CCC, 20(10), 1855-1863. doi:10.1007/s10552-009-9379-y

Hayanga, A. J., Mukherjee, D., Chang, D., Kaiser, H., Lee, T., Gearhart, S., et al. (2010). Teaching hospital status and operative mortality in the united states: Tipping point in the volume-outcome relationship following colon resections? Archives of Surgery (Chicago, Ill.: 1960), 145(4), 346-350. doi:10.1001/archsurg.2010.24

Hebert, P. L., Geiss, L. S., Tierney, E. F., Engelgau, M. M., Yawn, B. P., \& McBean, A. M. (1999). Identifying persons with diabetes using medicare claims data. American Journal of Medical Quality : The Official Journal of the American College of Medical Quality, 14(6), 270277. 
Hoff, G., \& Dominitz, J. A. (2010). Contrasting US and european approaches to colorectal cancer screening: Which is best? Gut, 59(3), 407-414. doi:10.1136/gut.2009.192948

Hood, S., Thompson, V. L., Cogbill, S., Arnold, L. D., Talley, M., \& Caito, N. M. (2010). African american's self-report patterns using the national cancer institute colorectal cancer screening questionnaire. Journal of Cancer Education : The Official Journal of the American Association for Cancer Education, 25(3), 431-436. doi:10.1007/s13187-010-0068-z

Hu, F. B., Manson, J. E., Liu, S., Hunter, D., Colditz, G. A., Michels, K. B., et al. (1999). Prospective study of adult onset diabetes mellitus (type 2) and risk of colorectal cancer in women. Journal of the National Cancer Institute, 91(6), 542-547.

Jemal, A., Siegel, R., Xu, J., \& Ward, E. (2010). Cancer statistics, 2010. CA: A Cancer Journal for Clinicians, 60(5), 277-300. doi:10.3322/caac.20073

Jin, T. (2008). Why diabetes patients are more prone to the development of colon cancer? Medical Hypotheses, 71(2), 241-244. doi:10.1016/j.mehy.2008.03.025

Kim, J., Mittal, R., Konyalian, V., King, J., Stamos, M. J., \& Kumar, R. R. (2007). Outcome analysis of patients undergoing colorectal resection for emergent and elective indications. The American Surgeon, 73(10), 991-993.

Klabunde, C. N., Schenck, A. P., \& Davis, W. W. (2006). Barriers to colorectal cancer screening among medicare consumers. American Journal of Preventive Medicine, 30(4), 313-319. doi:10.1016/j.amepre.2005.11.006 
Lemmens, V. E., Janssen-Heijnen, M. L., Verheij, C. D., Houterman, S., Repelaer van Driel, O. J., \& Coebergh, J. W. (2005). Co-morbidity leads to altered treatment and worse survival of elderly patients with colorectal cancer. The British Journal of Surgery, 92(5), 615-623. doi:10.1002/bjs.4913

Limburg, P. J., Anderson, K. E., Johnson, T. W., Jacobs, D. R.,Jr, Lazovich, D., Hong, C. P., et al. (2005). Diabetes mellitus and subsite-specific colorectal cancer risks in the iowa women's health study. Cancer Epidemiology, Biomarkers \& Prevention : A Publication of the American Association for Cancer Research, Cosponsored by the American Society of Preventive Oncology, 14(1), 133-137.

Limburg, P. J., Vierkant, R. A., Fredericksen, Z. S., Leibson, C. L., Rizza, R. A., Gupta, A. K., et al. (2006). Clinically confirmed type 2 diabetes mellitus and colorectal cancer risk: A population-based, retrospective cohort study. The American Journal of Gastroenterology, 101(8), 1872-1879. doi:10.1111/j.1572-0241.2006.00725.x

McKeown-Eyssen, G. (1994). Epidemiology of colorectal cancer revisited: Are serum triglycerides and/or plasma glucose associated with risk? Cancer Epidemiology, Biomarkers \& Prevention: A Publication of the American Association for Cancer Research, Cosponsored by the American Society of Preventive Oncology, 3(8), 687-695.

Meissner, H. I., Breen, N., Klabunde, C. N., \& Vernon, S. W. (2006). Patterns of colorectal cancer screening uptake among men and women in the united states. Cancer Epidemiology, Biomarkers \& Prevention : A Publication of the American Association for Cancer Research, 
Cosponsored by the American Society of Preventive Oncology, 15(2), 389-394. doi:10.1158/1055-9965.EPI-05-0678

Meyerhardt, J. A., Catalano, P. J., Haller, D. G., Mayer, R. J., Macdonald, J. S., Benson, A. B.,3rd, et al. (2003). Impact of diabetes mellitus on outcomes in patients with colon cancer. Journal of Clinical Oncology : Official Journal of the American Society of Clinical Oncology, 21(3), 433-440.

Mitchell, A. D., Inglis, K. M., Murdoch, J. M., \& Porter, G. A. (2007). Emergency room presentation of colorectal cancer: A consecutive cohort study. Annals of Surgical Oncology, 14(3), 1099-1104. doi:10.1245/s10434-006-9245-z

Mitry, E., Barthod, F., Penna, C., \& Nordlinger, B. (2002). Surgery for colon and rectal cancer. Best Practice \& Research.Clinical Gastroenterology, 16(2), 253-265. doi:10.1053/bega.2002.0284

Polednak, A. P. (2000). Inpatient hospital admission through an emergency department in relation to stage at diagnosis of colorectal cancer. Cancer Detection and Prevention, 24(3), 283289.

Potosky, A. L., Riley, G. F., Lubitz, J. D., Mentnech, R. M., \& Kessler, L. G. (1993). Potential for cancer related health services research using a linked medicare-tumor registry database. Medical Care, 31(8), 732-748.

Qaseem, A., Denberg, T. D., Hopkins, R. H.,Jr, Humphrey, L. L., Levine, J., Sweet, D. E., et al. (2012). Screening for colorectal cancer: A guidance statement from the american college of 
physicians. Annals of Internal Medicine, 156(5), 378-386. doi:10.1059/0003-4819-156-5201203060-00010

Redaelli, A., Cranor, C. W., Okano, G. J., \& Reese, P. R. (2003). Screening, prevention and socioeconomic costs associated with the treatment of colorectal cancer. PharmacoEconomics, 21(17), 1213-1238.

Rich, S. E., Kuyateh, F. M., Dwyer, D. M., Groves, C., \& Steinberger, E. K. (2011). Trends in self-reported health care provider recommendations for colorectal cancer screening by race. Preventive Medicine, 53(1-2), 70-75. doi:10.1016/j.ypmed.2011.05.014

Ries, L. A., Melbert, D., Krapcho, M., Stinchcomb, D. G., Howlader, N., \& Horner, M. J. (2007). SEER cancer statistics review, 1975-2005, national cancer institute.. Bethesda: National Cancer Institute.

Rim, S. H., Seeff, L., Ahmed, F., King, J. B., \& Coughlin, S. S. (2009). Colorectal cancer incidence in the united states, 1999-2004 : An updated analysis of data from the national program of cancer registries and the surveillance, epidemiology, and end results program. Cancer, 115(9), 1967-1976. doi:10.1002/cncr.24216

Satariano, W. A., \& Silliman, R. A. (2003). Comorbidity: Implications for research and practice in geriatric oncology. Critical Reviews in oncology/hematology, 48(2), 239-248.

Schenck, A. P., Klabunde, C. N., Warren, J. L., Jackson, E., Peacock, S., \& Lapin, P. (2011). Physician visits and colorectal cancer testing among medicare enrollees in north carolina and south carolina, 2005. Preventing Chronic Disease, 8(5), A112. 
Shack, L. G., Rachet, B., Williams, E. M., Northover, J. M., \& Coleman, M. P. (2010). Does the timing of comorbidity affect colorectal cancer survival? A population based study. Postgraduate Medical Journal, 86(1012), 73-78. doi:10.1136/pgmj.2009.084566

Siddiqui, A. A., Spechler, S. J., Huerta, S., Dredar, S., Little, B. B., \& Cryer, B. (2008). Elevated HbA1c is an independent predictor of aggressive clinical behavior in patients with colorectal cancer: A case-control study. Digestive Diseases and Sciences, 53(9), 2486-2494. doi:10.1007/s10620-008-0264-4

Smothers, L., Hynan, L., Fleming, J., Turnage, R., Simmang, C., \& Anthony, T. (2003). Emergency surgery for colon carcinoma. Diseases of the Colon and Rectum, 46(1), 24-30. doi:10.1097/01.DCR.0000044719.17980.4C

Vinikoor, L. C., Long, M. D., Keku, T. O., Martin, C. F., Galanko, J. A., \& Sandler, R. S. (2009). The association between diabetes, insulin use, and colorectal cancer among whites and african americans. Cancer Epidemiology, Biomarkers \& Prevention : A Publication of the American Association for Cancer Research, Cosponsored by the American Society of Preventive Oncology, 18(4), 1239-1242. doi:10.1158/1055-9965.EPI-08-1031

Warren, J. L., Klabunde, C. N., Schrag, D., Bach, P. B., \& Riley, G. F. (2002). Overview of the SEER-medicare data: Content, research applications, and generalizability to the united states elderly population. Medical Care, 40(8 Suppl), IV-3-18. doi:10.1097/01.MLR.0000020942.47004.03

Will, J. C., Galuska, D. A., Vinicor, F., \& Calle, E. E. (1998). Colorectal cancer: Another complication of diabetes mellitus? American Journal of Epidemiology, 147(9), 816-825. 
Wong, R. J. (2010). Marked variations in proximal colon cancer survival by race/ethnicity within the united states. Journal of Clinical Gastroenterology, 44(9), 625-630. doi:10.1097/MCG.0b013e3181c64a7a

Yancik, R., Wesley, M. N., Ries, L. A., Havlik, R. J., Long, S., Edwards, B. K., et al. (1998). Comorbidity and age as predictors of risk for early mortality of male and female colon carcinoma patients: A population-based study. Cancer, 82(11), 2123-2134. 
Table 1: Characteristics of CRC surgery patients by Emergency status

\begin{tabular}{|c|c|c|c|c|c|}
\hline \multirow[t]{2}{*}{ Patient Characteristic } & \multicolumn{4}{|c|}{ Emergency } & \multirow[t]{2}{*}{$p$} \\
\hline & & No & & Yes & \\
\hline & $\mathrm{N}$ & $\%$ & $\mathrm{~N}$ & $\%$ & \\
\hline Diabetes & & & & & 0.000 \\
\hline No & 14,629 & $77.4 \%$ & 1,782 & $81.4 \%$ & \\
\hline Yes & 4,263 & $22.6 \%$ & 408 & $18.6 \%$ & \\
\hline Coronary Athero & & & & & 0.000 \\
\hline No & 14,655 & $77.6 \%$ & 1,797 & $82.1 \%$ & \\
\hline Yes & 4,237 & $22.4 \%$ & 393 & $17.9 \%$ & \\
\hline COPD & & & & & 0.243 \\
\hline No & 16,864 & $89.3 \%$ & 1,937 & $88.4 \%$ & \\
\hline Yes & 2,028 & $10.7 \%$ & 253 & $11.6 \%$ & \\
\hline CHF & & & & & 0.275 \\
\hline No & 16,868 & $89.3 \%$ & 1,972 & $90.0 \%$ & \\
\hline Yes & 2,024 & $10.7 \%$ & 218 & $10.0 \%$ & \\
\hline Stage & & & & & 0.000 \\
\hline Early & 11,041 & $58.4 \%$ & 972 & $44.4 \%$ & \\
\hline Late & 7,851 & $41.6 \%$ & 1,218 & $55.6 \%$ & \\
\hline Age Group & & & & & 0.000 \\
\hline $66-69$ & 3,044 & $16.1 \%$ & 339 & $15.5 \%$ & \\
\hline $70-74$ & 4,098 & $21.7 \%$ & 455 & $20.8 \%$ & \\
\hline $75-79$ & 4,665 & $24.7 \%$ & 435 & $19.9 \%$ & \\
\hline $80-84$ & 3,957 & $20.9 \%$ & 488 & $22.3 \%$ & \\
\hline 85 and over & 3,128 & $16.6 \%$ & 473 & $21.6 \%$ & \\
\hline Sex & & & & & 0.960 \\
\hline Male & 8,223 & $43.5 \%$ & 952 & $43.5 \%$ & \\
\hline Female & 10,669 & $56.5 \%$ & 1,238 & $56.5 \%$ & \\
\hline Race & & & & & 0.017 \\
\hline White & 16,157 & $85.5 \%$ & 1,827 & $83.4 \%$ & \\
\hline Black & 1,447 & $7.7 \%$ & 203 & $9.3 \%$ & \\
\hline Other & 1,288 & $6.8 \%$ & 160 & $7.3 \%$ & \\
\hline Tumor Site & & & & & 0.000 \\
\hline Distal & 8,547 & $45.2 \%$ & 1,129 & $51.6 \%$ & \\
\hline Proximal & 10,345 & $54.8 \%$ & 1,061 & $48.4 \%$ & \\
\hline Quintile of office visits & & & & & 0.000 \\
\hline First & 3,933 & $20.8 \%$ & 402 & $18.4 \%$ & \\
\hline Second & 4,100 & $21.7 \%$ & 408 & $18.6 \%$ & \\
\hline Third & 3,898 & $20.6 \%$ & 418 & $19.1 \%$ & \\
\hline Fourth & 3,761 & $19.9 \%$ & 444 & $20.3 \%$ & \\
\hline Fifth & 3,200 & $16.9 \%$ & 518 & $23.7 \%$ & \\
\hline Region in the US & & & & & 0.000 \\
\hline WEST & 7,584 & $40.1 \%$ & 933 & $42.6 \%$ & \\
\hline MIDWEST & 3,051 & $16.1 \%$ & 281 & $12.8 \%$ & \\
\hline SOUTH & 3,614 & $19.1 \%$ & 370 & $16.9 \%$ & \\
\hline EAST & 4,643 & $24.6 \%$ & 606 & $27.7 \%$ & \\
\hline
\end{tabular}

Continued 
Table 1: Characteristics of CRC surgery patients by Emergency status

\begin{tabular}{|c|c|c|c|c|c|}
\hline \multirow[t]{2}{*}{ Patient Characteristic } & \multicolumn{4}{|c|}{ Emergency } & \multirow[t]{2}{*}{$p$} \\
\hline & & No & & Yes & \\
\hline Patient Location & & & & & 0.005 \\
\hline Big Metro & 10,305 & $54.5 \%$ & 1,284 & $58.6 \%$ & \\
\hline Metro & 5,391 & $28.5 \%$ & 586 & $26.8 \%$ & \\
\hline Urban & 1,154 & $6.1 \%$ & 123 & $5.6 \%$ & \\
\hline Less Urban & 1,659 & $8.8 \%$ & 159 & $7.3 \%$ & \\
\hline Rural & 383 & $2.0 \%$ & 38 & $1.7 \%$ & \\
\hline TOTAL & 18,892 & $100.0 \%$ & 2,190 & $100.0 \%$ & \\
\hline
\end{tabular}


Table 2: Characteristics of CRC surgery patients by Diabetes Status

\begin{tabular}{|c|c|c|c|c|c|}
\hline \multirow[t]{2}{*}{ Patient Characteristic } & \multicolumn{4}{|c|}{ Diabetes } & \multirow[t]{2}{*}{$p$} \\
\hline & & No & & Yes & \\
\hline & $\mathrm{N}$ & $\%$ & $\mathrm{~N}$ & $\%$ & \\
\hline Emergency & & & & & 0.000 \\
\hline No & 14,629 & $77.4 \%$ & 4,263 & $81.4 \%$ & \\
\hline Yes & 1,782 & $22.6 \%$ & 408 & $18.6 \%$ & \\
\hline Coronary Athero & & & & & 0.000 \\
\hline No & 13,430 & $81.8 \%$ & 3,022 & $64.7 \%$ & \\
\hline Yes & 2,981 & $18.2 \%$ & 1,649 & $35.3 \%$ & \\
\hline COPD & & & & & 0.000 \\
\hline No & 14,748 & $89.9 \%$ & 4,053 & $86.8 \%$ & \\
\hline Yes & 1,663 & $10.1 \%$ & 618 & $13.2 \%$ & \\
\hline CHF & & & & & 0.000 \\
\hline No & 15,038 & $91.6 \%$ & 3,802 & $81.4 \%$ & \\
\hline Yes & 1,373 & $8.4 \%$ & 869 & $18.6 \%$ & \\
\hline Stage & & & & & 0.154 \\
\hline Early & 3,761 & $22.9 \%$ & 1,117 & $23.9 \%$ & \\
\hline Late & 12,650 & $77.1 \%$ & 3,554 & $76.1 \%$ & \\
\hline Age Group & & & & & 0.000 \\
\hline $66-69$ & 2,601 & $15.8 \%$ & 782 & $16.7 \%$ & \\
\hline $70-74$ & 3,464 & $21.1 \%$ & 1,089 & $23.3 \%$ & \\
\hline $75-79$ & 3,828 & $23.3 \%$ & 1,272 & $27.2 \%$ & \\
\hline $80-84$ & 3,544 & $21.6 \%$ & 901 & $19.3 \%$ & \\
\hline 85 and over & 2,974 & $18.1 \%$ & 627 & $13.4 \%$ & \\
\hline Sex & & & & & 0.000 \\
\hline Male & 6,979 & $42.5 \%$ & 2,196 & $47.0 \%$ & \\
\hline Female & 9,432 & $57.5 \%$ & 2,475 & $53.0 \%$ & \\
\hline Race & & & & & 0.000 \\
\hline White & 14,257 & $86.9 \%$ & 3,727 & $79.8 \%$ & \\
\hline Black & 1,143 & $7.0 \%$ & 507 & $10.9 \%$ & \\
\hline Other & 1,011 & $6.2 \%$ & 437 & $9.4 \%$ & \\
\hline Tumor Site & & & & & 0.924 \\
\hline Distal & 7,535 & $45.9 \%$ & 2,141 & $45.8 \%$ & \\
\hline Proximal & 8,876 & $54.1 \%$ & 2,530 & $54.2 \%$ & \\
\hline Quintile of office visits & & & & & 0.000 \\
\hline First & 2,751 & $16.8 \%$ & 1,584 & $33.9 \%$ & \\
\hline Second & 3,248 & $19.8 \%$ & 1,260 & $27.0 \%$ & \\
\hline Third & 3,320 & $20.2 \%$ & 996 & $21.3 \%$ & \\
\hline Fourth & 3,541 & $21.6 \%$ & 664 & $14.2 \%$ & \\
\hline Fifth & 3,551 & $21.6 \%$ & 167 & $3.6 \%$ & \\
\hline
\end{tabular}


Neel Shah

Dissertation

Table 2: Characteristics of CRC surgery patients by Diabetes Status

\begin{tabular}{|c|c|c|c|c|c|}
\hline \multirow[t]{2}{*}{ Patient Characteristic } & \multicolumn{4}{|c|}{ Diabetes } & \multirow[t]{2}{*}{$p$} \\
\hline & & No & & Yes & \\
\hline Region in the US & & & & & 0.000 \\
\hline WEST & 6,757 & $41.2 \%$ & 1,760 & $37.7 \%$ & \\
\hline MIDWEST & 2,594 & $15.8 \%$ & 738 & $15.8 \%$ & \\
\hline SOUTH & 3,115 & $19.0 \%$ & 869 & $18.6 \%$ & \\
\hline EAST & 3,945 & $24.0 \%$ & 1,304 & $27.9 \%$ & \\
\hline Patient Location & & & & & 0.079 \\
\hline Big Metro & 8,963 & $54.6 \%$ & 2,626 & $56.2 \%$ & \\
\hline Metro & 4,649 & $28.3 \%$ & 1,328 & $28.4 \%$ & \\
\hline Urban & 1,011 & $6.2 \%$ & 266 & $5.7 \%$ & \\
\hline Less Urban & 1,454 & $8.9 \%$ & 364 & $7.8 \%$ & \\
\hline Rural & 334 & $2.0 \%$ & 87 & $1.9 \%$ & \\
\hline TOTAL & 16,411 & $100.0 \%$ & 4,671 & $100.0 \%$ & \\
\hline
\end{tabular}


Table 3: Association of Diabetes and Covariates with Emergency Condition for Surgery

\begin{tabular}{|c|c|c|c|c|c|c|}
\hline \multirow[b]{2}{*}{ Patient Characteristic } & & \multirow[b]{2}{*}{$p$} & \multirow[b]{2}{*}{ Sig } & \multirow[b]{2}{*}{ Odds } & \multicolumn{2}{|c|}{ 95\% C.I.for Odds } \\
\hline & & & & & Lower & Upper \\
\hline \multirow{4}{*}{ Comorbidities } & Diabetes & .063 & & 0.89 & 0.79 & 1.01 \\
\hline & Atherosclerosis & .003 & $* * *$ & 0.82 & 0.72 & 0.93 \\
\hline & COPD & .001 & $* * *$ & 1.28 & 1.11 & 1.49 \\
\hline & CHF & .927 & & 1.01 & 0.85 & 1.19 \\
\hline Stage & Late & .000 & $* * *$ & 1.75 & 1.60 & 1.91 \\
\hline \multirow[t]{4}{*}{ Region in the US } & WEST & .000 & Referent & & & \\
\hline & MIDWEST & .000 & $* * *$ & 0.75 & 0.65 & 0.87 \\
\hline & SOUTH & .006 & $* * *$ & 0.82 & 0.72 & 0.95 \\
\hline & EAST & .473 & & 1.04 & 0.93 & 1.17 \\
\hline Location of tumor & Proximal & .000 & $* * *$ & 0.78 & 0.71 & 0.85 \\
\hline \multirow[t]{5}{*}{ Age Group } & $66-69$ & .000 & Referent & & & \\
\hline & $70-74$ & .515 & & 1.05 & 0.91 & 1.22 \\
\hline & $75-79$ & .282 & & 0.92 & 0.79 & 1.07 \\
\hline & $80-84$ & .002 & $* * *$ & 1.28 & 1.10 & 1.48 \\
\hline & 85 and over & .000 & $* * *$ & 1.62 & 1.39 & 1.89 \\
\hline Sex & FEMALE & .994 & & 1.00 & 0.91 & 1.10 \\
\hline \multirow[t]{3}{*}{ Race } & White & .016 & Referent & & & \\
\hline & Black & .004 & $* * *$ & 1.27 & 1.08 & 1.49 \\
\hline & Other & .879 & & 1.01 & 0.85 & 1.21 \\
\hline \multirow{5}{*}{ Patient Location } & Big Metro & .263 & Referent & & & \\
\hline & Metro & .047 & $* * *$ & 0.90 & 0.81 & 1.00 \\
\hline & Urban & .333 & & 0.91 & 0.74 & 1.11 \\
\hline & Less Urban & .150 & & 0.87 & 0.73 & 1.05 \\
\hline & Rural & .664 & & 0.93 & 0.65 & 1.31 \\
\hline \multirow{5}{*}{$\begin{array}{l}\text { Quintile of Office } \\
\text { Visits }\end{array}$} & First & .000 & Referent & & & \\
\hline & Second & .571 & & 0.96 & 0.83 & 1.11 \\
\hline & Third & .807 & & 1.02 & 0.88 & 1.19 \\
\hline & Fourth & .130 & & 1.13 & 0.97 & 1.32 \\
\hline & Fifth & .000 & $* * *$ & 1.48 & 1.26 & 1.74 \\
\hline
\end{tabular}

*** Significant at the $\mathrm{p}=0.05$ level

Coronary Athero $=$ Coronary Atherosclerosis; $\mathrm{COPD}=$ Chronic Obstructive Pulmonary Disorder; $\mathrm{CHF}=$ Congestive Heart Failure

Referent group for Diabetes, Coronary Atherosclerosis, COPD and CHF are No Diabetes, No Coronary Atherosclerosis, No COPD and No CHF respectively

Referent group for female is male

Referent group for proximal tumor location is distal tumor location

First quintile in Office Visits represents highest number of office visits and fifth represents the lowest 


\section{CHAPTER FOUR}

ImPaCt Of Pre-eXisting Diabetes on Colorectal CANCER Mortality 


\section{Introduction}

Mortality from colorectal cancer (CRC) has been decreasing in the past 20 years due to advances in both early detection and treatment. (American Cancer Society, 2011) This decline in cancer mortality for the US population was statistically significant in 1994 through 1998 with rates leveling off from 1998-2000, which may have been due to a change in the classification of deaths due to cancer. (Ries et al., 2007) A significant part of the overall decline in cancer mortality, and the resultant increase in survival, appears to be due to the success of various initiatives by the National Cancer Institute. Despite the significant survival benefits seen in CRC due to increasing screening rates, disparities in screening, treatment, and survival persist and it remains third in terms of cancer incidence and mortality. (Gellad \& Provenzale, 2010) The reports of decreasing cancer mortality are specific to the cancer and do not include all-cause mortality. Thus, although individuals diagnosed with CRC have improved cancer-specific mortality, reducing all-cause mortality in CRC with comorbid conditions has become increasingly important. (Gross et al., 2006)

The majority of new CRC diagnoses occur in older individuals, with more than twothirds diagnosed in those over the age of 65 years. (Everhart \& Ruhl, 2009; Ries et al., 2007; Rim, Seeff, Ahmed, King, \& Coughlin, 2009)Comorbidity, or illnesses other than the primary illness under treatment, is more common in the elderly. (Shack, Rachet, Williams, Northover, \& Coleman, 2010) Older individuals also often present with chronic conditions that complicate the diagnostic and clinical management of CRC which leads to poorer prognosis and outcomes of the cancer. (Satariano \& Silliman, 2003; Yancik et al., 1998)The three most common comorbid conditions seen in elderly patients with CRC are congestive heart failure, chronic obstructive pulmonary disease and diabetes mellitus. (Gross et al., 2006) 
Numerous epidemiological and few pathophysiological studies have reported a positive association between diabetes and CRC. (Elwing, Gao, Davidson, \& Early, 2006; Giovannucci, 2001; Hu et al., 1999; Jin, 2008; Limburg et al., 2005; Limburg et al., 2006; McKeown-Eyssen, 1994; Vinikoor et al., 2009; Will, Galuska, Vinicor, \& Calle, 1998) Poorly controlled type 2 diabetes independently predicts early onset of CRC, a more advanced stage at the time of presentation, and a poorer 5-year survival. (Siddiqui et al., 2008). The influence of diabetes mellitus on the mortality of patients with established colorectal cancer has been demonstrated by various authors but with conflicting conclusions. Results from a clinical trial in 2003 were the first to document that even after adjustment for other predictors of colon cancer, patients with diabetes and high-risk stage II or stage III colon cancer experienced a significantly higher rate of overall cancer mortality and cancer recurrence than non-diabetics. (Meyerhardt et al., 2003) Only one other prospective study in the United States has investigated this relationship finding a similar positive association. (Coughlin, Calle, Teras, Petrelli, \& Thun, 2004). These studies are limited by either their small, younger sample that did not have other debilitating chronic diseases or relied on self-report data as end points. Retrospective studies have mixed conclusions about whether or not pre-existing diabetes affects CRC mortality. A study conducted in elderly patients in the Netherlands found that with co-morbidities such as diabetes, patients were treated less aggressively and had a worse survival than those with no concomitant disease. (Lemmens et al., 2005). Other retrospective cohort studies have concluded that diabetes did not affect short-term survival or cancer specific survival, or were inconclusive. (Shonka et al., 2006) (Gross et al., 2006; Jullumstro, Kollind, Lydersen, \& Edna, 2009) 
Treatment for cancer can greatly affect mortality and short as well as long term survival in patients with CRC. (Gill et al., 2004; Iwashyna \& Lamont, 2002) Surgical resection is the only curative treatment of colorectal cancer, performed as an open, surgical procedure requiring hospitalization. (Mitry, Barthod, Penna, \& Nordlinger, 2002; Redaelli, Cranor, Okano, \& Reese, 2003) Potentially fatal complications of colorectal cancer include bowel perforation, peritonitis, and obstruction. These complications are considered surgical emergencies and are the initial presentation of colorectal cancer in an estimated $15 \%$ to $30 \%$ of patients with colorectal cancer. (Diggs, Xu, Diaz, Cooper, \& Koroukian, 2007). In addition, patients with emergency room presentation of CRC have an increased 30-day mortality and decreased 5-year survival compared to those scheduled for elective surgery. (Mitchell, Inglis, Murdoch, \& Porter, 2007). The Colorectal Cancer Collaborative Group in England reported that outcomes of surgery in elderly patients are worse than those in younger patients because they were more likely to have increased frequency of comorbid conditions, later-stage at presentation with the disease, and undergo emergency surgery, and less likely to have curative surgery than younger patients. (Colorectal Cancer Collaborative Group, 2000)

Although elective surgical resection is the curative treatment for CRC, a proportion of patients present as surgical emergencies, which is a sign of failure to screen in a timely fashion. (Rabeneck, Paszat, \& Li, 2006) Patients with a new diagnosis of CRC who present with obstruction, or perforation, or those who require emergency admission to hospital have more advanced disease. (Scott, Jeacock, \& Kingston, 1995). Patients who are admitted emergently also have worse survival rates than those who are not. (Kim et al., 2007; Paulson, Wirtalla, Armstrong, \& Mahmoud, 2009; Smothers et al., 2003) However, these reports are however from 
studies that have included a small sample of patients from local hospitals that are not nationally representative.

Chemotherapy is used in patients at risk for metastases and those with poor prognosis following surgery. (Redaelli et al., 2003) Evidence from clinical trials suggests that adjuvant chemotherapy is associated with a 34\% reduction in mortality, and population-based observational studies have demonstrated similar survival benefits. (Gill et al., 2004) Prior work also has suggested that the survival benefits associated with adjuvant therapy do not diminish with increasing age. (Iwashyna \& Lamont, 2002) Previous evidence has shown that although a survival benefit was seen in diabetic patients who received chemotherapy rather than those diabetic patients who did not, presence of diabetes significantly reduced the use of adjuvant chemotherapy. (Gross, McAvay, Guo, \& Tinetti, 2007)

Therefore, besides having a comorbid condition such as diabetes, type of treatment, emergency admission, stage at diagnosis, age and other comorbid conditions play an important role in the survival of the colorectal cancer patient. No study has examined these factors together in a large nationally representative sample. The primary objective of the study is to explore the effect of diabetes on survival of elderly Medicare beneficiaries with CRC. A secondary objective is to explore the association of the covariates including the three most common comorbid conditions, in addition to diabetes (congestive heart failure (CHF), chronic obstructive pulmonary disease (COPD), and coronary atherosclerosis), emergency admission, and treatment variables (chemotherapy/radiation and surgery), and how they affect survival in a CRC patient. 


\section{Methods}

\section{$\underline{\text { Data }}$}

This retrospective cross sectional analysis employed the Surveillance, Epidemiology and End Results-Medicare (SEER-Medicare) files for the years 2003 to 2005. The data come from the SEER program of cancer registries that collect clinical, demographic, mortality and survival for persons with cancer and the Medicare claims for covered health care services from the time of a person's Medicare eligibility until death. The SEER-Medicare data reflect the linkage of two large population-based sources of data that provide detailed information about Medicare beneficiaries with cancer. The linkage of these two data sources results in a unique populationbased source of information that can be used for an array of epidemiological and health services research. Previous work has demonstrated excellent agreement among data sources in case ascertainment. (Potosky, Riley, Lubitz, Mentnech, \& Kessler, 1993) Currently, SEER has 17 high quality registries participating in the program, representing 12 states, and with the Medicare data it effectively represents the elderly population of the entire United States. (Warren, Klabunde, Schrag, Bach, \& Riley, 2002)

\section{$\underline{\text { Cohort }}$}

Patients with a newly diagnosed malignant adenocarcinoma of the colon or rectum were identified in the SEER-Medicare database between the years 2003-2005. With the stipulated inclusion criteria of 1) only one primary cancer, 2) eligibility for both Part A and B benefits for at least 12 months prior to cancer diagnosis, and 3) did not die in the same month as their cancer diagnosis, there were 30,340 cases aged 66 and over. Sixty-six was selected as the cut-off to ensure that each person would have at least 12 months of Medicare claims prior to the diagnosis 
of CRC. Cases with unknown race were eliminated $(\mathrm{N}=38)$. Cases were further deleted if the source of information was from autopsy or death certificate only $(\mathrm{N}=9)$. Finally, cases were deleted because their cancer stage was zero or unknown $(\mathrm{N}=5,059)$. The final cohort consists of 25,234 patients.

\section{$\underline{\text { Variables }}$}

Diabetic patients were identified using inpatient, outpatient, and physician claims for each patient during a period of 12 months before diagnosis of CRC. To maximize specificity a patient was identified as diabetic if he or she had at least one inpatient claim or two outpatient claims for diabetes. (Hebert et al., 1999) This process provides a specificity of 98.8\%. Comorbid conditions were searched using similar criteria and the three most common chronic conditions i.e. CHF, Coronary Atherosclerosis, and COPD were selected to be included as covariates.

SEER reports disease stage using the third edition of the American Joint Committee on Cancer (AJCC) definition for the 2003 cases and AJCC Cancer Staging Manual $6^{\text {th }}$ edition definition for cases diagnoses in 2004 and 2005. Comprehensive stage categories were collapsed into stages I, II, III and IV. Stage at diagnosis for colorectal cancer directly affects mortality and survival. Chances for survival are more than 90\% for Stage I, 82\% for Stage II, 57\% for Stage III and drop to 6\% for Stage IV patients. (Gloeckler Ries, L.A. 2003) Due to these differential survival rates between the stages, patients were categorized as being “Early Stage” (Stage I and II) or "Late Stage” (Stages III and IV) patients.

Age was categorized as 66-69 years, 70-74 years, 75-79 years, $80-84$ years, and 85 years and over. Race was categorized as white, black, and other. SEER areas to which the patients belonged were categorized as west, mid-west, south, and east depending on the region in the US. 
Location of the tumor was categorized as proximal (cecum to splenic flexure) and distal (descending colon to rectum). The categorization was based on the ease of cancer detection based on the method used for screening or diagnosis. Proximal cancers are identified primarily through the use of colonoscopy, unlike a sigmoidoscopy which would be unable to reach these areas. The number of physician office visits 12 months prior to cancer diagnosis was identified and the continuous variable was transformed into quintiles of office visits with the first quintile representing the highest number of office visits. Patients admitted emergently were identified as “emergency admission”.

Surgery for CRC, within 12 months after cancer diagnosis, was identified by using the International Classification of Diseases, Ninth Revision, Clinical Modification (ICD-9-CM) procedure codes for colon resection (codes 45.7x and 45.8), rectal resection (codes 48.4x, 48.5, 48.6x), and other operations on the intestine including colostomy and ileostomy (codes 46.1-2). (Diggs et al., 2007; Etzioni, Beart, Madoff, \& Ault, 2009; Hayanga et al., 2010) Since radiation claims formed only a small percentage of treatment claims in the Medicare files, chemotherapy and radiation received within 12 months after cancer diagnosis were collapsed to create the variable "chemotherapy/radiation".

\section{$\underline{\text { Statistical Analysis }}$}

The advantage of using survival statistics is that it considers when the patient was diagnosed, stage at diagnosis and the kind of treatment given in the stipulated time period. (Ries 2007) Patients that were newly diagnosed with CRC between 2003 and 2005 were examined up December $31^{\text {st }} 2007$ in this study which gives a follow up period of up to 5 years or 60 months. Mortality, on the other hand measures deaths due to cancer in a given time period, irrespective of 
when patients were diagnosed, and does not take into consideration treatment options. (Ries 2007) Hence for this study survival analysis techniques were employed.

Univariate statistics were used to describe the sample and bivariate statistics were used to explore the proportion of patients distributed between diabetics and nondiabetics. Pearson's chi-square statistic was used for the bivariate analysis. Cox proportional hazards models were used to examine the association between each patient characteristic and all cause mortality during the follow-up period. Data were censored at death or the end of calendar year 2007, whichever occurred first. Candidate covariates for the multivariate model included sociodemographic characteristics, cancer-specific characteristics (stage, tumor location), and individual conditions. To address variability in use of care the number of physician outpatient visits 12 months before cancer diagnosis was included in the model. To determine whether treatment differences mediated the relationship between specific chronic conditions and death, the analysis was repeated after adding cancer treatment-related variables to the model. All analyses were performed using IBM SPSS version 20.

\section{Results}

In a sample of 25,234 patients with newly diagnosed CRC from 2003 to 2005 there were 5.466 diabetics (21.7\%). The mean age of the study cohort was 77.5 years (range 66 to 114) and there were 55.1\% females. Patients were evenly distributed between all stages with 25\% diagnosed at stage I, 30.4\% at stage II, $26.1 \%$ at stage III, and $18.5 \%$ at stage IV. Tumors were equally divided as well, with $50.2 \%$ located in the proximal area of the colon. There were $18.0 \%$ patients who were admitted emergently. 
Table 1 shows the distribution of patients by patient characteristic. The highest proportion of patients by age belonged to 75-79 years group (23.8\%), and a majority of the patients were white (84.8\%). Presence of coronary atherosclerosis, COPD and CHF were 21.5\%, 11.1\%, and 10.9\% respectively. Emergency admission was represented by $18.0 \%$ of the cohort. Most of the newly diagnosed patients underwent surgery (83.5\%), and the number of patients that received chemotherapy or radiation was 34.5\%. A majority of patients belonged to Western US (40.6\%) and resided in a large metropolitan area (55.1\%).

Distribution of patients by diabetes status shows that with increasing age prevalence of diabetes increases, peaks between ages 75-79 years and then declines thereafter (Table 2). There were more diabetic males than females, and compared to Whites, Blacks, or Other races tended to have a greater proportion of the disease. Although diabetics were more likely to be diagnosed at early stages, they were also more likely to be admitted emergently. A greater proportion of diabetics underwent surgery for CRC with no difference seen in chemotherapy or radiation treatments between diabetics and nondiabetics. Diabetics also had a higher frequency of physician office visits than nondiabetics.

Table 3 shows the proportions of patients who died by comorbid conditions, treatment variables and demographic characteristics. Diabetic patients were significantly more likely to die within the five year period than nondiabetics, Similar results were seen in patients suffering from coronary atherosclerosis, COPD and CHF. Patients with late stage at diagnosis and distal tumor location were also more significantly more likely to die than those with early stage diagnosis and proximal tumors. Patients admitted emergently were more likely to die than those who were not. In this bivariate analysis although surgery had a beneficial effect on mortality, chemotherapy or 
radiation did not. Finally only patients with the greatest number of office visits were more likely to die compared to those with the lowest number of office visits.

The mortality risk (represented by hazard ratios or HR in Table 4) associated with diabetes in the cox proportional hazards model was significantly greater for diabetics than nondiabetics (HR 1.15, 95\% CI 1.09-1.20). This was seen for COPD (HR 1.33, 95\% CI 1.261.41) and CHF (HR 1.43, 95\% CI 1.35-1.52). Risk of mortality significantly increased with age with the HR for those over the age of 85 being more than twice as compared to those between 66-69 years (HR 2.30, 95\% CI 2.14-2.47). Women had a lower risk than men (HR 0.92955 CI 0.89-0.96) and Blacks had an 8\% higher risk than Whites (HR 1.08, 95\%CI 1.01-1.15). Presenting emergently significantly increased the risk of mortality (HR 1.61, 95\% CI 1.54-1.68). Surgery significantly reduced the risk of mortality (HR 0.41, 95\% CI 0.39-0.43) and although in bivariate analyses patients who received chemotherapy were more likely to die, the hazard model showed a significant benefit associated with chemotherapy or radiation (HR 0.70, 95\% CI 0.670.74). Patients with the highest number of office visits had improved risk of mortality compared to those with lower number of office visits.

Kaplan-Meier survival curves for diabetics, emergency admission patients, patients who underwent surgery and chemotherapy/radiation recipients are shown in Figs 1-4. The survival curve for surgery clearly shows a benefit beginning in the first year itself. Although there is a benefit seen in patients receiving chemotherapy/radiation, it is more pronounced only in later years. Diabetics clearly had a poorer survival benefit compared to nondiabetics which worsened with time. Those who were admitted emergently had lower survival from the time of diagnosis which progressively worsened with time compared to those who were not admitted emergently. 


\section{Discussion}

This study was conducted to explore the effect of diabetes on survival of elderly Medicare beneficiaries with CRC. The study also explores the association of the covariates including the three most common comorbid conditions (coronary atherosclerosis, CHF, and COPD), in addition to diabetes, emergency admission, and treatment variables and how they affect survival in a CRC patient.

The study shows that diabetics suffered worse mortality and survival than nondiabetics. Several factors need to be considered while interpreting this result. First, lack of mortality as well as survival benefit in diabetics is seen despite them being in the highest bracket of physician office visits. Increased number of office visits and visits with primary care physicians in elderly Medicare beneficiaries have previously been associated with increased CRC test use. (Schenck et al., 2011) Klabunde and colleagues have reported that having a chronic condition such as diabetes is a predictor of receiving a physician recommendation for CRC screening. (Klabunde, Schenck, \& Davis, 2006)(Klabunde et al., 2006) Increased number of physician office visits increases the chances of being recommended for a screening test and clinician recommendation for a screening test has been proven to be a strong predictor of adherence to CRC screening in the elderly as well as young patients to adhere to screening practices for CRC. (Felsen, Piasecki, Ferrante, Ohman-Strickland, \& Crabtree, 2011; Gilbert \& Kanarek, 2005) Second, although diabetics visited physician offices more frequently they were also admitted more emergently for CRC than non-diabetics. This study shows that there is a significant mortality risk associated with being admitted emergently. Besides being a sign of screening failure, emergent admissions have poorer outcomes than non-emergent admissions for CRC. Last, despite controlling for the 
treatment variables surgery and chemotherapy/radiation, which provide significant survival benefit, the study shows a decrease in survival benefit in diabetics.

Although it has been advised that among CRC patients, preexisting diabetes is associated with a higher risk of all-cause long-term mortality, this is the first study that explores this association in light of the aforementioned factors. Besides these factors it has been shown that because diabetes can lead to infections, metabolic derangements, and acute cardiovascular events, cancer patients, including those with CRC, diabetics may also be at a greater risk of short-term mortality, especially while surgery is being performed and even after surgery. (Richardson \& Pollack, 2005) A recent meta-analysis by Barone and colleagues concluded that compared to nondiabetics, cancer patients with preexisting diabetes are approximately $50 \%$ more likely to die after surgery. (Barone et al., 2010) They mention that this could be due to sepsis and other serious infections which could increase in diabetics especially after surgery due to a possible rise in blood sugar levels.

This study shows that patients with fewer office visits had a survival benefit. This could be explained by the fact that those with fewer office visits had fewer comorbid conditions in the first place and hence were predisposed to having a better prognosis and outcome. In addition, it has also been previously reported that elderly patients with CRC increase rather than decrease contact with primary care providers after diagnosis which continues through the first 5 years after cancer diagnosis. (Dobie, Saver, Wang, Green, \& Baldwin, 2011) However, this still does not fully explain the reason for lack of survival benefit seen in those with the highest frequency of office visits. This is an issue for further research that needs to be explored. 
This study is the first to report emergency admission and its risk associated with mortality and survival in a large group of elderly, nationally representative population of CRC patients. Despite implementation of national intervention strategies, up to 30\% percent of CRC patients are admitted emergently. (Kim et al., 2007; Polednak, 2000; Smothers et al., 2003) In this study diabetics presented more emergently than not. This clearly signifies failure to screen in a timely fashion and a possible failure of screening interventions and strategies. Diabetics also have worse survival than nondiabetics. Since diabetic CRC patients have worse outcomes than their nondiabetic counterparts they must take advantage of the fact that the cancer can be prevented with timely screening. Current screening guidelines do not consider diabetics as a special case for earlier screening or more frequent CRC screening. McBean and Yu have reported that elderly diabetic women are less likely than elderly non-diabetic women to receive colorectal cancer screening in the 11 SEER areas studied between 1999-2002. (McBean \& Yu, 2007) They have furthered the argument in favor of altering CRC screening guidelines for diabetics by mentioning that the American Diabetes Association (ADA) should include specific screening recommendation for such cancers in the Standards of Medical Care in Diabetes. They also suggest combining specific recommendations for people with diabetes in guidelines from federal or national organizations that promote the use of screening services but are not primarily or uniquely concerned with diabetes such as the CDC, the National Cancer Institute, the American Cancer Society, and the CMS.

This study has some limitations which must be considered in the interpretation of results. The study used previously employed algorithms to identify diabetic patients. However, the duration of diabetes as well as clinical values such as HbA1C which may have significantly affected the stage at which patients were diagnosed with CRC, were not available. Siddiqui et al 
have reported that uncontrolled diabetes and therefore increased $\mathrm{HbA1C}$ levels leads to diagnosis of CRC at later stages than diabetes that is under control. (Siddiqui et al., 2008) Timely screening plays a crucial role in detecting the cancer at earlier stages and the data did not allow us to check for frequency of screening. This is especially true for sigmoidoscopy and colonoscopy procedures which are recommended to be performed at five year and ten year intervals, respectively. In addition, SEER-Medicare data do not include other important measures of health status, such as body mass index, diet, functional disabilities or geriatric syndromes.

The study also has several strengths including stringent inclusion and exclusion criteria, and the use of population based data from a cancer registry that is globally recognized as an authoritative source of information on cancer incidence in the United States. Detailed demographic, cancer data on stage and tumor location, and treatment variables allowed the construction of a strong Cox proportional hazards model to study and understand the mortality risk associated with diabetes and the several covariates in CRC patients.

Diabetes has a poor effect on the survival and all-cause mortality of patients with CRC. Emergency admission and stage at diagnosis has a large effect on survival and therefore underscore the importance of early diagnosis. Diabetic patients should be screened and diagnosed in a timely fashion to prevent CRC or to have a better disease prognosis. 


\section{References}

American Cancer Society. (2011). Colorectal cancer facts \& figures 2011-2013. Atlanta, GA:

American Cancer Society.

Barone, B. B., Yeh, H. C., Snyder, C. F., Peairs, K. S., Stein, K. B., Derr, R. L., et al. (2010).

Postoperative mortality in cancer patients with preexisting diabetes: Systematic review and metaanalysis. Diabetes Care, 33(4), 931-939. doi:10.2337/dc09-1721

Coughlin, S. S., Calle, E. E., Teras, L. R., Petrelli, J., \& Thun, M. J. (2004). Diabetes mellitus as a predictor of cancer mortality in a large cohort of US adults. American Journal of Epidemiology, 159(12), 1160-1167. doi:10.1093/aje/kwh161

Diggs, J. C., Xu, F., Diaz, M., Cooper, G. S., \& Koroukian, S. M. (2007). Failure to screen: Predictors and burden of emergency colorectal cancer resection. The American Journal of Managed Care, 13(3), 157-164.

Dobie, S., Saver, B. G., Wang, C. Y., Green, P. K., \& Baldwin, L. M. (2011). Do primary care physicians lose contact with their colorectal cancer patients? Journal of the American Board of Family Medicine : JABFM, 24(6), 704-709. doi:10.3122/jabfm.2011.06.100192

Elwing, J. E., Gao, F., Davidson, N. O., \& Early, D. S. (2006). Type 2 diabetes mellitus: The impact on colorectal adenoma risk in women. The American Journal of Gastroenterology, 101(8), 1866-1871. doi:10.1111/j.1572-0241.2006.00651.x 
Etzioni, D. A., Beart, R. W.,Jr, Madoff, R. D., \& Ault, G. T. (2009). Impact of the aging population on the demand for colorectal procedures. Diseases of the Colon and Rectum, 52(4), 583-90; discussion 590-1. doi:10.1007/DCR.0b013e3181a1d183

Everhart, J. E., \& Ruhl, C. E. (2009). Burden of digestive diseases in the united states part II: Lower gastrointestinal diseases. Gastroenterology, 136(3), 741-754. doi:10.1053/j.gastro.2009.01.015

Felsen, C. B., Piasecki, A., Ferrante, J. M., Ohman-Strickland, P. A., \& Crabtree, B. F. (2011). Colorectal cancer screening among primary care patients: Does risk affect screening behavior? Journal of Community Health, 36(4), 605-611. doi:10.1007/s10900-010-9348-0

Gellad, Z. F., \& Provenzale, D. (2010). Colorectal cancer: National and international perspective on the burden of disease and public health impact. Gastroenterology, 138(6), 2177-2190. doi:10.1053/j.gastro.2010.01.056

Gilbert, A., \& Kanarek, N. (2005). Colorectal cancer screening: Physician recommendation is influential advice to marylanders. Preventive Medicine, 41(2), 367-379. doi:10.1016/j.ypmed.2005.01.008

Gill, S., Loprinzi, C. L., Sargent, D. J., Thome, S. D., Alberts, S. R., Haller, D. G., et al. (2004). Pooled analysis of fluorouracil-based adjuvant therapy for stage II and III colon cancer: Who benefits and by how much? Journal of Clinical Oncology : Official Journal of the American Society of Clinical Oncology, 22(10), 1797-1806. doi:10.1200/JCO.2004.09.059 
Giovannucci, E. (2001). Insulin, insulin-like growth factors and colon cancer: A review of the evidence. The Journal of Nutrition, 131(11 Suppl), 3109S-20S.

Gloeckler Ries, L. A., Reichman, M. E., Lewis, D. R., Hankey, B. F., \& Edwards, B. K. (2003). Cancer survival and incidence from the surveillance, epidemiology, and end results (SEER) program. The Oncologist, 8(6), 541-552.

Gross, C. P., Guo, Z., McAvay, G. J., Allore, H. G., Young, M., \& Tinetti, M. E. (2006). Multimorbidity and survival in older persons with colorectal cancer. Journal of the American Geriatrics Society, 54(12), 1898-1904. doi:10.1111/j.1532-5415.2006.00973.x

Gross, C. P., McAvay, G. J., Guo, Z., \& Tinetti, M. E. (2007). The impact of chronic illnesses on the use and effectiveness of adjuvant chemotherapy for colon cancer. Cancer, 109(12), 24102419. doi:10.1002/cncr.22726

Hayanga, A. J., Mukherjee, D., Chang, D., Kaiser, H., Lee, T., Gearhart, S., et al. (2010). Teaching hospital status and operative mortality in the united states: Tipping point in the volume-outcome relationship following colon resections? Archives of Surgery (Chicago, Ill.: 1960), 145(4), 346-350. doi:10.1001/archsurg.2010.24

Hebert, P. L., Geiss, L. S., Tierney, E. F., Engelgau, M. M., Yawn, B. P., \& McBean, A. M. (1999). Identifying persons with diabetes using medicare claims data. American Journal of Medical Quality: The Official Journal of the American College of Medical Quality, 14(6), 270277. 
Hu, F. B., Manson, J. E., Liu, S., Hunter, D., Colditz, G. A., Michels, K. B., et al. (1999). Prospective study of adult onset diabetes mellitus (type 2) and risk of colorectal cancer in women. Journal of the National Cancer Institute, 91(6), 542-547.

Iwashyna, T. J., \& Lamont, E. B. (2002). Effectiveness of adjuvant fluorouracil in clinical practice: A population-based cohort study of elderly patients with stage III colon cancer. Journal of Clinical Oncology : Official Journal of the American Society of Clinical Oncology, 20(19), 3992-3998.

Jin, T. (2008). Why diabetes patients are more prone to the development of colon cancer? Medical Hypotheses, 71(2), 241-244. doi:10.1016/j.mehy.2008.03.025

Jullumstro, E., Kollind, M., Lydersen, S., \& Edna, T. H. (2009). Diabetes mellitus and outcomes of colorectal cancer. Acta Oncologica (Stockholm, Sweden), 48(3), 361-367. doi:10.1080/02841860802637765

Kim, J., Mittal, R., Konyalian, V., King, J., Stamos, M. J., \& Kumar, R. R. (2007). Outcome analysis of patients undergoing colorectal resection for emergent and elective indications. The American Surgeon, 73(10), 991-993.

Klabunde, C. N., Schenck, A. P., \& Davis, W. W. (2006). Barriers to colorectal cancer screening among medicare consumers. American Journal of Preventive Medicine, 30(4), 313-319. doi:10.1016/j.amepre.2005.11.006

Lemmens, V. E., Janssen-Heijnen, M. L., Verheij, C. D., Houterman, S., Repelaer van Driel, O. J., \& Coebergh, J. W. (2005). Co-morbidity leads to altered treatment and worse survival of 
elderly patients with colorectal cancer. The British Journal of Surgery, 92(5), 615-623. doi:10.1002/bjs.4913

Limburg, P. J., Anderson, K. E., Johnson, T. W., Jacobs, D. R.,Jr, Lazovich, D., Hong, C. P., et al. (2005). Diabetes mellitus and subsite-specific colorectal cancer risks in the iowa women's health study. Cancer Epidemiology, Biomarkers \& Prevention : A Publication of the American Association for Cancer Research, Cosponsored by the American Society of Preventive Oncology, 14(1), 133-137.

Limburg, P. J., Vierkant, R. A., Fredericksen, Z. S., Leibson, C. L., Rizza, R. A., Gupta, A. K., et al. (2006). Clinically confirmed type 2 diabetes mellitus and colorectal cancer risk: A population-based, retrospective cohort study. The American Journal of Gastroenterology, 101(8), 1872-1879. doi:10.1111/j.1572-0241.2006.00725.x

McBean, A. M., \& Yu, X. (2007). The underuse of screening services among elderly women with diabetes. Diabetes Care, 30(6), 1466-1472. doi:10.2337/dc06-2233

McKeown-Eyssen, G. (1994). Epidemiology of colorectal cancer revisited: Are serum triglycerides and/or plasma glucose associated with risk? Cancer Epidemiology, Biomarkers \& Prevention : A Publication of the American Association for Cancer Research, Cosponsored by the American Society of Preventive Oncology, 3(8), 687-695.

Meyerhardt, J. A., Catalano, P. J., Haller, D. G., Mayer, R. J., Macdonald, J. S., Benson, A. B.,3rd, et al. (2003). Impact of diabetes mellitus on outcomes in patients with colon cancer. Journal of Clinical Oncology : Official Journal of the American Society of Clinical Oncology, 21(3), 433-440. 
Mitchell, A. D., Inglis, K. M., Murdoch, J. M., \& Porter, G. A. (2007). Emergency room presentation of colorectal cancer: A consecutive cohort study. Annals of Surgical Oncology, 14(3), 1099-1104. doi:10.1245/s10434-006-9245-z

Mitry, E., Barthod, F., Penna, C., \& Nordlinger, B. (2002). Surgery for colon and rectal cancer. Best Practice \& Research.Clinical Gastroenterology, 16(2), 253-265. doi:10.1053/bega.2002.0284

Paulson, E. C., Wirtalla, C., Armstrong, K., \& Mahmoud, N. N. (2009). Gender influences treatment and survival in colorectal cancer surgery. Diseases of the Colon and Rectum, 52(12), 1982-1991. doi:10.1007/DCR.0b013e3181beb42a

Polednak, A. P. (2000). Inpatient hospital admission through an emergency department in relation to stage at diagnosis of colorectal cancer. Cancer Detection and Prevention, 24(3), 283289.

Potosky, A. L., Riley, G. F., Lubitz, J. D., Mentnech, R. M., \& Kessler, L. G. (1993). Potential for cancer related health services research using a linked medicare-tumor registry database. Medical Care, 31(8), 732-748.

Rabeneck, L., Paszat, L. F., \& Li, C. (2006). Risk factors for obstruction, perforation, or emergency admission at presentation in patients with colorectal cancer: A population-based study. The American Journal of Gastroenterology, 101(5), 1098-1103. doi:10.1111/j.15720241.2006.00488.x 
Redaelli, A., Cranor, C. W., Okano, G. J., \& Reese, P. R. (2003). Screening, prevention and socioeconomic costs associated with the treatment of colorectal cancer. PharmacoEconomics, 21(17), 1213-1238.

Richardson, L. C., \& Pollack, L. A. (2005). Therapy insight: Influence of type 2 diabetes on the development, treatment and outcomes of cancer. Nature Clinical Practice.Oncology, 2(1), 48-53. doi:10.1038/ncponc0062

Ries, L. A., Melbert, D., Krapcho, M., Stinchcomb, D. G., Howlader, N., \& Horner, M. J. (2007). SEER cancer statistics review, 1975-2005, national cancer institute.. Bethesda: National Cancer Institute.

Rim, S. H., Seeff, L., Ahmed, F., King, J. B., \& Coughlin, S. S. (2009). Colorectal cancer incidence in the united states, 1999-2004 : An updated analysis of data from the national program of cancer registries and the surveillance, epidemiology, and end results program. Cancer, 115(9), 1967-1976. doi:10.1002/cncr.24216

Satariano, W. A., \& Silliman, R. A. (2003). Comorbidity: Implications for research and practice in geriatric oncology. Critical Reviews in oncology/hematology, 48(2), 239-248.

Schenck, A. P., Klabunde, C. N., Warren, J. L., Jackson, E., Peacock, S., \& Lapin, P. (2011). Physician visits and colorectal cancer testing among medicare enrollees in north carolina and south carolina, 2005. Preventing Chronic Disease, 8(5), A112.

Scott, N. A., Jeacock, J., \& Kingston, R. D. (1995). Risk factors in patients presenting as an emergency with colorectal cancer. The British Journal of Surgery, 82(3), 321-323. 
Shack, L. G., Rachet, B., Williams, E. M., Northover, J. M., \& Coleman, M. P. (2010). Does the timing of comorbidity affect colorectal cancer survival? A population based study. Postgraduate Medical Journal, 86(1012), 73-78. doi:10.1136/pgmj.2009.084566

Shonka, N. A., Anderson, J. R., Panwalkar, A. W., Reed, E. C., Steen, P. D., \& Ganti, A. K. (2006). Effect of diabetes mellitus on the epidemiology and outcomes of colon cancer. Medical Oncology (Northwood, London, England), 23(4), 515-519. doi:10.1385/MO:23:4:515

Siddiqui, A. A., Spechler, S. J., Huerta, S., Dredar, S., Little, B. B., \& Cryer, B. (2008). Elevated HbA1c is an independent predictor of aggressive clinical behavior in patients with colorectal cancer: A case-control study. Digestive Diseases and Sciences, 53(9), 2486-2494. doi:10.1007/s10620-008-0264-4

Smothers, L., Hynan, L., Fleming, J., Turnage, R., Simmang, C., \& Anthony, T. (2003). Emergency surgery for colon carcinoma. Diseases of the Colon and Rectum, 46(1), 24-30. doi:10.1097/01.DCR.0000044719.17980.4C

Surgery for colorectal cancer in elderly patients: A systematic review. colorectal cancer collaborative group. (2000). Lancet, 356(9234), 968-974.

Vinikoor, L. C., Long, M. D., Keku, T. O., Martin, C. F., Galanko, J. A., \& Sandler, R. S. (2009). The association between diabetes, insulin use, and colorectal cancer among whites and african americans. Cancer Epidemiology, Biomarkers \& Prevention : A Publication of the American Association for Cancer Research, Cosponsored by the American Society of Preventive Oncology, 18(4), 1239-1242. doi:10.1158/1055-9965.EPI-08-1031 
Warren, J. L., Klabunde, C. N., Schrag, D., Bach, P. B., \& Riley, G. F. (2002). Overview of the SEER-medicare data: Content, research applications, and generalizability to the united states elderly population. Medical Care, 40(8 Suppl), IV-3-18.

doi:10.1097/01.MLR.0000020942.47004.03

Will, J. C., Galuska, D. A., Vinicor, F., \& Calle, E. E. (1998). Colorectal cancer: Another complication of diabetes mellitus? American Journal of Epidemiology, 147(9), 816-825.

Yancik, R., Wesley, M. N., Ries, L. A., Havlik, R. J., Long, S., Edwards, B. K., et al. (1998). Comorbidity and age as predictors of risk for early mortality of male and female colon carcinoma patients: A population-based study. Cancer, 82(11), 2123-2134. 
Table 1. Characteristics of the sample*

\begin{tabular}{|c|c|c|}
\hline Characteristic & $\mathrm{N}$ & $\%$ \\
\hline \multicolumn{3}{|l|}{ Age } \\
\hline 66-69 & 4031 & 16.0 \\
\hline $70-74$ & 5411 & 21.4 \\
\hline $75-79$ & 6017 & 23.8 \\
\hline $80-84$ & 5302 & 21.0 \\
\hline 85 \& over & 4473 & 17.7 \\
\hline \multicolumn{3}{|l|}{ Sex } \\
\hline Male & 11329 & 44.9 \\
\hline Female & 13905 & 55.1 \\
\hline \multicolumn{3}{|l|}{ Race } \\
\hline White & 21396 & 84.8 \\
\hline Black & 2097 & 8.3 \\
\hline Other & 1741 & 6.9 \\
\hline \multicolumn{3}{|l|}{ Diabetes } \\
\hline No & 19768 & 78.3 \\
\hline Yes & 5466 & 21.7 \\
\hline \multicolumn{3}{|l|}{ Athero } \\
\hline No & 19797 & 78.5 \\
\hline Yes & 5437 & 21.5 \\
\hline \multicolumn{3}{|l|}{ COPD } \\
\hline No & 22443 & 88.9 \\
\hline Yes & 2791 & 11.1 \\
\hline \multicolumn{3}{|l|}{ CHF } \\
\hline No & 22474 & 89.1 \\
\hline Yes & 2760 & 10.9 \\
\hline \multicolumn{3}{|l|}{ Stage } \\
\hline Early & 6312 & 25.0 \\
\hline Late & 18922 & 75.0 \\
\hline \multicolumn{3}{|c|}{ Emergency Admission } \\
\hline No & 20699 & 82.0 \\
\hline Yes & 4535 & 18.0 \\
\hline \multicolumn{3}{|l|}{ Surgery } \\
\hline No & 4152 & 16.5 \\
\hline Yes & 21082 & 83.5 \\
\hline \multicolumn{3}{|c|}{ Chemotherapy/Radiation } \\
\hline No & 16522 & 65.5 \\
\hline Yes & 8712 & 34.5 \\
\hline
\end{tabular}

Continued 
Table 1. Characteristics of the sample*

\begin{tabular}{lrr}
\hline Region in US & & \\
West & 10245 & 40.6 \\
Midwest & 3947 & 15.6 \\
South & 4756 & 18.8 \\
East & 6286 & 24.9 \\
Patient Location & & \\
& & \\
Big Metro & 13913 & 55.1 \\
Metro & 7071 & 28.0 \\
Urban & 1556 & 6.2 \\
Less Urban & 2188 & 8.7 \\
Rural & 506 & 2.0 \\
\hline
\end{tabular}

*Sample equals 25,234 CRC patients 
Table 2 Characteristics of patients by diabetes status

\begin{tabular}{|c|c|c|c|c|c|}
\hline \multirow[t]{3}{*}{ Patient Characteristic } & \multicolumn{4}{|c|}{ Diabetes } & \multirow[t]{3}{*}{$p$} \\
\hline & \multicolumn{2}{|c|}{ No } & \multicolumn{2}{|c|}{ Yes } & \\
\hline & $\mathrm{N}$ & $\%$ & $\mathrm{~N}$ & $\%$ & \\
\hline Age Group & & & & & 0.000 \\
\hline $66-69$ & 3135 & $15.9 \%$ & 896 & $16.4 \%$ & \\
\hline $70-74$ & 4154 & $21.0 \%$ & 1257 & $23.0 \%$ & \\
\hline $75-79$ & 4561 & $23.1 \%$ & 1456 & $26.6 \%$ & \\
\hline $80-84$ & 4239 & $21.4 \%$ & 1063 & $19.4 \%$ & \\
\hline 85 \& over & 3679 & $18.6 \%$ & 794 & $14.5 \%$ & \\
\hline Sex & & & & & 0.000 \\
\hline Male & 8718 & $44.1 \%$ & 2611 & $47.8 \%$ & \\
\hline Female & 11050 & $55.9 \%$ & 2855 & $52.2 \%$ & \\
\hline Race & & & & & 0.000 \\
\hline White & 17050 & $86.3 \%$ & 4346 & $79.5 \%$ & \\
\hline Black & 1491 & $7.5 \%$ & 606 & $11.1 \%$ & \\
\hline Other & 1227 & $6.2 \%$ & 514 & $9.4 \%$ & \\
\hline Atherosclerosis & & & & & 0.000 \\
\hline No & 16273 & $82.3 \%$ & 3524 & $64.5 \%$ & \\
\hline Yes & 3495 & $17.7 \%$ & 1942 & $35.5 \%$ & \\
\hline COPD & & & & & 0.000 \\
\hline No & 17729 & $89.7 \%$ & 4714 & $86.2 \%$ & \\
\hline Yes & 2039 & $10.3 \%$ & 752 & $13.8 \%$ & \\
\hline CHF & & & & & 0.000 \\
\hline No & 18076 & $91.4 \%$ & 4398 & $80.5 \%$ & \\
\hline Yes & 1692 & $8.6 \%$ & 1068 & $19.5 \%$ & \\
\hline Stage & & & & & 0.207 \\
\hline Early & 10917 & $55.2 \%$ & 3071 & $6.2 \%$ & \\
\hline Late & 8851 & $44.8 \%$ & 2395 & $43.8 \%$ & \\
\hline Tumor Location & & & & & 0.681 \\
\hline Distal & 9852 & $49.8 \%$ & 2707 & $49.5 \%$ & \\
\hline Proximal & 9916 & $50.2 \%$ & 2759 & $50.5 \%$ & \\
\hline Emergency Admission & & & & & 0.004 \\
\hline No & 16288 & $82.4 \%$ & 4411 & $80.7 \%$ & \\
\hline Yes & 3480 & $17.6 \%$ & 1055 & $19.3 \%$ & \\
\hline Surgery & & & & & 0.000 \\
\hline No & 3357 & $17.0 \%$ & 795 & $14.5 \%$ & \\
\hline Yes & 16411 & $83.0 \%$ & 4671 & $85.5 \%$ & \\
\hline ChemRad & & & & & 0.302 \\
\hline No & 12911 & $65.3 \%$ & 3611 & $66.1 \%$ & \\
\hline Yes & 6857 & $34.7 \%$ & 1855 & $33.9 \%$ & \\
\hline
\end{tabular}

Continued 
Table 2 Characteristics of patients by diabetes status

\begin{tabular}{|c|c|c|c|c|c|}
\hline \multirow[t]{3}{*}{ Patient Characteristic } & \multicolumn{4}{|c|}{ Diabetes } & \multirow[t]{3}{*}{$p$} \\
\hline & \multicolumn{2}{|c|}{ No } & \multicolumn{2}{|c|}{ Yes } & \\
\hline & $\mathrm{N}$ & $\%$ & $\mathrm{~N}$ & $\%$ & \\
\hline Region in the US & & & & & 0.000 \\
\hline West & 8181 & $41.4 \%$ & 2064 & $37.8 \%$ & \\
\hline Midwest & 3079 & $15.6 \%$ & 868 & $15.9 \%$ & \\
\hline South & 3733 & $18.9 \%$ & 1023 & $18.7 \%$ & \\
\hline East & 4775 & $24.2 \%$ & 1511 & $27.6 \%$ & \\
\hline Patient Location & & & & & 0.141 \\
\hline Big Metro & 10838 & $54.8 \%$ & 3075 & $56.3 \%$ & \\
\hline Metro & 5539 & $28.0 \%$ & 1532 & $28.0 \%$ & \\
\hline Urban & 1241 & $6.3 \%$ & 315 & $5.8 \%$ & \\
\hline Less Urban & 1748 & $8.8 \%$ & 440 & $8.0 \%$ & \\
\hline Rural & 402 & $2.0 \%$ & 104 & $1.9 \%$ & \\
\hline \multicolumn{6}{|l|}{ Quintile of Physician } \\
\hline Visits & & & & & 0.000 \\
\hline First (Highest) & 3230 & $16.3 \%$ & 1867 & $34.2 \%$ & \\
\hline Second & 3767 & $19.1 \%$ & 1465 & $26.8 \%$ & \\
\hline Third & 3853 & $19.5 \%$ & 1130 & $20.7 \%$ & \\
\hline Fourth & 4125 & $20.9 \%$ & 782 & $14.3 \%$ & \\
\hline Fifth (Lowest) & 4793 & $24.2 \%$ & 222 & $4.1 \%$ & \\
\hline
\end{tabular}

*Patients are representative of 19,768 nondiabetics and 5,466 diabetics 
Table 3 Characteristics of patients by mortality status

\begin{tabular}{|c|c|c|c|c|c|}
\hline \multirow[t]{3}{*}{ Patient Characteristic } & \multicolumn{4}{|c|}{ Died } & \multirow[t]{3}{*}{$p$} \\
\hline & \multicolumn{2}{|c|}{ No } & \multicolumn{2}{|c|}{ Yes } & \\
\hline & $\mathrm{N}$ & $\%$ & $\mathrm{~N}$ & $\%$ & \\
\hline Age Group & & & & & 0.000 \\
\hline 66-69 & 2755 & $19.6 \%$ & 1276 & $11.4 \%$ & \\
\hline $70-74$ & 3435 & $24.4 \%$ & 1976 & $17.7 \%$ & \\
\hline $75-79$ & 3505 & $24.9 \%$ & 2512 & $22.5 \%$ & \\
\hline $80-84$ & 2702 & $19.2 \%$ & 2600 & $23.3 \%$ & \\
\hline 85 \& over & 1683 & $12.0 \%$ & 2790 & $25.0 \%$ & \\
\hline Sex & & & & & 0.182 \\
\hline Male & 6269 & $44.5 \%$ & 5060 & $45.4 \%$ & \\
\hline Female & 7811 & $55.5 \%$ & 6094 & $54.6 \%$ & \\
\hline Race & & & & & 0.000 \\
\hline White & 11979 & $85.1 \%$ & 9417 & $84.4 \%$ & \\
\hline Black & 1032 & $7.3 \%$ & 1065 & $9.5 \%$ & \\
\hline Other & 1069 & $7.6 \%$ & 672 & $6.0 \%$ & \\
\hline Diabetes & & & & & 0.000 \\
\hline No & 11191 & $79.5 \%$ & 8577 & $76.9 \%$ & \\
\hline Yes & 2889 & $20.5 \%$ & 2577 & $23.1 \%$ & \\
\hline Atherosclerosis & & & & & 0.000 \\
\hline No & 11302 & $80.3 \%$ & 8495 & $76.2 \%$ & \\
\hline Yes & 2778 & $19.7 \%$ & 2659 & $23.8 \%$ & \\
\hline COPD & & & & & 0.000 \\
\hline No & 12867 & $91.4 \%$ & 9576 & $85.9 \%$ & \\
\hline Yes & 1213 & $8.6 \%$ & 1578 & $14.1 \%$ & \\
\hline CHF & & & & & 0.000 \\
\hline No & 13059 & $92.7 \%$ & 9415 & $84.4 \%$ & \\
\hline Yes & 1021 & $7.3 \%$ & 1739 & $15.6 \%$ & \\
\hline Stage & & & & & 0.000 \\
\hline Early & 9977 & $70.9 \%$ & 4011 & $36.0 \%$ & \\
\hline Late & 4103 & $29.1 \%$ & 7143 & $64.0 \%$ & \\
\hline Tumor location & & & & & 0.022 \\
\hline Distal & 6917 & $49.1 \%$ & 5642 & $50.6 \%$ & \\
\hline Proximal & 7163 & $50.9 \%$ & 5512 & $49.4 \%$ & \\
\hline Emergency Admission & & & & & 0.000 \\
\hline No & 12293 & $87.3 \%$ & 8406 & $75.4 \%$ & \\
\hline Yes & 1787 & $12.7 \%$ & 2748 & $24.6 \%$ & \\
\hline
\end{tabular}

Continued 
Table 3 Characteristics of patients by mortality status

\begin{tabular}{|c|c|c|c|c|c|}
\hline \multirow[t]{3}{*}{ Patient Characteristic } & \multicolumn{4}{|c|}{ Died } & \multirow[t]{3}{*}{$p$} \\
\hline & \multicolumn{2}{|c|}{ No } & \multicolumn{2}{|c|}{ Yes } & \\
\hline & $\mathrm{N}$ & $\%$ & $\mathrm{~N}$ & $\%$ & \\
\hline Surgery & & & & & 0.000 \\
\hline No & 1426 & $10.1 \%$ & 2726 & $24.4 \%$ & \\
\hline Yes & 12654 & $89.9 \%$ & 8428 & $75.6 \%$ & \\
\hline Chemo-Radiation & & & & & 0.001 \\
\hline No & 9349 & $66.4 \%$ & 7173 & $64.3 \%$ & \\
\hline Yes & 4731 & $33.6 \%$ & 3981 & $35.7 \%$ & \\
\hline Region in the US & & & & & 0.000 \\
\hline West & 5843 & $41.5 \%$ & 4402 & $39.5 \%$ & \\
\hline Midwest & 2245 & $15.9 \%$ & 1702 & $15.3 \%$ & \\
\hline South & 2515 & $17.9 \%$ & 2241 & $20.1 \%$ & \\
\hline East & 3477 & $24.7 \%$ & 2809 & $25.2 \%$ & \\
\hline Patient Location & & & & & 0.615 \\
\hline Big Metro & 7717 & $54.8 \%$ & 6196 & $55.5 \%$ & \\
\hline Metro & 3997 & $28.4 \%$ & 3074 & $27.6 \%$ & \\
\hline Urban & 877 & $6.2 \%$ & 679 & $6.1 \%$ & \\
\hline Less Urban & 1208 & $8.6 \%$ & 980 & $8.8 \%$ & \\
\hline Rural & 281 & $2.0 \%$ & 225 & $2.0 \%$ & \\
\hline \multicolumn{6}{|l|}{ Quintile of Physician } \\
\hline Visits & 14080 & & 11154 & & 0.000 \\
\hline First (Highest) & 2443 & $17.4 \%$ & 2654 & $23.8 \%$ & \\
\hline Second & 2961 & $21.0 \%$ & 2271 & $20.4 \%$ & \\
\hline Third & 2969 & $21.1 \%$ & 2014 & $18.1 \%$ & \\
\hline Fourth & 3014 & $21.4 \%$ & 1893 & $17.0 \%$ & \\
\hline Fifth (Lowest) & 2693 & $19.1 \%$ & 2322 & $20.8 \%$ & \\
\hline
\end{tabular}

*Patients are representative of 14,080 who did not die and 11,154 who died 
Table 4. Cox Proportional Hazards Model for time to mortality in CRC patients over a 5 year period

\begin{tabular}{|c|c|c|c|c|c|c|}
\hline \multirow[b]{2}{*}{ Patient Characteristic } & & \multicolumn{4}{|c|}{ 95.0\% CI for HR } & \multirow[b]{2}{*}{ Sig } \\
\hline & & HR & Lower & Upper & $p$ & \\
\hline \multirow{4}{*}{ Comorbidities } & Diabetes & 1.12 & 1.06 & 1.17 & .000 & $* * *$ \\
\hline & Atherosclerosis & 0.98 & 0.94 & 1.03 & .482 & \\
\hline & COPD & 1.33 & 1.26 & 1.41 & .000 & $* * *$ \\
\hline & $\mathrm{CHF}$ & 1.43 & 1.35 & 1.52 & .000 & $* * *$ \\
\hline \multirow{5}{*}{ Age Group } & $66-69$ & & & & .000 & $* * *$ \\
\hline & $70-74$ & 1.18 & 1.10 & 1.27 & .000 & $* * *$ \\
\hline & $75-79$ & 1.42 & 1.33 & 1.52 & .000 & $* * *$ \\
\hline & $80-84$ & 1.72 & 1.60 & 1.84 & .000 & $* * *$ \\
\hline & 85 and over & 2.30 & 2.14 & 2.47 & .000 & $* * *$ \\
\hline \multirow{5}{*}{$\begin{array}{l}\text { Sex } \\
\text { Race }\end{array}$} & FEMALE & 0.92 & 0.89 & 0.96 & .000 & $* * *$ \\
\hline & White & & & & .000 & $* * *$ \\
\hline & Black & 1.08 & 1.01 & 1.15 & .020 & $* * *$ \\
\hline & Other & 0.85 & 0.78 & 0.92 & .000 & $* * *$ \\
\hline & Emergency & 1.61 & 1.54 & 1.68 & .000 & $* * *$ \\
\hline \multicolumn{7}{|l|}{ Admission Type } \\
\hline \multirow[t]{2}{*}{ Treatment } & Surgery & 0.41 & 0.39 & 0.43 & .000 & $* * *$ \\
\hline & Chemo/Rad & 0.70 & 0.67 & 0.74 & .000 & $* * *$ \\
\hline \multirow{6}{*}{$\begin{array}{l}\text { Tumor Location } \\
\text { Stage } \\
\text { Region in the US }\end{array}$} & Proximal & 0.94 & 0.91 & 0.98 & .003 & $* * *$ \\
\hline & Late Stage & 3.74 & 3.59 & 3.91 & .000 & $* * *$ \\
\hline & WEST & & & & .000 & $* * *$ \\
\hline & MIDWEST & 0.97 & 0.91 & 1.03 & .252 & \\
\hline & SOUTH & 1.11 & 1.05 & 1.18 & .000 & $* * *$ \\
\hline & EAST & 0.93 & 0.88 & 0.97 & .002 & $* * *$ \\
\hline \multirow{5}{*}{ Patient Location } & Big Metro & & & & .663 & \\
\hline & Metro & 0.92 & 0.80 & 1.05 & .214 & \\
\hline & Urban & 0.93 & 0.81 & 1.06 & .273 & \\
\hline & Less Urban & 0.95 & 0.82 & 1.11 & .530 & \\
\hline & Rural & 0.94 & 0.82 & 1.09 & .420 & \\
\hline \multirow[t]{5}{*}{$\begin{array}{l}\text { Quintile of Office } \\
\text { Visits }\end{array}$} & $\begin{array}{l}\text { First Quintile } \\
\text { (Highest) }\end{array}$ & & & & .000 & \\
\hline & Second & 0.89 & 0.84 & 0.94 & .000 & $* * *$ \\
\hline & Third & 0.87 & 0.82 & 0.92 & .000 & $* * *$ \\
\hline & Fourth & 0.84 & 0.79 & 0.90 & .000 & $* * *$ \\
\hline & Fifth (Lowest) & 0.93 & 0.87 & 1.00 & .042 & $* * *$ \\
\hline
\end{tabular}

Referent categories for Diabetes, COPD, Athero and CHF are no diabetes, no Athero, no COPD and no CHF

Referent category for sex is MALE, Tumor location is distal, Stage is early stage, and for treatment is no surgery and no Chemo/rad 
Fig 1. Kaplan-Meier Curve for Diabetes

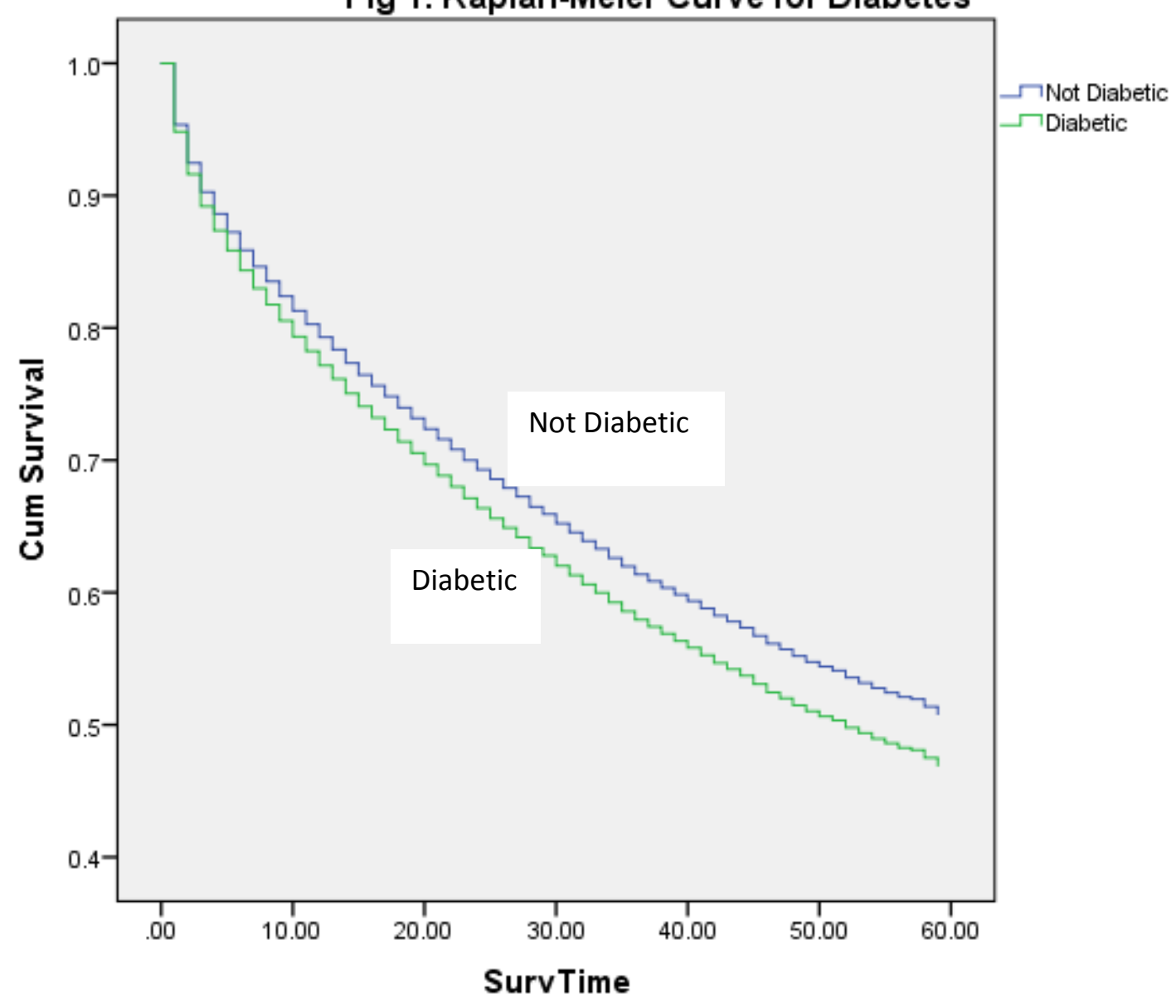

$P=0.000$ 
Fig 2. Kaplan-Meier Curve for Emergency Admission

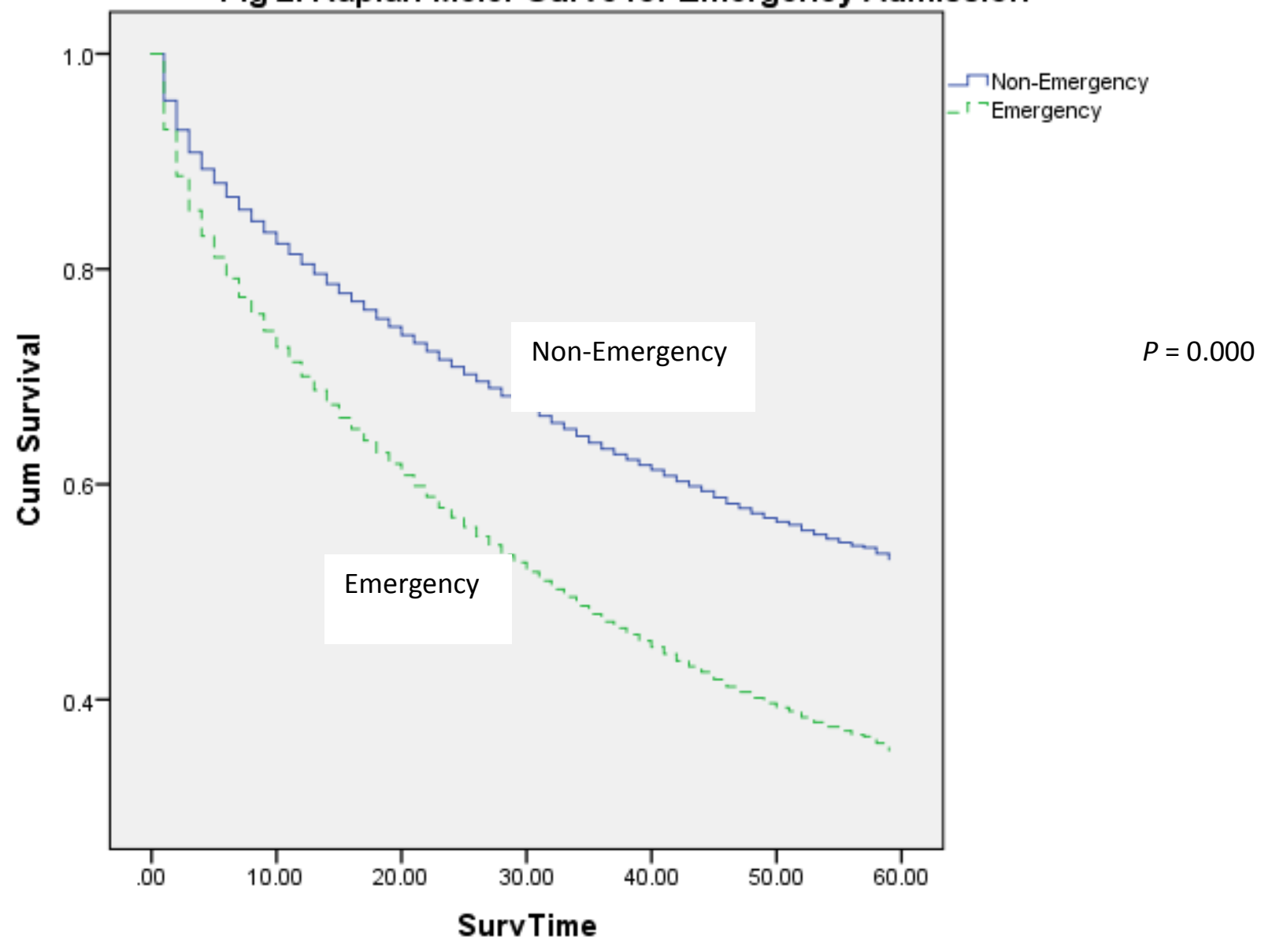


Fig 3. Kaplan-Meier Curves for Surgery

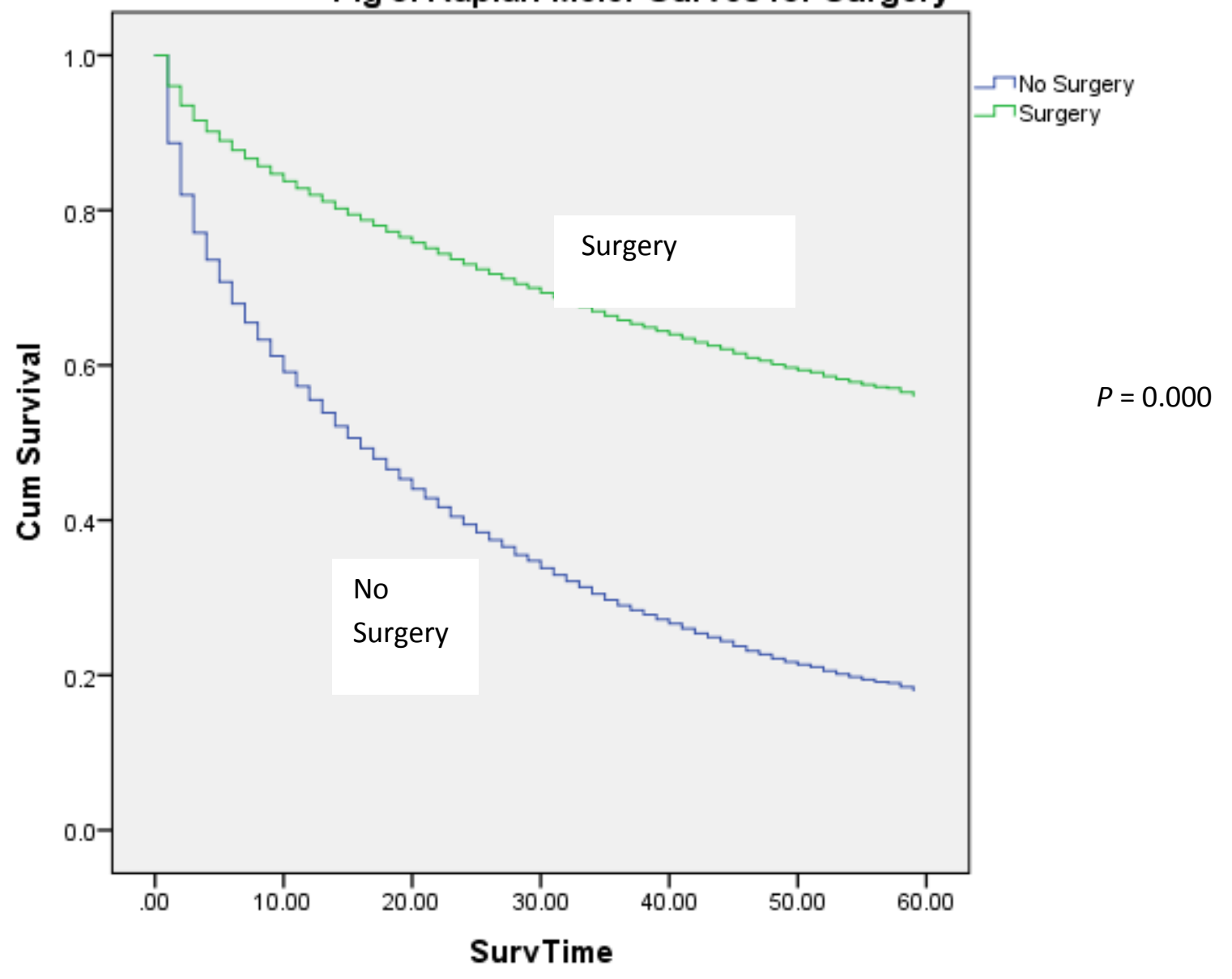


Fig 4. Kaplan-Meier Curves for Chemotherapy/Radiation

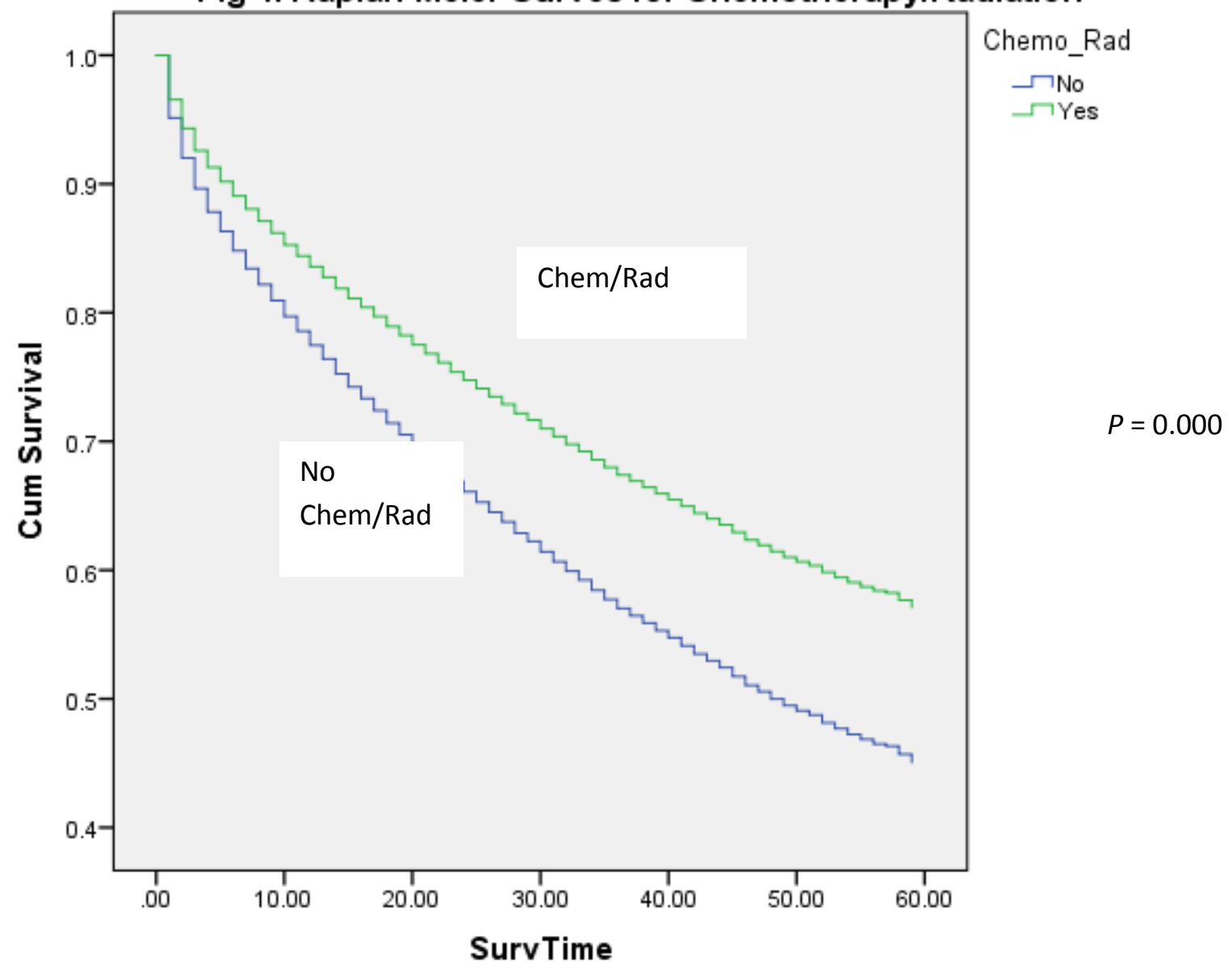




\section{CHAPTER FIVE \\ DISCUSSION}

To explore the outcomes of CRC in diabetic elderly patients the study used a large nationally representative sample and focused on main aims. The first aim was to investigate the association between diabetes and stage at diagnosis of CRC in an elderly population. The association of covariates such as the three most common comorbidities: coronary atherosclerosis, chronic obstructive pulmonary disease (COPD), and congestive heart failure (CHF); age; race; sex; region in the US; patient location; and the frequency of physician office visits with stage at CRC diagnosis was also evaluated.

The second aim was to check the association of diabetes with CRC presenting as an emergency condition for surgery in the elderly. This was followed by an investigation of predictors of emergency condition of CRC surgery in the elderly using large nationally representative registry data. The predictors that were explored included were the three most common comorbidities: coronary atherosclerosis, chronic obstructive pulmonary disease (COPD), and congestive heart failure (CHF); age; race; sex; region in the US; patient location; the frequency of physician office visits; and stage at CRC diagnosis.

Finally, the study explored the effect of diabetes on survival of elderly Medicare beneficiaries with CRC. It also explored the association of the covariates including three most common comorbid conditions, in addition to diabetes, emergency admission, and treatment variables and how they affect survival in a CRC patient.

For all three aims, the linked Surveillance, Epidemiology and End-Results (SEER)Medicare data which is a large population-based source of information for cancer-related 
epidemiologic and health services research was utilized. The use of the SEER-Medicare data consists of CRC cases from 17 registries from 2003-2005, and provides several strengths such as exploring a nationally representative elderly population. This is unique since previous studies have studied the disease in either smaller regions of the country, fewer registries, or have included patients that were not elderly. This is also the first study to explore the association of diabetics with stage at diagnosis of CRC in such a large representative sample in the US. The association of diabetes with emergency condition for CRC surgery including bowel perforation, bowel obstruction, and peritonitis has never before been studied in an elderly population; this study investigates this along with relevant covariates. The association of diabetes, other frequently seen chronic comorbid conditions, emergency admissions and treatment variable, along with tumor location, office visits, region and other demographic characteristics finally come together to check survival and mortality in this unique sample.

\section{Diabetes and Stage at Diagnosis}

The association of diabetes with stage at diagnosis of CRC has been previously studied in the US and other countries in smaller samples with conflicting results. In this study diabetes does not show a significant association with stage at diagnosis for CRC. If left uncontrolled, diabetes outcomes in CRC patients are even worse than those with controlled diabetes. (Siddiqui, A.A. 2008) In addition, diabetic CRC patients tend to have poorer outcomes than non-diabetic patients, and therefore it can be argued that the cancer should be detected at an earlier stage in diabetics than in non-diabetics due to the survival benefit provided at being treated at earlier stages. 
This study also showed that diabetics visited physicians more frequently than nondiabetics and were more likely to have comorbid conditions such as coronary atherosclerosis, COPD and CHF. This would predispose them to greater recommendations for screening for various diseases including CRC and therefore it would be reasonable to expect them to be diagnosed at earlier stages than non-diabetics. However, after adjusting for the number of physician office visits this was not so. A review of barriers and facilitators to screening for CRC in patients over the age of 65 suggests that although Medicare's coverage of screening colonoscopy was consistently reported as a facilitator, the most cited barrier was lack of screening recommendation by a physician. (Guessous, I. 2010) Compared to average risk patients, i.e. patients over the age of 50 with no chronic diseases or history of cancer, diabetics are considered as increased-risk for colorectal cancer. A recent study that examined screening patterns in individuals with varying risk for CRC found that compared to average risk patients, diabetics were less likely to be recommended by physicians for CRC screening and were also less likely to be adherent to a recommendation if one was made. (Felsen, C.B. 2011)

It is important to note that patients over the age of 80 are more likely to be diagnosed at a later stage than younger patients. This could be due to some guidelines cautioning against use of invasive methods for screening for patients over the age of 75 due to possible adverse effects of screening. (Qaseem,A. 2012) All guidelines specifically do not recommend using any invasive method for screening patients over the age of 85 .

The results in this study show that tumors detected within the proximal region in the colon are found to have progressed much more than the ones located in the distal region. Distal tumors are easier to detect with less invasive procedures such as sigmoidoscopy which cannot look at the large intestine in its entirety and is recommended more frequently than colonoscopies. 
Although, both invasive procedures are equally sensitive, sigmoidoscopes cannot reach the proximal areas of the large intestine leading to tumors in those areas to go undetected. (Schoen, R.E. 2012) Proximal tumor location, even after controlling for stage, has also been significantly associated with poorer mortality and survival as compared to distally located colon cancers. (Wray, C.M. 2009)

\section{Diabetes and Emergency Condition for CRC surgery}

This study is the first to report the association of diabetes with emergency surgery for CRC, and explore the predictors of emergency colorectal cancer surgery in a large nationally representative sample. The study showed that the odds of being an emergency patient for CRC surgery were lower for diabetic patients; this association was not significant. However, this result must be interpreted in light of the fact that diabetic patients belonged to the highest quintile in terms of physician office visits. Previous reports on a Medicare population have mentioned that having any physician office visit, increased number of office visits, and visits with primary care physicians were associated with increased CRC test use.(Schenck et al., 2011) Klabunde and colleagues have reported that having a chronic condition such as diabetes is a predictor of receiving a physician recommendation for CRC screening.(Klabunde, Schenck, \& Davis, 2006) Increased number of physician office visits increases the chances of being recommended for a screening test; and clinician recommendation for a screening test has been proven to be a strong predictor in the elderly as well as young patients to adhere to screening practices for CRC.(Felsen, Piasecki, Ferrante, Ohman-Strickland, \& Crabtree, 2011; Gilbert \& Kanarek, 2005) 
Compared to Whites, Black patients were more likely to be classified as an emergency condition for CRC surgery. It has been reported that Blacks, Hispanics, and American Indians/Alaska Natives were less likely to report receiving a recommendation for sigmoidoscopy compared to Whites.(Coughlin \& Thompson, 2005) Whites are also more likely than Blacks to report ever receiving a provider recommendation for a colonoscopy. Although the proportion of patients receiving recommendations for colonoscopy/sigmoidoscopy increased over time, the gap between races remained unchanged, even after controlling for insurance status.(Rich et al., 2011) A study by Hood and colleagues has reported that although over $80 \%$ of their sample of 439 blacks was covered by insurance, less than $50 \%$ reported receiving a recommendation to screen for CRC.(Hood et al., 2010)

Once again the intermediate outcome for the elderly patients over the age of 80 was poorer with the odds of being an emergency case for CRC surgery being higher for this group. This could, again, be due to several guidelines cautioning against use of invasive methods for screening for patients over the age of 75 and all guidelines specifically not recommending using any invasive method for screening patients over the age of 85 due to possible adverse effects of screening.(Qaseem et al., 2012)

The results of this study also showed that having a proximal tumor decreased the odds of being an emergency case for CRC surgery. This study is the first to report an association between tumor location and emergency condition for surgery for CRC. However, it has been reported that screening for CRC does not have a survival benefit in patients with proximal cancers despite recent epidemiologic studies suggesting an overall shift to more proximal sites of colon cancer distribution.(Wong, 2010) Proximal cancer tumor biology also makes it hard for them to be detected. There are underlying differences in the biology of proximal and distal CRC 
neoplasia that may contribute to the variable effectiveness of colonoscopy.(Baxter, Warren, Barrett, Stukel, \& Doria-Rose, 2012) This may mean that proximal tumors were possibly underrepresented in the sample in this study.

\section{Diabetics and CRC mortality and survival}

In the analysis to explore the effect of diabetes on survival of elderly Medicare beneficiaries with CRC which also investigated the association of the covariates including three most common comorbid conditions, in addition to diabetes, emergency admission, and treatment variables, the study shows that diabetics suffered worse mortality and survival than nondiabetics. Several factors need to be considered while interpreting this result. Firstly, lack of mortality as well as survival benefit in diabetics is seen despite them being in the highest bracket of physician office visits. Increased number of office visits, and visits with primary care physicians in elderly Medicare beneficiaries have previously been associated with increased CRC test use. (Schenck et al., 2011) Klabunde and colleagues have reported that having a chronic condition such as diabetes is a predictor of receiving a physician recommendation for CRC screening. (Klabunde, Schenck, \& Davis, 2006)(Klabunde et al., 2006) Increased number of physician office visits increases the chances of being recommended for a screening test; clinician recommendation for a screening test has been proven to be a strong predictor in the elderly as well as young patients to adhere to screening practices for CRC. (Felsen, Piasecki, Ferrante, Ohman-Strickland, \& Crabtree, 2011; Gilbert \& Kanarek, 2005)

Secondly, although diabetics were the most frequent visitors to physician offices they were also admitted more emergently for CRC than non-diabetics. This study shows that there is a significant mortality risk associated with being admitted emergently. Besides being a sign of 
screening failure, emergent admissions have poorer outcomes than non-emergent admissions for CRC.

Lastly, despite controlling for the treatment variables surgery and chemotherapy/radiation, which provide significant survival benefit, the study shows a decrease in survival benefit in diabetics. Although it has been advised that among CRC patients, preexisting diabetes is associated with a higher risk of all-cause long-term mortality, this is the first study that explores this association in light of the aforementioned factors.

Besides these factors it has been shown that because diabetes can lead to infections, metabolic derangements, and acute cardiovascular events, cancer patients, including those with CRC and diabetes may also be at greater risk of short-term mortality, especially while surgery is being performed, and even after surgery. (Richardson \& Pollack, 2005) A recent meta-analysis by Barone and colleagues has concluded that compared to nondiabetics, cancer patients with preexisting diabetes are approximately 50\% more likely to die after surgery. (Barone et al., 2010) They mention that this could be due to sepsis and other serious infections which could increase in diabetics especially after surgery due to a possible rise in blood sugar levels.

This study is the first to report emergency admission and its risk associated with mortality and survival in a large group of elderly, nationally representative population of CRC patients. Despite implementation of national intervention strategies up to 30\% percent of CRC patients are admitted emergently. (Kim et al., 2007; Polednak, 2000; Smothers et al., 2003) In this study diabetics presented more emergently than not. This clearly signifies failure to screen in a timely fashion and a possible failure of screening interventions and strategies. Diabetics also have worse survival than nondiabetics. 


\section{Limitations}

This study must also be interpreted in the lights of its limitations. The study used previously employed algorithms to identify diabetic patients. However, the duration of diabetes as well as clinical values such as HbA1C which may have significantly affected the stage at which patients were diagnosed with CRC, were not available. Siddiqui et al have reported that uncontrolled diabetes and therefore increased HbA1C levels leads to diagnosis of CRC at later stages than diabetes that is under control.(Siddiqui et al., 2008) Most colorectal cancers start off as benign adenomatous polyps that turn into adenocarcinomas over several years (cancers that begin in cells that make and release mucus and other fluids). As many as 50\% of the Western populations develop adenomatous polyps in their lifetime but the lifetime risk for colon cancer is about 5\% and only one in ten adenomas lead to cancer formation (Holt, Kozuch, \& Mewar, 2009). It cannot be determined which individuals with adenomas (or a histologically normal colon at risk for adenoma and cancer formation) will develop a cancer and therefore, preventive methods use detection and removal of benign neoplastic colorectal adenomas which lowers colon cancer formation and mortality (Muller \& Sonnenberg, 1995). This study was unable to determine the duration and size of benign polyps, if any, in this sample which may have influenced the time at which the cancer was detected, the stage and the prognosis of the disease.

Timely screening plays a crucial role in detecting the cancer at earlier stages and the data did not allow us to check for frequency of screening. This is especially true for sigmoidoscopy and colonoscopy procedures which are recommended to be performed at five year and ten year intervals respectively. In addition, SEER-Medicare data do not include other important measures of health status, such as body mass index, diet, functional disabilities or geriatric syndromes. 


\section{Conclusions and Future directions}

This study has several strengths including stringent inclusion and exclusion criteria, and the use of population based data from a cancer registry that is globally recognized as an authoritative source of information on cancer incidence and in the United States. Detailed demographic, cancer data on stage and tumor location, and treatment variables allowed the construction of a strong cox proportional hazards model to study and understand the mortality risk associated with diabetes and the several covariates in CRC patients.

The association between diabetes and stage at colorectal cancer, although not statistically significant in this study, must be further explored. Dialogue between the physician and diabetic patient should be encouraged to discuss screening for CRC. Diabetic patients should be screened for the cancer either more frequently or begin at an age earlier than the average risk patient in order to detect the cancer at earlier stages. Patient physician interaction is of prime importance and there needs to be improved intervention and strategies for escalating physician recommendation in this subgroup of the population.

This study shows that patients with fewer office visits had a survival benefit. This could be explained by the fact that those with fewer office visits had fewer comorbid conditions in the first place and hence were predisposed to having a better prognosis and outcome. In addition, it has also been previously reported that elderly patients with CRC increase rather than decrease contact with primary care providers after diagnosis which continues through the first 5 years after cancer diagnosis. (Dobie, Saver, Wang, Green, \& Baldwin, 2011) However, this still does not fully explain the reason for lack of survival benefit seen in those with the highest frequency of office visits. This is an avenue for further research that needs to be explored 
Emergency surgery for CRC can have a significant impact on the progression of the disease. Predictors of emergency surgery such as race, and tumor location, must be explored further to avoid the burden associated with the condition. Stage at diagnosis is significantly associated with emergency surgery; which can be avoided by earlier diagnosis of the cancer. Further investigation into the association between tumor location and emergency condition for CRC surgery is warranted.

Diabetes has a poor effect on the survival and all-cause mortality of patients with CRC. Emergency admission and stage at diagnosis has a large effect on survival and therefore underscore the importance of early diagnosis. Diabetic patients should be screened and diagnosed in a timely fashion to prevent CRC or have a better disease prognosis.

This study points to a greater need for further investigation in the differential prevalence of colorectal tumor location in the elderly. Tumor location in diabetics must be studied further with a focus on detecting proximal tumors at earlier stages. Future studies should also investigate use of screening methods and their association with tumor location in the colorectal region and how it affects outcomes such as survival and mortality.

Current screening guidelines do not consider diabetics as a special case for earlier screening or more frequent CRC screening. McBean and Yu have reported that elderly diabetic women are less likely than elderly non-diabetic women to receive colorectal cancer screening in the 11 SEER areas studied between 1999-2002. (McBean \& Yu, 2007) They have furthered the argument in favor of altering CRC screening guidelines for diabetics by mentioning that the American Diabetes Association (ADA) should include specific screening recommendation for such cancers in the Standards of Medical Care in Diabetes. They also suggest combining specific 
recommendations for people with diabetes in guidelines from federal or national organizations that promote the use of screening services but are not primarily or uniquely concerned with diabetes such as the CDC, the National Cancer Institute, the American Cancer Society, and the CMS. An example of such joint advocacy leading to success in the promotion of preventive services among people with diabetes was the effort to encourage influenza and pneumococcal immunization. During the 1990s, the CDC, the CMS, and the ADA all stressed that elderly individuals with diabetes should be vaccinated. As a result, in 2001, rates of influenza and pneumococcal vaccination were higher in individuals with diabetes 65 years or older compared with the total elderly population.

Colorectal cancer can be prevented by timely screening. Since diabetic CRC patients have worse outcomes than their nondiabetic counterparts they must take advantage of this fact and prevent further burden associated with the disease. Combining the efforts of healthcare providers, policy makers and intervention strategies the frequency and timeliness of screening can greatly be improved.

\section{References}

Barone, B. B., Yeh, H. C., Snyder, C. F., Peairs, K. S., Stein, K. B., Derr, R. L., et al. (2010). Postoperative mortality in cancer patients with preexisting diabetes: Systematic review and metaanalysis. Diabetes Care, 33(4), 931-939. doi:10.2337/dc09-1721 Baxter, N. N., Warren, J. L.,

Barrett, M. J., Stukel, T. A., \& Doria-Rose, V. P. (2012). Association between colonoscopy and colorectal cancer mortality in a US cohort according to site of cancer and colonoscopist 
specialty. Journal of Clinical Oncology : Official Journal of the American Society of Clinical Oncology, doi:10.1200/JCO.2011.40.4772

Coughlin, S. S., Calle, E. E., Teras, L. R., Petrelli, J., \& Thun, M. J. (2004). Diabetes mellitus as a predictor of cancer mortality in a large cohort of US adults. American Journal of Epidemiology, 159(12), 1160-1167. doi:10.1093/aje/kwh161

Dobie, S., Saver, B. G., Wang, C. Y., Green, P. K., \& Baldwin, L. M. (2011). Do primary care physicians lose contact with their colorectal cancer patients? Journal of the American Board of Family Medicine : JABFM, 24(6), 704-709. doi:10.3122/jabfm.2011.06.100192

Felsen, C. B., Piasecki, A., Ferrante, J. M., Ohman-Strickland, P. A., \& Crabtree, B. F. (2011). Colorectal cancer screening among primary care patients: Does risk affect screening behavior? Journal of Community Health, 36(4), 605-611. doi:10.1007/s10900-010-9348-0

Gilbert, A., \& Kanarek, N. (2005). Colorectal cancer screening: Physician recommendation is influential advice to marylanders. Preventive Medicine, 41(2), 367-379. doi:10.1016/j.ypmed.2005.01.008

Guessous I, Dash C, Lapin P, et al. Colorectal cancer screening barriers and facilitators in older persons. Prev Med. 2010;50(1-2):3-10. doi: 10.1016/j.ypmed.2009.12.005.

Holt, P. R., Kozuch, P., \& Mewar, S. (2009). Colon cancer and the elderly: from screening to treatment in management of GI disease in the elderly. Best Pract Res Clin Gastroenterol., 889907. 
Hood, S., Thompson, V. L., Cogbill, S., Arnold, L. D., Talley, M., \& Caito, N. M. (2010). African american's self-report patterns using the national cancer institute colorectal cancer screening questionnaire. Journal of Cancer Education : The Official Journal of the American Association for Cancer Education, 25(3), 431-436. doi:10.1007/s13187-010-0068-z

Kim, J., Mittal, R., Konyalian, V., King, J., Stamos, M. J., \& Kumar, R. R. (2007). Outcome analysis of patients undergoing colorectal resection for emergent and elective indications. The American Surgeon, 73(10), 991-993.

Klabunde, C. N., Schenck, A. P., \& Davis, W. W. (2006). Barriers to colorectal cancer screening among medicare consumers. American Journal of Preventive Medicine, 30(4), 313-319. doi:10.1016/j.amepre.2005.11.006

McBean, A. M., \& Yu, X. (2007). The underuse of screening services among elderly women with diabetes. Diabetes Care, 30(6), 1466-1472. doi:10.2337/dc06-2233

Muller, A., \& Sonnenberg, A. (1995). Protection by endoscopy against death from colorectal cancer. A case-control study among veterans. Arch Intern Med , 1741-8.

Qaseem A, Denberg TD, Hopkins RH,Jr, et al. Screening for colorectal cancer: A guidance statement from the american college of physicians. Ann Intern Med. 2012;156(5):378-386. doi: 10.1059/0003-4819-156-5-201203060-00010.

Rich, S. E., Kuyateh, F. M., Dwyer, D. M., Groves, C., \& Steinberger, E. K. (2011). Trends in self-reported health care provider recommendations for colorectal cancer screening by race. Preventive Medicine, 53(1-2), 70-75. doi:10.1016/j.ypmed.2011.05.014 
Richardson, L. C., \& Pollack, L. A. (2005). Therapy insight: Influence of type 2 diabetes on the development, treatment and outcomes of cancer. Nature Clinical Practice.Oncology, 2(1), 48-53. doi:10.1038/ncponc0062

Schenck, A. P., Klabunde, C. N., Warren, J. L., Jackson, E., Peacock, S., \& Lapin, P. (2011). Physician visits and colorectal cancer testing among medicare enrollees in north carolina and south carolina, 2005. Preventing Chronic Disease, 8(5), A112.

Schoen RE, Pinsky PF, Weissfeld JL, et al. Colorectal cancers not detected by screening flexible sigmoidoscopy in the prostate, lung, colorectal, and ovarian cancer screening trial. Gastrointest Endosc. 2012;75(3):612-620. doi: 10.1016/j.gie.2011.10.024.

Siddiqui AA, Spechler SJ, Huerta S, Dredar S, Little BB, Cryer B. Elevated HbA1c is an independent predictor of aggressive clinical behavior in patients with colorectal cancer: A casecontrol study. Dig Dis Sci. 2008;53(9):2486-2494. doi: 10.1007/s10620-008-0264-4.

Wong, R. J. (2010). Marked variations in proximal colon cancer survival by race/ethnicity within the united states. Journal of Clinical Gastroenterology, 44(9), 625-630. doi:10.1097/MCG.0b013e3181c64a7a

Wray CM, Ziogas A, Hinojosa MW, Le H, Stamos MJ, Zell JA. Tumor subsite location within the colon is prognostic for survival after colon cancer diagnosis. Dis Colon Rectum. 2009;52(8):1359-1366. doi: 10.1007/DCR.0b013e3181a7b7de. 